II.

\title{
Beiträge zur Physiologie der Zelle, insbesondere über die Oxydationsgeschwindigkeit in Zellen
}

von

Otto Warburg, Heidelberg.

Während der physiko-chemische Mechanismus der alkoholischen Gärung, einer arbeitliefernden Reaktion der Hefezelle, seit den Zeiten Lavoisiers bis in die jüngste Gegenwart in einer Reihe zum Teil glänzender Experimentaluntersuchungen studiert wurde, ist die arbeitliefernde Reaktion der höher organisierten Lebewesen, die Sauerstoffatmung, bisher nur selten Gegenstand ähnlicher T'ntersuchungen gewesen. -

In Laufe der letzten 5 Jahre habe ich mich eingehend mit der Sauerstoffatmung vom chemischen und ply,silko-chemischen Standpunkt aus beschäftigt; die wichtigsten Resultate sind in der folgenden Abhandlung zusammengestellt, von früheren Arbeiten nur diejenigen besprochen, die mir für die chemische und physiko-chemische Seite des Problems wichtig erscheinen. Wie weit man den Begriff der Sauerstolfatmung, als Sammelnamen für eine Gruppe intrazellulärer Reaktionen, zu fassen hat, darüber gehen die Insichten auseinander; eine allgemein betriedigende Definition aufzustellen, ist nicht leicht, und zunächst auch nicht notwendig, wenn man sich an die typischen Fälle hïlt. Ist hier von „Sauerstoffatmung" oder „Oxydationen" die Rede, so handelt es sich im allgemeinen um Reaktionen, bei denen auf 10 Moleküle verschwundenen Sauerstoffs etwa 7 bis 10 Moleküle Kohlensüure entstehen. -

Die Versuche wurden zum Teil in der zoologischen Station in Neapel, zum grösseren Teil im Laboratorium der Heidelberger medizinischen Klinik ausgeführt. Herrn Geheimrat $\mathrm{K}$ r e h l schulde ich vielen Dank für stetige Förderung und vielfache Anregung. - Wesentlich erleichtert wurde mir die ungestörte Fortführung meiner Arbeiten durch zweimalige namhafte Zuwendungen von der Jagor-Stiftung in Berlin. 
Inhaltsübersicht.

Kapitel I. Oxydationsgeschwindigkeit und A rbejt . . . . . . . . . 255 Der Quotient $\frac{\text { geleistete Arbeit }}{\text { maximale Arbeit der Atmung. }}-$ - Das Zentralnervensystem des Kaltblüters. - Die kernhaltigen roten Blutzellen. - Das Ei während der Furchung. - Hypothese betreff. die Atmungsarbeit.

Kapitel II. Die Arbeit bei Hemmung der Oxydationen . . . . . . . . Zweierlei Folgen der Sauerstaffentziehung: 1. An Stelle der Sauerstoffatmung tritt eine andere energieliefernde Reaktion und es wird weiter Arbeit geleistet. 2. Die Arbeitsleistungen werden mehr oder weniger schnell eingestellt. - Wärmeproduktion nach Sauerstoffentziehung. - Chemische Vorgänge nach Sauerstoffentziehung.

Kapitel III. Oxydationsgeschwindigkeit und Sauerstoffkonzentration. Höhere Tiere. Bei erheblicher Anderung im Sauerstoffgehalt der Aussenluft ändert sich die Sauerstoffkonzentration in den Geweben nur wenig. - Niedere Tiere. - Pflanzen. - Isolierte Zellen. - Die Bedingung, dass die Zellen mit den verschiedenen Sauerstoffkonzentrationen sich annähernd im Gleichgewicht befinden. - Theoretische Bemerkung: Die Sauerstoffkonzentration an den Reaktionsorten in der Zelle. Analoga aus der Fermentkinetik.

Kapitel IV. Die Beeinflussung der Oxydationsgeschwindigkeit durch lipoidunlösliche und lipoidlösliche Stoffe........... . . . 268

1. Allgemeines.

2. Die Einteilung nach dem Gesichtspunkt der Lipoidlöslichkeit. - Ubber die Eigenschaften der Grenzschicht lebender Zellen.

3. Die lipoidunlöslichen Stoffe und rote Blutzellen.

a) Aufnahme in die Zelle.

b) Wirkung auf die Oxydationsgeschwindigkeit.

4. Die lipoidunlöslichen Stoffe und Seeigeleier.

a) Die Oxydationsgeschwindigkeit im Seeigelei und ihr Zusammenhang mit der Entwickeiungsgeschwindigkeit.

b) Aafnalume in die Zelle.

c) Die Wirkung der Salze fixer Alkalien und alkalischer Erden anf die Oxydationsgesch windigkeit.

d) Die Wirkung der Schwermetalle auf die Oxydationsgeschwindigkeit.

e) Die Wirkung der OH-Ionen auf die Oxydationsgeschwindigkeit.

f) Die Wirkung hypertonischer Lösungen auf die Oxydationsgeschwindigkeit. 5. Die lipoidlöslichen Stoffe.

a) Aufnahme in die Zelle. Qualitatives und Quantitatives. Theorie der Verteilung.

b) Einteilung in nichtspezifische und spezifische lipoidlösliche Stoffe.

c) Oxydationshemmungen durch nichtspezifische Stoffe. - Die wirksamen Konzentrationen. - Welche Atomgruppen bestimmen die Wirkungsstärken? - Allgemeingültigkeit. - Das Anwachsen der Wirkung mit der Konzentration. - Der Mechanismus der Hemmungen. Hemmung von Fermentreaktionen in vitro. Niederschlagsbildung bierbei. -

d) Oxydationsbeschleunigungen durch nichtspezifische lipoidlösliche Stoffe.

e) Oxydationsgeschwindigkeit und spezifische lipoidlösliche Stoffe: Die Aldehyde - Ammoniak und Ammoniakderivate - Blausäure.

f) Kombinationswirkungen: Nichtspezifische Stoffe untereinander und mit Aldehyden. - Nichtspezifische Stoffe und Blausäure. 
Beiträge z. Physiologie der Zelle, insbesondere üb. die Oxydationsgeschwindigkeit in Zellen. $25 \overline{5}$

Kapitel V. Die Beeinflussung der Oxydationsgeschwindigkeit durch die Temperatur . . . . . . . . . . . . . . . . . . . . . . 309

Kapitel VI. Über den Mechanismus der Sauerstoffatmung . . . . . . 313

1. Die Fragestellung.

2. Physiko-chemische Definition der Zellstruktur.

3. Trennung von Arbeitsfähigkeit und arbeitliefernder chemischer Reaktion mittels des Azetonverfahrens.

4. Zellstruktur und Oxydationsgeschwindigkeit.

5. Zellstruktur und Gärungsgeschwindigkeit.

6. Dio chemische Oxydationskatalyse.

7. Theorie der Strukturwirkung.

\section{Kapitel I.}

\section{Oxydationsg'eschwindigkeit und Arbeit.}

\section{Literatur. ${ }^{1}$ )}

1. Pfeffer, Studien zur Energetik der Ptlanze. Abhandlungen der mathem.-phys. Klasse der Kgl. Süchs. Gesellsch. der Wissenschaften. 18. Nr. 3.

2. Derselbe, Pflanzenphysiologie. Bd. I.

3. W in terstein, Zeitschr. f. allgemeine Physiologie 6. 315 (1907).

4. Ryuta Usui, Pflügers Archiv 147. 100 (1912).

5. Verworn, Archiv für (Anat. u.) Physiologie 1900. Suppl. S. 152.

6. O. W a rburg, Hop pe-Seyler Zeitschr. 59. 112 .(1909).

7. W. Trendelenburg, Zeitschr. f. Biologie 5̃7. 495 (1912).

8. O. Meyerhof, Pflügers Archiv 146. 159 (1912).

9. J. Loeb, Die chemische Entwickelungserregung des tierischen Eies. Berlin 1909.

10. O. Warburg, Hoppe-Seyler Zeitschr. 66. 305 (1910).

11. O. Me yerh of, Biochemische Zeitschrift 35. $246 ; 280$ u. 316 (1911).

12. M. Rubner, Kraft u. Stoff im Haushalte der Natur, Leipzig 1909.

13. O. Neyerh of, Sitzungsberichte der Heidelberger Akad. der Wissensch. Jahrgang 1912. 1. Abhandlung.

14. Pasteur, Études sur la bière, Paris 1876.

15. O. W arburg, Münch. med. Wochenschr., Nr. 47 (1912).

Die Arbeitsleistungen tierischer Zellen stammen aus der freien Energie chemischer Reaktionen, die wir als die energieliefernden oder arbeitliefernden anderen intrazellulären Reaktionen gegenüberstellen (Pfeffer [1 und 2]); arbeitliefernde Reaktionen sind eine Anzahl Gärungen, die alkoholische, die

1) Abkürzungen für dieses Referat: ${ }_{n} \mathrm{H}$ oppe-Seyler $=\mathrm{H}$ oppe-Seylers Zeitschr. für Physiologische Chemie_ - „Pflügers Archiv" = Archiv für die gesamte Physiologie. „Schmiedebergs Archiv" = Archiv für experimentelle Pathologie und Pharmakologie. 
Buttersäure-, die Essig-Gärung, vor allem aber die Atmungsreaktion der höher organisierten Lebewesen, die Sauerstoffatmung.

Wir wollen uns in diesem Kapitel mit der quantitativen Beziehung zwischen Arbeitsleistung und Sauerstoffatmung beschäftigen, uns also fragen, wie gross die in einer bestimmten Zeit geleistete Arbeit ist im Vergleich zur Geschwindigkeit der arbeitliefernden Reaktion, der Oxydationsgeschwindigkeit.

Gleichgültig ob Kohlehydrat, Fett oder Eiweiss verbrennt, entstehen pro $\mathrm{mg}$ verbrauchten Sauerstoffs annähernd gleiche Wärmemengen, etwa 3,2-3,5 Grammkalorien. Setzen wir, was für die Oxydation von Wasserstoff oder Kohlenstoff mit einiger Annäherung erlaubt ist') die Wärmetönung gleich der Abnahme der freien Energie, so ist mit der Oxydationsgeschwindigkeit die maximale Arbeit annähernd gegeben, pro mg verbrauchten Sauerstoffs kann in maximo eine Arbeit von 3,2-3,5 Grammkalorien geleistet werden; aus dem Quotienten $\frac{\text { geleistete Arbeit }}{\text { Oxydationsgeschwindigkeit }}$ lässt sich, indem wir für die Oxydationsgeschwindigkeit den kalorischen Wert des Sauerstoffs einsetzen, der Quotient $\frac{\text { geleistete Arbeit }}{\text { maximale Arbeit der Atmung }}$ bilden. Diesen Quotienten wollen wir als Arbeitsquotienten bezeichnen. Er ist bisher mit einiger Sorgfalt nur am arbeitenden Muskel - offenbar weil hier die Arbeit leicht gemessen werden kann - studiert worden (vgl. Kapitel VI, Abschnitt 2), mit dem Resultat, dass er: hier zwischen clen Quotienten unserer gebräuchlichen technischen Maschinen liegt: der Arbeitsquotient der Muskelmaschine kann den unserer Dampfuaschinen erheblich ïbertreffen, ist aber stets kleiner als in den gebräuchlichen galvanischen Elementen.

Arbeitsquotienten, wie sie für den tätigen Muskel gefunden werden, sind nun keineswegs die Regel, sie sind in vielen Fallen ganz auffallend klein, so klein, dass der Zühler des Quotienten ausserhalb des Bereichs der Messbarkeit liegt. Derartige Fälle, die ich für besondersinteressant halte, wollen wir im tolgenden besprechen.

1. Das isolierte Zentralnervensystem rom Frosch verbraucht nach Winterstein (3) $480 \mathrm{mg}$, nach O. Warburg und Usui (4) $160 \mathrm{mg}$ Sauerstolf pro $\mathrm{kg}$ und Stunde. Legen wir die Zahlen ron O. Warburg and ('sui²) zugrunde, so beträgt also die maximale Arbeit pro Kilo und Stunde etwa t-500 Grammkalorien. Irgendwelche Arbeitsleistungen kennen wir nicht, die Formelemente des Zentralnervensystems bewegen sich nicht, teilen sich nicht und wachsen nicht. Der Arbeitsquotient scheint hier sehr klein zu sein. Wir können das auch so ausdrücken, dass die mechanische Bedeutung der Sauerstoffatmung in diesem Fall unbekannt ist; dass die Atmung nicht überflüssig und nutzlos ist, ètwa ein Überbleibsel aus den Zeiten des Wachstums, das geht hervor aus den bekannten Ver-

1) Vergl. Nerast, Theoret. Chemie (6) Seite 698.

2) Die eher zu niedrig, als zu hoch sind. 
Beiträge z. Physiologie d. Zelle. insbesondere über die Oxydationsgeschwindigkeit in Zellen. 257

suchen Verworns und seiner Schule (5). Durchspült man nümlich das Zentralnervensystem rom Frosch mit sauerstofffreier Kochsalzlösung, so erlischt sehr bald seine Reflexerregbarkeit, um sofort wiederzukehren, wenn die Kochsalzlüsung mit Sauerstoff beladen ist. Für die Funktion also ist die Sauerstoffatmung notwendig.

2. In den kernhaltigen roten Blutzellen mancher Tiere, warmblütiger (O. Warburg [6]) oder kaltblütiger (W. Trendelenburg [7]), ist die Oxydationsgeschwindigkeit eine recht erhebliche; in kalorischem Mass ausgedrückt, kann sie beispielsweise für Gänseblutzellen pro $\mathrm{kg}$ und Stunde 500 Grammkalorien betragen. Was zunächst die mechanische Arbeit anbetrilft, so steht es hier ebenso wie beim Zentralnervensystem vom Frosch, sie ist unmessbar klein: die Zellen sind unbeweglich, teilen sich nicht und wachsen nicht. Sie gehen langsam im Kreislauf zugrunde. Thre physiologische Aufgabe besteht in dem Transport von Sauerstoff aus den Kapillaren der Lunge in die Gewebe, wobei ihr Farbstoff abwechselnd oxydiert und reduziert wird. Oxydation und Reduktion sind mit Arbeitsleistung von seiten der Zellen nicht verbunden, derselbe Vorgang kann sich getrennt von der Zelle in reinen Farbstofflösungen abspielen. Auch andere chemische Arbeit wird in so geringem Betrag geleistet, dass sie im Verhältnis zur maximalen Arbeit der Atmung nicht in Betracht kommt. Das kann festgestellt werden, indem man die Würunemenge, die pro mg verbrauchten Sauerstoffs erscheint, direlit bestimmt. Chemische Arbeit müsste dann in die energetischen Gleichungen als latente Würme eingehen und weniger Wärme erscheinen, als dem kalorischen Wert des Sauerstoffs entspricht. In der Tat aber ist, nach Untersuchungen von $\mathrm{O}$. MI eyerhof (8), die produzierte Wärmemenge gleich der aus dem Sauerstoffverbrauch . berechneten Verbrennungswärme.

Auch in den Blutzellen also scheint der Arbeitsquotient sehr klein zu sein.

3. Bei der Furchung des tierischen Eies, der Zelldurchschnürung, Kernbewegung und dem Kernwachstum wird Arbeit geleistet; z. B. chemische oder sichtbare mechanische. Die arbeitliefernde Reaktion für die Furchung des Echinideneies ist die Sauerstoffatmung, denn die Furchungsarbeit wird eingestellt, wenn wir die Oxydationen durch Sauerstoffentziehung verhindern (J. Lo eb [9]).

Zunächst lässt sich zeigen, dass die chemische Arbeit im Laufe der Furchung sehr klein ist im V'ergleich zur maximalen Arbeit der Atmung. Vergleicht man nämlich die Wärmemengen, die pro $\mathrm{mg}$ verbrauchten Sauerstoffs während der Furchung und bei aufgehobener Furchung ${ }^{1}$ ) entwickelt werden, so findet man keinen Unterschied. Die pro mg Sauerstoff produzierten Wärmemengen sind diegleichen, ob Kernesich neu bilden oder nicht (O. Meyerhof [11]).

1) Die Furchung lässt sich aufheben, ohne dass gleichzeitig die Wärmeproduktion erheblich absinkt.

Asher-Spir o, Ergebnisse der Physiologie. XIV. Jahrganı̆. 
Über den Umafang an mechanischer Arbeit, die. während der Entwickelung geleistet wird, gibt die Kalorimetrie offenbar keinen Aufschluss, denn ein Teil der mechanischen Arbeit, z. B. dic Bewcgung der Kerne oder Chromosomen, geht im Ei wieder in Wärme über. Folgende Überlegung jedoch führt hier weiter: Im befruchteten Ei entstehen in der Zeiteinheit, je nach dem Furchungsstadium, eine verschiedene Anzahl annähernd gleichgrosser Kerne; beispielsweise in der ersten halben Stunde nach der Befruchtung ein Kern; in der zehnten halben Stunde 64 Kerne, noch später 500 Kerne. Wir haben also Zellen zur Verfügung, in denen die Grösse der sichtbaren mechanischen Arbeit sehr verschieden ist; käme diese erheblich in Betracht im Vergleich zur maximalen Arbeit der Atmung, so müsste sich auch die Oxydationsgeschwindigkeit während der verschiedenen Furchungsstadien erheblich unterscheiden. Das ist nun durchaus nicht der Fall, die Oxydationsgeschwindigkeit wächst nicht entfernt im Vorhältnis der sichtbaren mechanischen Arbeitsleistungen, sondern viel langsamer. Ferner: In spiiteren Entwickelungsstadien nimmt die Geschwindigkeit der Kernentstehung so erheblich ab, dass weniger Kerne in der Zeiteinheit entstehen, als in trüheren Entwickelungsstadien ${ }^{1}$ ): die Oxydationsgeschwindigkeit jedoch ist später keineswegs kleiner, soudern sie wächst dauernd. Ein Zusammenhang zwischen sichtbarer Arbeitsleistung und Oxydationsgeschwindigkeit ist also nicht erkennbar oder anders ausgedrückt: nur ein kleiner Teil der durch die Atmung verfügbaren Arbeit wird zur Leistung der sichtbaren Arbeit benützt. Der Arbeitsquotient sch eint sehr klein zu sein.

In diesem Zusammenhang liessen sich auch Versuche anführen, in denen die Aufhebung von Wachstumsvorgüngen künstlich herbeigeführt wurde, durch ungenügende Nährböden (R ubner [12], O. Neyerh of [13]) oder narkotische Substanzen (O. Warburg [10]). Die Oxydationsgeschwindigkeit nimmt dann unter gewissen Bedingungen gar nicht oder nicht im Verhältnis zur Wachstumshemnung ab. Doch ist unter solchen Bedingungen der Einwand nicht ganz abzuweisen, dass nach der künstlichen Unterbrechung der Wachstumsvorgänge die arbeitliefernde Reaktion ungenutzt weitergeht.

Die minimale Grösse der Arbeitsquotienten in den angeführten Fällen gibt Anlass zu folgender Fragestellung: Ist anzunehmen, dass die lebendigen Maschinen, die, wie die Muskelmaschine berweist, mit Arbeitsquotienten von $20 \%$ und mehr arbeiten können, in vielen Fällen nur mit Quotienten von $1 / 100$ oder $1 / 1000 \%$ arbeiten, dass also oft die maximale Arbeit der Atmung

1) Aus einer Arbeit von Otto Koehler (Archiv für Zellforschung Bd. 8, Seite 272), ergibt sich beispielsweise, dass 5 Stunden nach der Befruchtung 50 Kerne in 100 Minuten entsteben; 11 Stunden nach der Befruchtung 160 Kerne in 100 Vinuten; 17 Stunden nach der Befruchtung 40 Kerne in 100 Minuten. 
fast völlig ungenutzt bleibt? Oder aber, weisen die niedrigen Quotienten vielleicht darauf hin, dass wir die Arbeit, die die Atmung leistet, nur zum kleinsten Teile kennen ${ }^{1}$ )?

Wir hätten dann nach unsichtbaren, allgenein für die Erhaltung des Zelllebens notwendigen Arbeitsleistungen zu suchen. Diesen Gedauken habe ich schon früher gelegentlich (15) angedeutet und die Vermutung ausgesprochen, dass mechanische Arbeitsleistungen im Bereich sehr kleiner Dimensionen notwendig sein könnten, damit die Struktur der Zelle, die räumliehe Trennung von Stoffen, die Zusammensetzung der semipermeabeln Wände usw. - erhalten würde. In der Tat lässt sich schwer denken, auf welche Weise unter den in der Zelle gegebenen Bedingungen eine räumliche Trennung verschiedenartiger Stoffe irn Laufe des Lebens aufrecht erhalten werden könnte ohne dauernde Arbeitsleistungen; ohne dass von selbst verlaufende Vorgänge wie Diffusionen dauernd rückgängig gemacht würden.

1) Hier liegt die Annahme zugrunde, dass die physiko-chemische Bedeutung der Atmung im wesentlichen eine energetische, keine stoffliche ist, dass also die Zelle nicht Sauerstoff verbraucht, um, wio Pflüger glaubte, aus Eiweiss durch Einfügung des Sauerstoffs das labile, das "lobendige" Eiweiss zu fabrizieren, sondern weil die bei der Oxydation freiwerdende Energie nötig ist. Schon Pfeffer, der diese Auffassung zuerst physiko-chemisch formulierte (1), wies daranf hin, dass die Trennung eines Naturvorgangs nach der energetischen und nach der stofflichen Seite immer willkürlich, bis zu einem gewissen Grade falsch ist; in der Tat kennen wir Fälle, in denen die stoffliche Bedeutung der Atmung ganz 2 weifellos ist. Als Beispiel möshte ich eine interessante Beobachtung von Pastear(14) anführen: In der Hefezelle gibt es zwei Arten von arbeitliefernden chemischen Reaktionen, die Sauerstoffatmung und die alkoholische Gürung. Bei Sauerstoffabschluss lebt die Hefe monatelang und vermehrt sich; allmäblich aber degeneriert sie, die Zellen füllen sich mit Körnchen und die Zellteilungen hören auf. Lässt man solche Zellen kurze Zeit Sauerstoff atmen, so sind sie daraufhin wieder imstande, monatelang unter Sauerstoffabschluss zu wachsen. Die Bedeutang der Sauerstoffatmung kann hier nicht in der Lieferung von Energie bestehen, da ja die Hefe, wie ihr Wachstum ohne Sauergtoff zeigt, imstande ist, ibre Arbeitsleistungen auf Kosten der alkoholischen Gärung zu vollbringen. Quantitativ aber, gegenüber dem Gesamtumsatz, tritt diese stoffliche Rolle der Sauerstoffatmung ganz zurück, anders ausgedrückt: die Sauerstoffmengen, die die Hefe im Laufe ihres Lebens für chemische Zwecke benötigt, sind ganz ausserordentlich klein im Vergleich zum Gesamtumsatz. Mit den durch unser Beispiel angedeuteten Einschränkungen also und beim heutigen Stand unserer Kenntnisse halte ich es für durchaus zweckmässig und fruchtbar, das Hauptgewicht auf die energetische Seite der Atmnng zu legen, wie das besonders M. $R a b n$ er tut. 
Kapitel II.

\section{Die Arbeit bei Hemmung der Oxydationen ${ }^{1}$ ).}

\section{Literatur.}

1. Pasteur, îtudes sur la bière. Paris 1876 .

2. Hermann, Untersuchungen über den Stoffwechsel der Muskeln. Berlin 1867.

3. N. Zuntz, Oppenheimers Handbuch der Biochemic. 4. 837.

4. O. Meyerh of, Pflügers Archiv 146, 159 (1912). Sitzungsberichte der Heidelberger Akademie der Wissensch. Jahrgang 1912. 1. Abhandlung.

5. Pfeffer, Cntersuchungen aus dem botan. Institut zu Tübingen Bd. I (1881-1885)..

6. Adrian Brown, Journal of the Chemical Society 61, 369 (1892).

7. Hans Buchner u. Rapp in Die Zymasegärung. München u. Berlin 1903.

Wenn wir sauerstoffatmenden Zellen die Sauerstoffzufuhr abschneiden, etwa indem wir sie in eine Wasserstoffatmosphäre bringen, so können zwei Fïlle eintreten: entweder an Stelle der Sauerstoffatmung tritt eine andere arbeitliefernde chemische Reaktion und es wird weiter Arbeit geleistet; oder die Arbeitsleistungen werdon, mehr oder weniger schnell, eingestellt.

Als Beispiel für den ersten Fall sei mucor mucedo genannt, der bei Sauerstoffzuluhr Nahrungsstoffe wie Zucker zu Kohlensäure verbremnt, bei Sauerstoffmangel jedoch Zucker zu Alkohol und Kohlensäure vergärt und imstande ist, auf Kosten der einen oder anderen Reaktion Arbeit zu leisten (Pasteur [1]).

Als Beispiel, das einen C̈bergang zu Fall II zu bilden scheint, wollen wir den Froschmuskel anführen. Seine energieliefernde chemische Reaktion ist bei ausreichender Zufuhr von Sauerstoff die Sauerstoffatmung; betrachten wir nämlich einen Muskel, nachdem er Arbeit geleistet hat und in seinen ursprünglichen Zustand zurückgeführt ist, so ist die einzige Veränderung, die in dem System, abgesehen von der Leistung der mechanischen Arbeit, vor sich ging, die Oxydation einer bestimmten Menge organischen Brennmaterials. Der Zusammenhang zwischen Arbeit und Oxydation - die Oxydation als energieliefernde Reaktion des arbeitenden Muskels - ist absolut feststehend, gleichgültig, auf welchem Weg ${ }^{2}$ ) chemische

1) Die Absicht war keineswegs, hier unsere Kenntnisse über „Das Leben ohne Sauerstoff " zusammenzustellen, um so weniger, als das von E. J. Lesser in diesen Ergebnissen Bd. 8, S. 742) eingehend geschehen ist; ich habe aus dem grossen Gebiet nur das Wenige herausgegriffen, was auf das Verhalten normalerweise sauerstoffatmender Zellen unter Sauerstoffmangel Bezug hat.

2) Über diesen Weg ist bis heute nichts bekannt, eine Diskussion der Möglichkeiten und Literatur siehe z. B. bei W. Pauli, „Kolloidchemie der Muskelkontraktion“, Dresden und Leipzig. 1912. 
Beiträge z. Physiologie d. Zelle, insbesondere über die Oxydationsgeschwindigkeit in Zellen. 261

Energieder Oxydation in mechanische Arbeit übergeführt wird. Seit Hermann (2) wissen wir nun, dass der Froschmuskel auch nach Unterbrechung der Sauerstoffzufuhr noch einige Zeit Arbeit leisten kann, und man hat daran gedacht (N. Z untz 3), dass unter diesen Bedingungen eine chemische Reaktion, unter deren Endprodukten Milchs äure auftritt, die arbeitliefernde chemische Reaktion wäre. Die im einzelnen noch unaufgeklärte Milchsäurebildung also sollte im anoxybiotisch arbeitenden Froschmuskel etwa der alkoholischen Gärung des anoxybiotisch wachsenden mucor mucedo entsprechen. Der bündige Nachweis, dass dem so ist, fehlt; geben wir dem Mucor keinen Zucker, so vermag er ohne Sauerstoff nicht zu wachsen; für den Froschmuskel jedoch ist bisher nicht nachgewiesen, dass er ohne Milchsäurebildung keine anoxybiotische Arbeit leisten kann. Es kommt hinzu, dass die anoxybiotische Arbeitsfähigkeit des Froschmuskels nur eine sehr beschränkte ist, der Muskel "ermüdet", wie man sagt, bei Sauerstoffabschluss sehr rasch; der Muskel verändert sich dauernd bei anoxybiotischer Arbeit. Der Froschmuskel steht also den obligat oxybiotischen Organismen entschieden näher als den fakultativ anoxybiotischen. und die vorliegenden Tatsachen stehen nicht in Widerspruch zu der Auffassung, dass eine zweite arbeitliefernde chemische Reaktion, die an Stelle der Sauerstoffatmung treten könnte, im Froschmuskel nicht existiert. Die anoxybiotische Arbeit entstammte dann Energiepotentialen, die durch die Sauerstoffatmung gebildet würden und bei Abschluss des Sauerstoffs gewissermassen noch im Überschuss vorhanden wären.

Klare Beispiele für Fall II - Arbeitseinstellung nach Unterbrechung der Sauerstoffzufuhr - lassen sich in fast beliebiger Menge anführen; die meisten sauerstoffatmenden tierischen Zellen gehören hierher, stellen also Bewegung, Wachstum, Zellteilung und andere Arbeitsleistungen schnell ein, wenn ihnen der Sauerstoff entzogen wird. Selbstverständlich bedarf es stets einer gewissen, durch die Versuchsanordnung gegebenen Zeit, bis die letzten Sauerstoffspuren aus den Reaktionsorten der Zellen entfernt sind, so dass Einstellung der Sauerstoffzufuhr und Einstellung der Arbeitsleistungen zeitlich nie zusammenfallen können. -

Die Wärmeproduktion lebender Zellen entstammt zum weitaus überwiegenden Teil der Wärmetönung der arbeitliefernden chemischen Reaktionen ${ }^{1}$ ); die übrigen intrazellulüren chemischen Reaktionen verlaufen teils zu langsam, teils ist ihre Wärmetönung zu gering, als dass sie kalorisch gegen die arbeitliefernden in Betracht kämen ${ }^{2}$ ). Tritt also nach Sauerstoffentziehung

1) Arbeitliefernde chemische Reaktionen mit negativer Wärmelösung sind bis jetzt in Zellen nie angetroffen worden.

2) Von dieser.Regel gibt es einige Ausnahmen; so kommt die Würmetönung der Hämoglobin-Sauerstoff bindung in den roten Blutzellen allerdings in Betracht gegenüber der Wärmetönung ihrer Sauerstoffatmung. 
an Stelle der Sauerstoffatmung keine andere arbeitliefernde chemische Reaktion, so wird die Wärmeproduktion der Zellen sehr steil abfallen. In der Tat konnte O. Mey e rhof (4) für Vibrio Metschnik off und Vogelerythrocyten zeigen, dass die Wärmeproduktion bei Abschluss von Sauerstoff sehr erheblich, sicher auf weniger als den hundertsten Teil der oxybiotischen Wärmeproduktion, abfällt. Von einem etwas veränderten Standpunkt aus können wir dieses Resultat auch als rigoroseren Nachweis dafür verwerten, dass in den genamnten Zellarten nach Sauerstoffentziehung auf Kosten chemischer Energie keine Arbeit geleistet wird, auch keine unsichtbare.

Zellen, in denen nur eine arbeitliefernde chemische Reaktion vorkommt und von diesen wieder Zellen mit Sauerstoffatmung, scheinen mir besonder's geeignete Versuchsobjekte, um der oben (Kapitel I) aufgeworfenen Frage nach der Bedeutung der Atmungsarbeit näher zu kommen; denn hier haben wir die Möglichkeit, durch einen sehr einfachen experimentellen Eingriff - Austreibung des Sauerstoffs - die Arbeitsfähigkeit aufzuheben.

\section{Chemische Vorgäinge nach Sauerstoffentziehung.}

Auf Grund von Experimenten, in denen sauerstoffatmenden Zellen zeitweise die Sauerstoffzutuhr abgeschnitten wurde, kain Pfeffer (5) zu folgender Vorstellung über die chemischen Vorgänge bei Sauerstoffabschluss:

Derselbe Vorgang-Zertrümmerungvon Molekülen - sollte unabhängig von An-oder Abwesenheit von Sauerstoff, in lebenden Zellen ständig vor sich gehen; bei Anwesenheit von Sauerstoff sollten diese Trümmer oxydiertwerden, sonst abersich zu Gärungsprodukten umlagern.

Die Theorie sagt also erstens, dass dem Lingriff des Sauerstoffs vorbereitende Spaltungen vorausgehen, eine recht plausible, bisher allerdings nicht bewiesene Anmahme. Sie sagt zweitens, dass die Spaltungen auch bei Sauerstoffabschluss weitergehen. Dieser Punkt - so wesentlich für das Verständnis der Folgen des Sauerstoffmangels - scheint mir im Widerspruch zu einer Anzahl Erfahrungen zu stehen. Ich denke dabei weniger an das Verschwinden der Wärmeproduktion bei Sauerstoftmangel, das sich als Argument nur mit Einschränkungen hier anfühıren lässt. Denn die Wärmetönungen der Spaltungsreaktionen sind gegen die der Oxydationen sehr gering, beispielsweise würde die Wärmeproduktion auf 3 bis $5 \%$ der oxybiotischen abfallen, wenn gleichviel Zuckermoleküle, statt zu Kohlensüure und Wasser verbrannt zu werden, zu Alkohol und Kohlensäure zerfielen. Damit nähern wir uns aber schon den durch die Methodik der Würmemessung gesteckten Grenzen. - Viel bedenklicher für die Theorie sind die Beobachtungen über Sauerstoffatmung und intramolekulare Atmung der Hefezelle. Be- 
Beiträge z. Physiologie d. Zelle, insbesondere über die Oxydationsgeschwindigkeit in Zellen. 263

stimmen wir die Gärungsgeschwindigkei einer unter Sauerstoffabschluss gärenden Hefe, führen dann Sauerstoff zu und bestimmen nunmehr bei Anwesenheit von Sauerstołf die Gärungsgeschwindigkeit, so finden wir keinen Linterschied, obwohl bei Gegenwart von Sauerstoff reichlich Sauerstoff konsu mi ert wird. Die gleiche Menge Zucker wird weiter vergoren und a us serdem noch Zucker verbrannt. (Adrian Brown [9]; Hans Buchner und Rapp [10]). Versenken wir die Hefe wieder in sauerstofffreie Flüssigkeit, so wird jetzt nicht mehr Zucker vergoren. Die im Sinne der Theorie ständig weitergebildeten Zuckertrünmer sind also nicht imstande, sich zu Gärungsprodukten umzulagern. Wenn aber eine Zelle, in der schon normalerweise Gärungen so ausgiebig ror sich gehen, die Vorstufen der Sauerstoffatmung nicht in Gürungsprodulte umlagern kann, um so weniger wird man diese Fähigkeit Zellen zutrauen, die normalerweise Gürungen nicht vollbringen.

$\mathrm{Ob}$ nun nach dem Pfefferschen Schema unmessbar kleine Quantitäten reagieren oder nicht - uns interessiert im wesentlichen, was nach Sauerstoffabschluss praktisch passiert. Möglicherweise existiert eine Verkettung, wie sie Pfeffer annimmt, in besonderen Fiallen, bei mucor mucedo, vicia faba und ähnlichen, von Pflanzenphysiologen besonders eitrig studierten Objekten. Im allgemeinen aber nehmen wir an, dass in sauer. stoffatmenden Zellen, nach Sauerstoffentziehung, auch die Entstehung der Torstufen der Sauerstoffatmung praktisch sistiert ist.

\section{Kapitel III.}

\section{Oxydationsgeschwindigkeit und Sauerstoffkonzentration.}

\section{Literatur.}

1. Regnault u. Reiset, Ann. de Chimie et Physique, T. 26. 299 (3ième série).

2. Barcroft and King, Journal of Physiology, 39. 374. (1909).

3. Derselbe a. Orbeli, Journal of Physiology, 41. 355. (1910).

4. Torsten Thu nberg, Skandinav. Archiv f. Physiologie 17. 133. (1905).

5. Martin Henze, Bioch. Zeitschr. 26. 255. (1910).

6. Pfeffer, Pflanzenphysiologie Bd. I.

7. Johannsen, Arbeiten aus dem botan. Inst. zu Tübingen Bd. I. (1881-1885).

8. Je nty s, Arbeiten aus d. botan. Inst. zu Tübingen Bd. II. (1888).

9. Paul Bert, La pression barométrique. Paris 1878.

10. Pflüger, Pflügers Archiv 10. 251. 6. 43.

11. Herbert Freundlich, Kapillarchemie. Leipzig 1909.

12. Adrian Brown, Journal of the Chemical Society 81. 373. (1902).

13. Harden „Alkoholic Fermentation“ London 1911. 
Seit Lavoisier und Reignet und Reiset wissen wir (1), dass die Grösse des Gaswechsels vieler Tiere sich nicht ändert, wenn der Sauerstoffgehalt der umgebenden Luft in weiten Grenzen variiert. Die Versuchstiere waren Wirbeltiere mit ausgebildetem Zirkulationssystem. Ïndern wir den Sauerstoffgehalt der umgebenden Luft, so ändert sich die Sauerstoffskonzentration im Plasma der Lungenkapillaren annähernd im gleichen Verhältnis. Die Sauerstoffmenge jedoch, die die Blutzellen, gebunden an Hämoglobin enthalten, ändert sich nicht proportional der Sauerstoffkonzentration im Plasma. Vermehren wir beispielsweise den Sauerstoffgehalt der Luft auf das Doppelte der Nornn und damit auch die Sauerstoffkonzentration im Plasma der Lungenkapillaren um annähernd den gleichen Betrag, so wächst die an das Hämoglobin gebundene Sauerstoffmenge nur um wenige Prozente. Daraus folgt, dass die Sauerstoffmenge in einem bestimmten Blutvolumen oder die Sauerstoffmenge, die den Geweben zugeführt wird, trotz sehr erheblicher Änderungen, im Sauerstoffgehalt der Aussenluft ziemlich konstant bleiben kann. Das Blut, das bei doppeltem Sauerstoffdruck in den Lungenkapillaren gesättigt ist, wird wïhrend der Passage durch die Gewebskapillaren sehr rasch seines kleinen Mehrgehalts an Sauerstoff beraubt und gibt nunmehr seinen Sauerstoff; also die Hauptmenge, unter den gleichen Konzentrationsverhält. nissen ab, wie Blut, das unter Normaldruck in den Lungenkapillaren gesättigt ist. Ebenso können wir mit dem Sauerstoffdruck in der Aussenluft schon sehr erheblich unter den Normalwert herabgehen, ohne dass sich der Sauerstoffgehalt des Blutes und damit die Sauerstoffkonzentration in den Geweben erheblich ändert; nach einer von Barcroft und $\mathrm{Camis}$ für menschliches Blut aufgenommenen Dissoziationskurve ( $\mathrm{Bar}$ croft und King [2]) ist bei Normaldruck etwas mehr als $90 \%$, bei Verminderung des Sauerstoffdruckes auf ein Drittel des Normalwertes, noch $80 \%$ des Blutfarbstoffs rnit Sauerstolf gesätigt. Höhere Tiere also sind wenig geeignete Versuchsobjekte, wenn Beziehungen zwischen Oxydationsgeschwindigkeit und Sauerstoffkonzentration in der Zelle ermittelt werden sollen ${ }^{1}$ ).

Das Verhalten niederer Tiere gegen Änderungen des Sauerstoffgehalts der umgebenden Milieus hat zuerst Thunberg (4) studiert. Nach Thunberg soll der Gaswechsel einer Schnecke, limax, des Mehlwurms und des Regenwurms in Bereichen, in denen der Gaswechsel hölierer Tiere konstant bleibt, deutlich zunehmen, wenn der Sauerstoffdruck wächst. Der Gaswechsel

1) Selbst wenn wir mit dem Sauerstoffdruck in der Aussenluft so weit heruntergehen, dass der Sauerstoffgehalt des Blutes sich erheblich ändert, ist noch möglich, dass den Zellen der Sauerstoff unter fast normalen Konzentrationen dargeboten wird, denn die „Spannungskurve ${ }^{\mu}$ kann sich bei Sauerstoffmangel in dem Sinne ändern (Barcroft 3), das für eine gegebene Oxyhämoglobinkonzentration die Sauerstoffspannung und damit die Sauerstoffkonzentration in Plasma wächst. 
Beiträge z. Physiologie d. Zelle, insbesondere über die Oxydationsgeschwindigkeit in Zellen. 265

der Thunbergschen Objekte sank jedoch in dem ,Miikrorespirometer" während der Versuche dauernd. $a b$, so dass die Zahlen nicht besonders überzeugend wirken.

Übersichtlicher sind die Versuche von Martin Henze (6) an Seetieren, der nur solche Objekte benutzte, die unter konstanten Bedingungen in gleichen Zeiten gleichen Sauerstoffkonsum aufwiesen und der auch Tiere, die lebhafte unregelmässige Bewregungen ausführten, nicht untersuchte, da ihr Gaswechsel unter sonst konstanten Bedingungen oft in weiten Grenzen wechselte. Henze fand für Aktinien, dass beim Einbringen in sauerstoffreicheres Wasser ihr Sauerstoffkonsum sofort stieg und dass dieser Mehrverbrauch 24 Stunden lang anhielt. Wurden die Tiere in normales Seewasser zurückgebracht, so fiel der Sauerstoffverbrauch wieder auf den normalen Anfangsbetrag. Ähnlich lagen die Verhältnisse für ein anderes anthozoon, anemonia sulcata, und für einen marinen Ringelwurm, sipunculus nudus. Dagegen liess sich, unter gleichen Bedingungen, ein Einfluss der Sauerstoffkonzentration nicht feststellen, wenn Tiere mit ausgebildetem Zirkulationssystern, wie carcinus, aplysia oder eledone geprüft wurden. Die Arbeit von Henze ist insofern unvollständig, als die Kohlensäure nur ausnahmsweise und dann nicht sehr genau bestimmt wurde. Soviel sich aber aus den wenigen Daten ersehen lässt, steigt die $\mathrm{CO}_{2}$-Produktion nicht im Verhältnis des Sauerstoffkonsums an.

Änderungen der Sauerstoffkonzentration im umgebenden Milieu also, die den Gaswechsel höherer Tiere kaum modifizieren, werden von einigen niederen Tieren mit einer erheblichen Änderung des Sauerstoffkonsums beantwortet. Wie die höheren Tiere, so verhalten sich im allgemeinen auch die Pflan zen, deren Atmung vielfach unverïndert bleibt, ,wenn der Sauerstoff der Luft auf die Hälfte reduziert oder auf die 5-10fache Dichte gebracht ist" (P feffer [7]). Wird der Sauerstolfdruck sehr erheblich vergrössert, so niramt die Oxydationsgeschwindigkeit in Planzen zunächst $\mathrm{zu}$, allerdings nur wenig (Johannsen [8]; Jentys [9]); später werden die Pflanzen geschädigt und die Oxydationsgeschwindigkeit nimmt ab. Diese Abnahme bei sehr hohen Sauerstoffdrucken ist von Paul Bert an Tieren innerhalb ziemlich langer Versuchszeiten beobachtet worden (10), auch hier handelt es sich nicht um eine direkte Wirkung des Sauerstoffs auf die Oxydationsgeschwindigkeit, sondern primär um eine Schädigung der Tiere, die allmählich bei den hohen Drucken zugrunde gehen. Es beruht also auf einer falschen Interpretation von Berts Versuchen, wenn Pflüger (11) die tierische Verbrennung mit dem Leuchten des Phosphors vergleicht, das nur in Sauerstoff relativ niedrigen Druckes beobachtet wird.

Was isolierte Zellen betrifft, so habe ich bisher stets an verschiedenartigstem Material (Bakterien, Seeigeleier, rote Blutzellen), eine weitgehende Unabhängigkeit des Sauerstoffkonsums von der 
Sauerstoffkonzentration in der umspülenden Lösung beobachtet. Ein Experiment mit roten Blutzellen sei hier augeführt: Nach Barcroft und $\mathrm{King}(2)$ gibt Blut den chemisch gebundenen Sauerstoff bei tiefen Temperaturen erst bei sehr niedrigen Drucken ab. Für Gänseblut liegt dieser „Dissoziationsdruck" bei $0^{0}$ unter $5 \mathrm{~mm}$ Sauerstoff, d. h. bei 5 mm Sauerstoff ist die Hämoglobinsauerstolfverbindung nur sehr wenig dissoziiert. Lassen wir also Gänseblutzellen ihren chemisch gebundenen Sauerstoff. bei $0^{\circ}$ veratmen, so wissen wir, dass der Sauerstoff bei einem kleineren Druck als $5 \mathrm{~mm}$ konsumiert wird. Andererseits können wir Gänseblutzellen dadurch, dass wir sie in viel Flüssigkeit bringen, im wesentlichen physikalisch gelösten Sauerstoff veratmen lassen. Waren nun Gänseblutzellen bei $0^{\circ}$ in einer Probe auf den chemisch gebundenen Sauerstoff, in einer $z$ weiten auf den physikalisch gelösten Sauerstoff, dessen durchschnittlicher Druck während der Atmung $75 \mathrm{~mm}$ betrug, angewiesen, so war die Oxydationsgeschwindigkeit die gleiche. Eine Verminderung der Sauerstoffkonzentration auf weniger als $1 / 15$ also war ohne Einfluss.

Fassen wir die vorliegenden Erfahrungen über den Einfluss der Sauerstoffkonzentration zusammen, so sind erhebliche Änderungen der Oxydationsgeschwindigkeit bisher nur bei einigen niederen Tieren beobachtet worden. Es fragt sich, ob wir aus diesen Beobachtungen schliessen sollen, dass in den Zellen einiger Metazoen sich die Oxydationsgeschwindigkeit mit der Sauerstoffkonzentration besonders stark indert. Hier ist folgendes zu beachten: Wenn wir die Oxydationsgeschwindigkeiten bei den Sauerstoffkonzentrationen $c_{1}$ und $c_{2}$ messen, so ist eine Schlussfolgerung auf die Vorgänge in der Zelle nur dann statthaft, wenn die Sauerstoffkonzentrationen in der Zelle mit $c_{1}$ und $c_{2}$ annähernd im Gleichgewicht sind. Wird für diesen Ausgleich nicht gesorgt, so untersucht man de facto die Oxy-dationsgeschwindigkeiten bei Konzentrationen, die zu $c_{1}$ und $c_{2}$ in keiner irgendwie definierten Beziehung stehen, Diffusionen, Konvektionsströme usw. können dann die Oxydationsgeschwindigkeit bestimmen. M. Henze (6) hat das sehr anschaulich gezeigt in Versuchen an befruchteten Seeigeleiern.

Wenn er diese Zellen während des Atmungsversuchs in ständiger Bewegung hielt (er füllte eine Flasche mit Eiern und Scewasser völlig an und drehte sie in einem Thermostaten; die Eier schwebten dann dauernd zwischen Boden und Stopfen), so konnte eine Änderung des Gaswechsels mit der Sauerstoffkonzentration nicht konstatiert werden; wohl aber, wenn er die Eier am Boden der Flasche liegen liess. Im zweiten Fall befand sich natürlich nur die oberste Schicht der Wier mit der Sauerstoffkonzentration des Seewassers im Gleichgewicht, während für den Sauerstoffverbrauch in tieferen Schichten die Diffusionsgeschwindigkeit dahin und somit auch die Sauerstoffkonzentration in der überstehenden Flüssigkeit massgebend war. 
Beitrïge z. Physiologie d. Zelle, insbesondere über die Oxydationsgeschwindigkeit in Zellen. 266

Ich vermute mit Henze, dass sich die Zellen im Innern von Metazoenleibern bezüglich der Sauerstoffversorgung in ühnlicher Lage befinden künnen, wie die Seeigeleier am Boden der nicht bewegten Flaschen; dass sich die Z ellen der Metazoen, obwohl das ganze Tier eine starke Änderung des Sauerstoffkonsums bei verschiedenen Sauerstoffdrucken zeigt, nicht anders verhalten, als Bakterien, Seeigeleier, Blutzellen oder Pfanzenzellen. Für diese Interpretation spricht, dass niedere Tiere mit ausgebildetem Zirkulationssystem in ihrem Sauerstoffkonsum ebenso unabhëngig von der Sauerstoffkonzentration sind wie isolierte Zellen.

\section{Theoretisches:}

Aus Tatsachen, die im VI. Kapitel mitgeteilt werden, geht hervor, dass die Oxydationen in lebenden Zellen nicht im Hüssigen Zellinhalt, sondern an den Strukturteilen vor sich gehen. Die Konzentration eines Stoffes an den Grenzflüchen wächst nicht proportional der Konzentration in dem umspülenden Medium, sondern langsamer ( $\mathrm{rgl}$. die "Adsorptionsisotherme" H. Freundlichs [12]); wir können also behaupten, dass die Sauerstoffkonzentrationen an den Reaktionsarten in der Zelle sich nicht proportional den Konzentrationen in der umspülenden Flüssigkeit, sondern langsamer ändern werden. Das ist ein Gesichtspunkt.

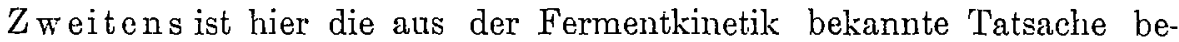
merkenswert, dass unter gewissen Bedingungen die Gesch windigkeit einer Fermentreaktion unabhängigsein kann von der Konzentration des Substrats, z. B. dann, wenn viel Substrat und wenig Ferment vorhanden ist.

Für die Rohrzuckerinversion durch Invertase gibt $A d r i a n$ Brown folgende Zahlen (13):

Gramm Rohrzucker in $100 \mathrm{ccm}$

$$
4,89
$$

19,91

$\cdot 29,96$

40,02
Gramm Rohrzucker in 60 Minuten invertiert.

1,23

1,36

1,36

1,24

1,076

Brown erklärt diese Konstanz der Umsatzgeschwindigkeit bei verschiedener Zuckerkonzentration recht plausibel so, dass die Zersetzung der Enzym-Zuckerverbindung relativ langsam vor sich geht, und dass die Umsatzgeschwindigkeit durch die Zersetzungsgeschwindigkeit dieser Enzymverbindung bestimmt wird; ist alles Enzym durch den Zucker "besetzt", so hat natürlich weiterer Zusatz von Zucker keinen Einfluss mehr auf die Umsatzgeschwindig- 
keit. - Ebenso ist die Gärungsgeschwindigkeit im Hefepresssaft, von einer gewissen niedrigen Zuckerkonzentration an, unabhängig von der Zuckerkonzentration (Harden [14]).

\author{
Kapitel IV.
}

\title{
Die Beinflussung der Oxydationsgeschwindigkeit durch lipoidunlösliche und lipoidlösliche Stoffe.
}

\section{Literatur.}

1. Overton, Nagels Handbuch der Physiologie. Bd. II.

2. Siebeck, Pflügers Archiv. 14S. 443 (1912).

3. Ruhland, Jahrb. f. wissenschaftl. Botanik. 51. 376 (1912).

4. Gryns, Pflügers Archiv. 63. 86 (1896).

5. Hedin, Pflügers Archiv. 6S. 229 (1897).

6. E. Masing, Pflü yers Arehiv. 149. 227 (1912).

7. O. Warburg, Hoppe-Seyler s. Zeitschr. 70. 413 (1911).

8. Eda ard Grafe, Hop pe-Seyler s. Zeitschr. 79. 421 (1912).

9. J. Loeb, Untersuchungen über die künstliche Parthenogenese. Leipzig 1906.

10. O. Warburg, Hoppe-Seyler. 66. 305 (1910).

11. J. Loeb und Wasteneys, Biochemische Zeitschr. 36. 345 (1911).

12. O. W arburg, Hoppe-Seyler. 57. 1 (1908).

13. J. Loeb, Handbuch der Biochemie, herausgeg. v. Oppenheimer. Bd. II. 1. Seite. 105 (1910).

14. Mc Clendon u. Mitchell, Journal of Biological Chemistry. 10. 4.59 (1912).

15. Curt Herbst, Archiv für Entwickelungsmechanik. 5. 650 (1897). 7. 486 (1898). 11. 617 (1901). 17. 306 (1903).

16. Höber, Physikalische Chemie der Zelle u. Gewebe. III. Anflage.

17. J. Loeb u. W asteneys, Biochem. Zeitschr. 28. 340 (1910). 31. 168 (1911).

18. O. Meyerhof, Bioch. Zeitschr. 33. 291 (19t1).

19. Curt Herbst, Archiv f. Entwickelungsmechanik. 7. 486 . 17. 385 .

20. J. Loeb, Archiv f. Entwickelungsmechanik 7. 631 und Pflügers Archiv. Bd. 103.

21. Derselbe u. Wasteneys, Bioch. Zeitschr. 37. 410 (1911).

22. Overton, Pflügers Archiv. 92. 115 (1902) u. 105. 176 (1904).

23. W. Stra ub, P flügers Archiv. 119. 127 (1907).

24. O. M e y er h of, Biochem. Zeitschr. 35. 246 .

25. Paul Ehrlich, Das Sauerstoftbedürfnis des Orianismus. Berlin 1885.

26. Pfeffer, Untersuchungen aus dem botan. Institut zu Tübingen $1886 \mathrm{Bd}$. Il. Seite 179.

27. O. Warburg u. Wiesel, Pflügers Archiv. 144. 465.

28. J. Trabbe, in Abderhaldens Arbeitsmethoden V. 1357 (1912).

29. O. Warburg, Hoppe-Seyler s. Zeitschr. 69. 452 (1910).

30. Ryuta Usui, Hoppe-Seyler s. Zeitschr. 81 . 175 (1912).

31. Overton, Studien üher die Narkose. Jena 1901.

32. O. W a rburg, Verhandlungen des Deutschen Kongresses für innere Medizin. 28. 553 (1911).

33. Derselbe u. Usui, Pflügers Archiv. 147. 100, 
34. Alfred Dorner, Hoppe-Seyler s. Zeitschr. 81. 99 (1912).

35. O. Warburg, Hoppe-Seyler s. Zeitschr. 76. 331 (1911).

36. E. Buchner, H. Buchner u. M. Hahn, Die Zymasegärung. 1903.

37. Spiro, Hofmeisters Beiträge. 4. 317.

38. Hans Meyer, Schmiedebergs Archiv. 42. 109 u. Baum 42. 119. 46. 338.

39. J. Traube, Pflügers Archiv. 123. 419 (1908).

40. Johannsen, Das Xtherverfahren beim Frühtreiben. Jena 1906.

41. J. Loeb, Die chemische Entwicklungserregung des tierischen Eies. Berlin 1909.

42. O. W arburg, Hoppe-Seyler s. Zeitschr. 71. 479 (1911).

43. M athews n. Walker, Journ. of Biological Chemistry. 6. 21 (1909).

44. Dieselben, Journ. of Biological Chemistry. 6. 29 (1909).

45. Rona u. Michaelis, Bioch. Zeitschr. 15. 209.

\section{Allgemeines.}

Die Grösse, mit deren Beeinflussung wir uns beschältigen werden, ist eine chemische Umsatzgeschwindigkeit, die wir durch Bestimmung der in der Zeiteinheit verbrauchten Sauerstoff- oder der in der Zeiteinheit produzierten Kohlensäuremenge messen. Die Geschwindigkeit dieses Umsatzes ist ohne weiteres nicht der chemischen Reaktionsgeschwindigkeit des Sauerstoffs mit dem organischen Brennmaterial gleichzusetzen; wir haben es hier zu tun mit einer Kette von Einzelvorgüngen. In einer solchen Kette wird die Geschwindigkeit des Umsatzes bestimmt durch die Geschwindigkeit des langsamsten Einzelvorgangs; dessen Geschwindigkeit also ist es, die wir messen. Je nach den besonderen Bedingungen kann einmal der eine, ein anderes Mal der andere Einzelvorgang der langsamste sein, so dass die Möglichkeit besteht, dass wir unter verschiedenen Bedingungen die Geschwindigkeit ganz verschiedener Prozesse messen, obwohl wir stets dieselbe Grösse, Sauerstoffverbrauch oder Kohlensäureproduktion, bestimmen ${ }^{1}$ ). Denken wir uns beispielsweise dieselbe Zelle einmal mit Zucker ernährt, einmal hungernd und einmal in einer Sauerstofflösung sehr kleiner Konzentrationen, so könnte im ersten Fall die chemische Reaktionsgeschwindigkeit des Sauerstoffs mit dem Zucker, im zweiten Fall die Mobilisierungsgeschwindigkeit des Reservekohlchydrats, im dritten Fall die Diffusionsgeschwindigkeit des Sauerstoffs die Menge des in der Zeiteinheit verbrauchten Sauerstoffs bestimmen. Wir werden im folgenden Kapitel sehen, dass die Diffusionen in der Regel schneller verlaufen als die chemischen Einzelvorgänge, dass sie mithin in der Regel die Umsatzgeschwindigkeit nicht bestimmen. Doch wird man gut tun, bei allen Beeinflussungen der Oxydationsgeschwindigkeit wenigstens mit der Möglichkeit zu rechnen, dass die Diffusionen den chemischen Vorgängen nicht mehr nachkommen.

1) Vergleiche hierzu das schöne Kapitel "The Mechanism of Fermentation" bei Harden, "Alkoholic Fermentation" London 1911. 


\section{Einteilung der Stoffe nach dem Gesichtspunkt der Lipoillöslichkeit.}

In der Überschrift dieses Kapitels sind die oxydationsbeeinflussenden Stoffe eingeteilt in lipoidlösliche und lipoidunlösliche, in solche, die sich in Fetten lösen und solche, die sich in Fetten nicht lösen. Diese Einteilung beruht auf der im Laufe von Jahren festgestellten, durch Hunderte von Experimenten erhärteten Tatsache, dass in der Wirkung dieser beiden Körperklassen auf die Atmung ein tiefgreifender Unterschied besteht.

Es wäre übertrieben, diesen Unterschied allein auf Durchlässigkeit oder Undurchlässigkeit der protoplasmatischen Grenzschicht zurückzuführen; immerhin aber spielt die Frage der Durchlässigkcit sowohl hier als auch überhaupt für das Verständnis der Oxydationsbeeinflussungen eine so grosse Rolle, dass wir uns mit den Eigenschaften der protoplasmatischen Grenzschicht eingehend beschäftigen müssen.

Narh Overton (1) besteht die Grenzschicht lebender Zcllen aus fettähnlichen Stoffen. Substanzen, die sich in Fetten lösen, gelangen durch Verteilung und Diffusion in das Innere der Zelle, die übrigen Substanzen auf unbekannte Art, vielleicht nur mittels Arbeitsleistungen des Protoplasten. Wir wissen heute, dass Overton mit dieser Theorie za weit ging. Wir kennen einerseits lipoidunlösliche Stoffe, die in die lebende Zelle hineinkommen, ohne dass irgend ein Anhaltspunkt für gleichzeitige Arbeitsleistung des Protoplasten vorliegt; und wir kennen andrerseits lipoidlösliche Stoffe, die nicht in das Innere der Zelle hineinkommen. Als Beispiel für den ersten Fall seien Versuche von Siebeck (2) angeführt, nach denen die Nierenepithelien und die Muskeln von Fröschen Kaliumchlorid aufnehmen, ohne dass die Zellgrenzschichten irreversibel verändert werden. Ein Beispiel für den zweiten Fall ist die von Ruhland gefundene Tatsache, dass einige basische lipoidlösliche Farbstoffe (3) die Zellgrenzschicht mancher Pflanzenzellen micht passieren. Die Farbstoffe, für die Ruhland dieses Verhalten feststellte, sind in wässrigen Lösungen kolloidal gelöst, sie diffundieren nicht in Gelatinegallerten.

Es hat vielleicht nichts Gezwungenes, wenn wir kolloidal gelöste Stoffe, vor allem solche mit erheblicher Teilchengrösse, gesondert behandeln und unser Interesse auf diejenigen Stoffe, die in echter Lösung an die protoplasmatische Grenzschicht herantreten, konzentrieren. Es lassen sich dann heute unter Berücksichtigung aller vorliegender Erfahrungen folgende Thesen aufstellen:

1. Sowohl lipoidlösliche als auch lipoidunlösliche Stoffe können die Grenzschicht lebender Zellen, ohne Arbeitsleistung von seiten des Protoplasten, passieren.

2. Wir kennen keine lipoidlöslichen Substanzen, die aus echter Lösung in das Innere der Zelle nicht eindringen. Dagegen kennen wir eine 
grosse Zahl lipoidunlöslicher Substanzen, für die eine Aufnahme in lebende Zellen nicht nachzuweisen ist. Welche Eigenschaften für lipoidunlösliche Substanzen entscheidend sind bezüglich Aufnehmbarkeit oder Nichtaufnehmbarkeit, ist unbekannt. Die Grenzschicht ein und derselben Zelle kann sich ganz verschieden verhalten gegenüber so ähnlichen Stoffen, wie Kaliumchlorid und Natriumachlorid, das eine Salz durchtreten lassen, das andere nicht.

3. Kennen wir die Konzentration eines lipoidlöslichen Stoffes in der Aussenflüssigkeit, so kennen wir damit auch die Konzentration des Stoffes in den wässerigen Zellphasen im Gleichgewicht. Diese letztere Konzentration ist gegeben durch das physikalische Gesetz der Verteilung. Haben wir aussen $1 \%$ Trethan in $0,9 \%$ iger Kochsalzlösung, so haben wir auch in Zellinnern, wenn es dort $0,9 \%$ ige Kochsalzlösung gibt, $1 \%$ Urethan usw.

Kennen wir dagegen die Konzentration eines lipoidunlöslichen Körpers in der Aussenfüssigkeit, und wissen wir, dass die Zellgrenzschicht für ihn passierbar ist, so können wir über die Konzentration dieses Stoffes im Zellinnern gar nichts aussagen.

Der Inhalt dieser drei Thesen lässt sich kurz so zusammenfassen: Bringen wir eine Zelle mit echtgelösten lipoidlöslichen Stoffen in Berührung, so wissen wir nicht nur, dass diese Stoffe in die Zelle hineinkommen, sondern wir wissen auch annähernd, wieviel von ihnen hineinkommt. Bringen wir dagegen Zellen mit lipoidunlöslichen Stoffen in Berührung, so kionnen wir gar nichts vorhersagen, weder qualitativ noch quantitativ; wenn wir wissen wollen, was passiert, so bleibt uns nichts übrig, als eine besondere Untersuchung von Substanz zu Substanz, von Zelle zu Zelle.

Die vorstehenden Schlusssätze behalten nun geradezu ihre Gültigkeit, wenn wir nicht das Aufnahmevermögen der Zellen, sondern die Beeinflussung der Oxydationsgeschwindigkeit zur Lipoid-Löslichkeit oder Unlöslichkeit in Beziehung setzen. Lassen wir lipoidlösliche Stoffe auf Zellen einwirken, so finden wir bei den verschiedenartigsten Zellen stets die gleiche Art der Oxydationsbeeinflussung; wenn wir für eine Zelle eine solche Wirkung konstatiert haben, so können wir sie für andere Zellen qualitati und quantitativ mit ziemlicher Sicherheit voraussagen. Für lipoidunlösliche Stoffe jedoch, Salze, Zuckerarten, Aminosäuren konnte irgend eine Regelmässigkeit nicht entdeckt werden, sie hemmen die Oxydationsgeschwindigkeit, beschleunigen sie oder lassen sie unverändert. Das ist ganz verschieden von Substanz zu Substanz, von Zelle zu Zelle ${ }^{1}$ ).

1) Eine andere, von vornherein vielleicht näherliegende Einteilung der oxydationsbeeinflussonden Stoffe, nämlich in Leiter und Nichtleiter, wäre durchaus unsachgemüss, weil die lipoidunlöslichen Nichtleiter, wie Zucker und Glykokoll, in ihrer Wirkung anf die Atmung den lipoidunlöslichen Leitern viel näher stehen, als den lipoidlöslichen Nichtleitern. 
Bei der nun folgenden Besprechung der einzelnen Körperklassen werden wir ihr Verhalten der Zellgrenzschicht gegenüber mit besonderer Aufmerksamkeit behandeln und dem Bericht über die Oxydationsbeeinflussung stets vorausschicken, was wir ïber die Aufnahme in die Zelle qualitativ und quantitativ wissen.

\section{Die lipoidunlöslichen Stoffe und roten Blutzellen.}

a) Aufnahme in die Zelle. Nach Gryns (4) dringen die Salze der Alkalien und Erdalkalien, die Aminosäuren und Zuckerarten in lebende Vogelblutzellen nicht ein. Gryns schloss das daraus, dass dem Vogelblutserum isotone Lösungen dieser Stoffe die Blutkörperchen nicht zur Auflösung brachten, bzw. ihr Volumen unverändert liessen. Würden sie in die roten Blutzellen eindringen, so würde der von innen auf der Zellgrenzschicht lastende osmotische Druck dauernd wachsen und sie schliesslich zersprengen. Die Schlüsse, die Gryns aus seinen Versuchen zog, fanden eine gute Bestätigung durch Hedin (5) , der die gleichen Substanzen zu einem Gemisch von Rinderserum und Rinderblutzellen zusetzte und dann in dem Serum die Konzentration der zugesetzten Stoffe durch Messung der Gefrierpunktserniedrigung bestimmte. Es ergab sich, dass Zuckerarten, Aminosäuren und Salze der Alkalien und Erdalkalien sich in einem Gemisch von Blutzellen und Serum zu der gleichen Konzentration aufiösten, wie in der Serumkomponente dieses Gemisches; die Zellkomponente also hatte sich an der Verdünnung nicht beteiligt, mit anderen Worten, die Stoffe waren nicht merklich in die Blutzellen eingedrungen. Was übrigens die Permeabilität für 'Traubenzucker anbetrifft, so verhalten sich nach einer kürzlich erschienenen Arbeit von Masing (6) die roten Blutzellen verschiedener Tiere offenbar verschieden, die Gänseerythrozyten waren undurchlässig für Zucker, menschliche Erythrozyten dagegen nahmen sehr erhebliche Zuckermengen auf, so dass beispielsweise, wenn die Zuckerkonzentration aussen 1 war, sie in der Zelle (die Zelle summarisch als zweites Lösungsmittel betrachtet) $\frac{6}{10}$ bis $\frac{7}{10}$ war. Wie dieser Unterschied zu erklären ist, wissen wir nicht; wichtig für die Zellphysiologie ist jedenfalls die Tatsache, dass die kernhaltigen nnd stark atmenden Gänseblutzellen Zucker in merklichen Mengen nicht hineinlassen, während kernlose und kaum mehr atmende, also nicht mehr intakte Blutzellen, für Zucker permeabel sind.

b) Wirkung auf Oxydationsgeschwindigkeit. Wie wirken nun diese Stoffe, die also in das Zellinnere in merklichen Mengen nicht hineinkommen, auf die Oxydationsgeschwindigkeit? Die Antwort lautet: zunächst gar nicht, wenn wir sie in serumisotonen Lösungen einwirken lassen. Bringen wir rote Vogel-Blutzellen aus einer Ringerlösung in eine Lösung 
Beiträge z. Physiologie d. Zelle, insbosondere über die Oxydationsgeschwindigkeit in Zellen. 273

vou Alkalisalzen, Erdalkalisalzen, Zuckern oder Aminosäuren, so ündert sich der Sauerstoffverbrauch im Lauf einiger Stunden nicht, er ist der gleiche in einer etwa $5 \%$ igen Traubenzuckerlösung und einer etwa 21/2\%igen Baryumchloridlösung (0. Warburg [7]). Erst ganz allmählich macht sich ein Einfluss lipoidunlüshicher Stoffe bemerkbar, nämlich ein (wahrscheinlich irreversibler) Abfall der Oxydationsgeschwindigkeit, sowohl in Baryumchlorid als auch in Natriumchlorid (O. Warburg und Grafe [8]).

Es lag sehr nahe, die Indifferenz der Atmung gegen lipoidunlösliche Stoffe einerseits, die Impermeabilität der Zellen gegen die gleichen Stoffe andererseits in ursiichlichen Zusammenhang zu bringen und die Theorie aufzustellen, dass diese Stoffe aul die Atmung zunächst nicht wirken, weil die Plasmahaut sie nicht oder nur sehr langsam in das Zellinnere hineinlässt. Die Richtigkeit dieser Theoric konnte durch einen sehr einfachen Tersuch erwiesen werden. Es gelingt nämlich, die Plasmahaut anzureissen oder zu durchlöchern (näheres vgl. Kapitel VI), ohne gleichzeitig die Atmang zu schädigen. Derartig rerletzte Formelemente reagieren ganz anders auf lipoidunlösliche Stoffe, Baryumchlorid bringt hier fast sofort die Atmung zum Stillstand und bewirkt in kürzester Zeit Veränderungen, wie sie bei intakten Zellen selbst im Laufe vieler Stunden njcht hervorgebracint werden. Die nachstehende Tabelle gibt einige zahlenmässige Belege, die Oxýdationsgeschwindigkeiten (in willkürlichen Einheiten) beziehen sich auf gleiche Zellmengen ein und derselben Zellsuspension bei gleicher Atmungszeit (70 Minuten) und bei gleicher Temperatur $\left(38^{\circ}\right)$.

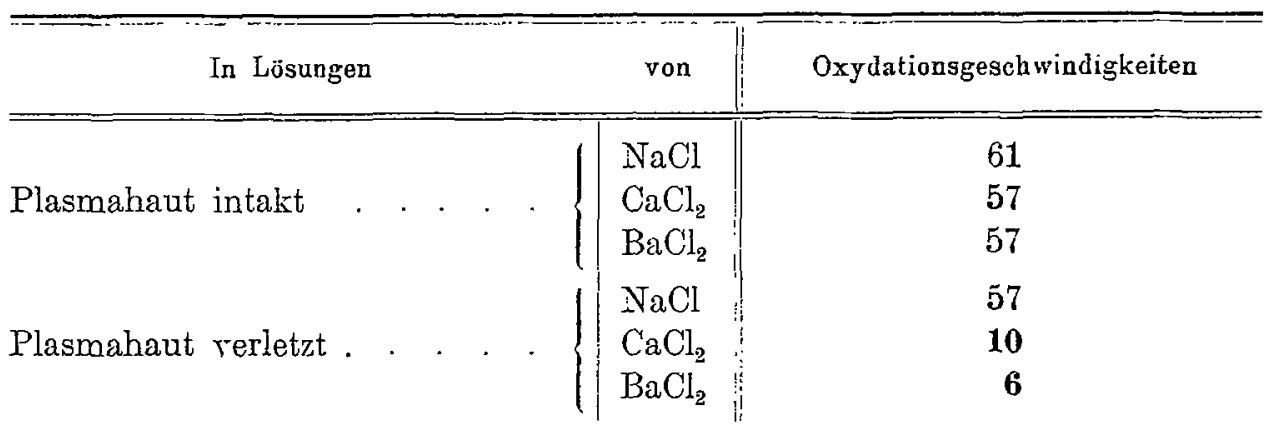

\section{Die lipoidunlöslichen Stoffe und Seeigeleier.}

a) Vorbemerkung: Die Indifferenz der Atmung intakter Zellen gegen lipoidunlösliche Stoffe ist keineswegs eine allgemein gültige Regel, das zeigen die Experimente an Seeigeleiern, in denen die Oxydationsgeschwindigkeit durch viele lipoidunlösliche Stoffe sehr erheblich geändert wird.

Ehe ich $z u$ der Besprechung der einzelnen Versuche übergehe, möchte ich einiges über Seeigeleier als Material für Atmungsexperimente voraus- 
schicken. Bei den roten Blutzellen liegen die Verhältnisse insofern besonders einfach, als sie sich weder teilen noch bewegen. Eine Oxydationsbeeinflussung an diesem Material wird also stets insoweit eine direkte sein, als der Umweg über Beeinflussung von Zellteilıng oder Bewegung ausgeschlossen ist. Beim Seeigelei jedoch, das sich nach der Befruchtung oder nach der Behandlung mit einer Reihe von Chemikalien rasch veründert, erscheint die Sache zunächst etwas komplizierter. Bei der Entwicklungserregung des Seeigeleis durch Sperma oder durch parthenogenetisch wirkende Mittel, wie sie von Jacques Loeb, Herbst, Delage und andern angewandt wurden, schnellt die Oxydationsgeschwindigkeit um mehrere hundert Prozent empor (O. Warburg 10). Wenn wir also hier die Oxydationen beschleunigen und gleichzeitig die. Furchung in Gang setzen, so kann die Frage aufgeworfen werden, ob die Oxydationsbeschleunigungen im unbefruchteten Ei als die Folgen der Entwicklungserregung, im befruch te ten Ei als die Folgen von Ïnderungen der Entwicklungsgeschwindigkeit aufzufassen sind. Diese Frage muss mit „nein" beantwortet werden. İs lässt sich nämlich, auf Grund des vorliegendeu Tatsachenmaterials, über die Bezieliungen zwischen Entwicklungsgeschwindigkeit und Oxydationsgeschwindigkeit folgendes sagen:

1. Ohne Atmung keine Furchung. Entziehen wir dem Ei den Sauerstoff, so bleibt die Furchung sofort stehen (J. Loeb [9]). 2. Wenn wir bei konstanter Temperatur die Oxydationsgeschwindigkeit jm befruchteten Ei erheblich verändern, so ändert sich unter allen Umständen auch die Furchungsgeschwindigkeit. Dieser Satz darf nicht so verstanden werden, dass sich die Furchungsgeschwindigkeit stets im gleichen Sinn ändert, wie die Oxydationsgeschwindigkeit. Beispielsweise kann die Furchungsgeschwindigkeit praktisch gleich Null werden, wenn wir die Oxydationsgeschwindigkeit verdoppeln. Wir können unseren Satz auch so ausdrücken; dass die Furchungsgeschwindigkeit auf keine Weise konstant gehalten werden kann, wenn wir die Oxydationsgeschwindigkeit erheblich ündern (O. W a r burg [10]). 3. Dagegen gelingt das Umgekehrte, wir können die Oxydationsgeschwindigkeit konstant halten und die Furchungsgeschwindigkeit ändern, beispielsweise ohne deutliche Änderung der Oxydationsgeschwindigkeit die Furchungsgeschwindigkeit von ihrer normalen Höhe praktisch auf Null herunterdrücken (O. Warburg [10j).

Die Furchungsgeschwindigkeit ist also abhängig von der Oxydationsgeschwindigkeit, die Oxydationsgeschwindigkeit jedoch in weiten Grenzen unabhängig von der Furchungsgeschwindigkeit (O. Warburg [10]), oder wie es später Jaques Loeb ausdrückte, die Oxydationsvorgänge sind die unabbängige Variable bei den Entwicklungsvorgängen [11]).

Ich kenne keinen Fall, in dem eine erhebliche Oxydationsbeschleunigung des befruchteten Eies, bei konstanter Temperatur, begleitet war von einer 
Beschleunigung der Furchung; im Gegenteil, eine erhebliche Oxydations. beschleunigung war stets verbunden mit einer Sistierung der Furchung.

Was das unbefruchtete $\mathrm{Ei}$ anbetrifft, so verhindern die meisten oxydationsbeschleunigenden und entwicklungserregenden Mittel die Entwicklung vollständig, solange die Eier den betreffenden Mitteln ausgesetzt werden. Die Entwicklung beginnt erst, wenn die Fier in reines Seewasser zurückgebracht werden; die Oxydationsbeschleunigung jedoch setzt schon während der Exposition in den betreffenden Witteln ein, sodass die Unabhängigkeit der Oxydationsbeschleunigung von der Entwicklung hier ebenso klar ist, wie beim befruchteten Ei. Allerdings gibt es einige Substanzen, z. B. sehr verdünnte Alkalien, in denen es schon vor dem Zurückbringen in reines Seewassen zu Furchungen kommen kann; Oxydationsanstieg und Furchungsbeginn sind also hier nicht zeitlich getrennt. Dass aber auch in derartigen Fällen die Oxydationsbeschleunigung unabhängig von dem Furchungsbeginn ist, lässt sich nachweisen, inden man die Konzentrationen der wirksamen Substanzen passend vergrössert: die Wirkung auf die Oxydationsgeschwindigkeit bleibt dann ziemlich unverïndert oder wird stärker, die Furchung steht still. Im folgenden sind, um den Überblick über die Tersuchsresultate zu erleichtern, nur solche Anordnungen beschrieben, in denen Oxydationsbeschleunigung bei aufgehobener Furchung beobachtet wurde.

b) Die Aufnahme in die Zelle. Was die Permeabilitiat der Seeigeleier für lipoidunlösliche Stoffe anbetrifft, so sind wir hier weniger gut orientiert, als über die Permeabilität der roten Blutzellen, quantitative Untersuchungen liegen nicht vor. Das einzige, was wir wissen, beschränkt sich auf das OH-Ion, das in das lebende befruchtete Strongylocentrotusei nicht merklich eindringt (vgl. Kapitel VI). Um so reichlicher ist die Zahl der Hypothesen, die bezüglich der Permeabilität der Seeigeleier gegenüber lipoidunlöslichen Stoffen, besonders gegenüber Salzen, gemacht wurden. So wirken nach Jaques Loeb die Salze und die OH-Ionen, nachdem sie in das $\mathrm{Ei}$ hineindiffundiert sind (13), nach Wac Clendon auf dieselbe Weise oder indem sie die Grenzschicht für andere Ionen passierbar machen (14). Beide Vorstellungen aber sind durch keinerlei Tatsachen gestützt, und verdanken ihre Entstehung im wesentlichen der Meinung, dass die Salze auf die chemischen Vorgänge im Ei nur wirken können, wenn sie in das Innere hineinkommen.

c) Die Wirkung derSalze der fixen Alkalien und alkalischen Erden auf die Oxydationsgeschwindigkeit. Unter ,normaler" Oxydationsgeschwindigkeit verstehen wir im folgenden die Oxydationsgeschwindigkeit im Wasser des Neapler Golfs. Nach den Untersuchungen von Herbst (15) sind die Salze, die in einigermassen erheblichen Quantitäten im Seewasser vertreten sind, alle notwendig zur Entwicklung und zum Wachstum der 
Seeigellarven, d. h. auf die Dauer sterben die Larven ab, wenn wir einen dieser Seewasserbestandteile fortlassen. Da mit dem Absterben der Larven auch die Atmung verschwindet, so kennen wir also keine einfachere Salzlösung, als das Seewasser, in der die Oxydationsgeschwindigkeit auf die Dauer normal ist.

Die Zeiten, um die es sich bei den Herbstschen Experimenten handelt, sind relativ lange; für kurze Versuchszeiten - meine eigenen Experimente beziehen sich nur auf wenige Stunden - gibt es viel einfachere Salzlösungen als das Seewasscr, in denen die Eier nicht zugrunde gehen und in denen die Oxydationsgeschwiudigkeit normal ist. Die einfachste derartige künstliche Salzlösung ist für das Neapler Strongylocentrotusci eine dem Seewasser isotone Lösung von Natriumchlorid und Calciumchlorid, die mit Natronlauge, oder besser einem Gemisch von Natronlauge und Natriumbikarbonat auf den OH-Ionen-Gehalt des Seewassers gebracht ist. Die Zusammensetzung dieser Lösung ist folgende: $100 \mathrm{ccm}$ Natriumchlorid $+2 \mathrm{ccm}$ Calciumchloridiösung, beide ${ }^{6 / 3}$ normal; dazu $0,5 \mathrm{ccm} 1 / 2$ normale Natriumbikarbonatlösung und $0,2 \mathrm{ccm} \mathrm{1/10} \mathrm{normale} \mathrm{Natronlauge.} \mathrm{In} \mathrm{einer} \mathrm{derartigen} \mathrm{Lösung}$ ist die Oxydationsgeschwindigkeit des befruchteten Strongylocentrotuseies innerhalb kurzer Versuchszeiten etwa gleich der in Seewasser. Für etwas längere Versuchszeiten empfiehlt sich noch ein Zusatz von $2,2 \mathrm{ccm}^{6} / 10$ normaler Kaliumchloridlösung. Eine solche Lösung wollen wir im folgenden als ,künstlicbe Salzlösung“" bezeichnen, sie ist im wesentlichen die van t'Hoffsche Lösung Jaques Loebs (9), unterscheidet sich von ihr nur durch ihren höheren osmotischen Druck.

Ausser Natriumchlorid, Kaliumchlorid und Calciumchlorid enth:ïlt das Seewasser in erheblichen Quantitäten noch Magnesiumchlorid und Magnesiumsulfat. Der Zusatz dieser Salze zu unserer künstlichen Salzlösung hatte innerhalb kurzer Versuchszeiten keinen deutlichen Einfluss auf die Oxydationsgeschwindigkeit. Beispielsweise (O. W arburg [10]) wurden folgende Zahlen erhalten (Oxydationsgeschwindigkeiten in willkürlichen Einheiten).

Befruchtete Eier.

\begin{tabular}{|c|c|}
\hline Zusammensetzung der Lösung & Oxydationsgeschwindigkeit \\
\hline I. $\begin{aligned} 100 \text { Moleküle } \mathrm{NaCl}+2,2 \mathrm{KCl}+2,0 \quad \mathrm{CaCl}_{2} \\
+7,8 \mathrm{NgCl}_{2}+3,8 \mathrm{MgSO}_{4} \\
(+ \text { Bikarbonat-NaOH}) .\end{aligned}$ & 7,8 \\
\hline $\begin{aligned} \text { II. } 100 \text { Moleküle } \mathrm{NaCl}+2,2 \mathrm{KCl}+2,0 \mathrm{CaCl}_{2} \\
(+ \text { Bikarbonat-NaOH}) .\end{aligned}$ & 7,5 \\
\hline III. $\begin{aligned} 100 \text { Moleküle } \mathrm{NaCl}+2,0 \mathrm{CaCl}_{2} \\
(+ \text { Bikarbonat-NaOH}) .\end{aligned}$ & 8,2 \\
\hline
\end{tabular}


Beiträge z. Physiologie d. Zelle, insbesondere über die Oxydationsgeschwindigkeit in Zellen. 277

Wir sehen also, dass wir sämtliche Salze, bis auf Natriumchlorid und Calciumchlorid, aus dem Seewasser entfernen können, ohne dass sich, iunerhalb kurzer Zeiten, die Oxydationsgeschwindigkeit ändert.

Lassen wir jedoch auch noch das Calcium fort, ist es mit der Indifferenz zu Ende. In einer reinen Kochsalzlösung sinkt die Oxydationsgeschwindigkeit sehr rasch ab; warum, das lehrt ein Blick ins Miskroskop: Die Eier werden durch die reine Kochsalzlösung zerstört.

Die schädliche Wirkung der reinen Kochsalzlösung ist wohl zuerst von Sidney Ringer (16) erkannt und systematisch studiert worden. Ringers Versuchsobjekte waren überlebende Froschmuskeln, die in reiner Kochsalzlösung geschädigt wurden und durch Zusatz kleiner Calciummengen wieder in ihren normalen Zustand gebracht werden konnten. Die Schïdigung durch die reine Kochsalzlösung war also eine reversible. Den Erfahrungen Rin gers hat Jaques Loeb eine Reihe hüchst interessanter Beobachtungen hinzugefügt (13). Fundulusembryonen, die in reinem destilliertem Wasser leben können, sterben in reinen Kochsalzlösungen rasch ab; durch die verschiedenartigsten Salze, selbst Zink- und Bleichlorid, kann diese Giftwirkung aufgehoben werden. Auch die erwähnte Giftwirkung der Kochsalz lösung auf befruchtete Seeigeleier ist von $\mathrm{Jaques}$ Loeb entdeckt worden.

Die Giftwirkung der reinen Kochsalzlösung auf das befruchtete Ei kaun durch kleine Mengen Natriumcyanid aufgehoben oder sehr stark verzögert werden $(\mathrm{O}$. Warburg 10.) Diese merkw ürdige Hemmung der Giftwirkung konnte auf verschiedene Weise zustande kommen. Es war möglich, dass die Plasmahaut eines atmenden Eies empfindlicher ist als die Plasmahaut eines nichtatmenden Eies, oder aber es konnte die Kochsalzlösung die Oxydationsgeschwindigkeit abnorm heraufsetzen und das Ii gewissermassen an einer allzugrossen Intensität der Atmung zugrunde gehen. Um hier zu entscheiden bestimmte ich die Oxydationsgeschwindigkeit befruchteter Eier in reinen Kochsalzlösungen. Das Resultat war, wie erwälnt, dass der Sauerstoffverbrauch absank. Ich ordnete nunmehr den Versuch so an, dass ich die Oxydationsgeschwindigkeit bei Gegenwart von Cyanid bestimmte. Natürlich musste dann der Vergleichslösung ebenfalls Cyanid zugesetzt werden, die auch sonst bezüglich des osmotischen Drucks und der OH-Ionenkonzentration mit der reinen Kochsalzlösung übereinstimmte, sich von ihr nur unterschied durch den Gehaltan Kaliumchlorid und Calciumchlorid. Bei dieser Versuchsanordnung war die Oxydationsgeschwindigkeit in der reinen Kochsalzlösung um mehrere hundert Prozent grösser, als in der Kontrollösung. Ich schloss daraus, dass auch bei Abwesenheit von Cyanid die Oxydationsgeschwindigkeit in der reinen Kochsalzlösung abnorm gesteigert sein.

Die Cyanidversuche wurden von Jaques Loeb und Wasteneys (17) wiederholt und bestätigt, meine Schlussfolgerung jedoch, dass auch bei $\mathrm{Ab}$ - 
resenheit von Cyanid die Oxydationen beschleunigt würden, für übereilt erklärt. Auf die einzelnen Einwände dieser Forscher sei hier nicht nüher eingegangen, weil unterdessen von $\mathrm{O}$. Meyerhof die strittige Frage durch ein direktes Experiment entschieden wurde. Neyerhof (18) stellte nämlich fest, dass auch bei Abwesenheit von Cyanid die Oxydationsgeschwindigkeit in einer reinen Kochsalzlüsung um mehrere hundert Prozent emporschnellt. Die direkte Messung gelang Me yerh of mit Hilfe eines sehr einfachen Kunstgriffs, er nahm so viele Eier, dass der Sauerstoftiverbrauch schon nach ganz kurzer Zeit gemessen werden konnte, nach Zeiten, in denen der grösste Teil der Eier noch nicht zugrunde gegangen war. Später hat auch ein amerikanischer Forscher, Mac Cle n d on (14), Oxydationsbeschleunigung in reinen cyanidfreien Natriumchloridlösungen beobachtet. Sein Versuchsmaterial waren unbefruchtete Arbaciaeier).

Wir können es also als feststehend betrachten, dass reine Natriumchloridlösungen die Oxydationsgeschwindigkeit im befruchteten Seeigelei sehr erheblich steigern. Wir können es als höchstwahrscheinlich betrachten, dass der Cyanidzusatz die Giftwirkung der Natriumchloridlösung deshalb vermindert, weil das Cyanid durch seine bekannte oxydationshemmende Wirkung die abnorme Atmungssteigerung kompensiert. Damit soll nicht gesagt sein, dass die reine Kochsalzlösung auf das Seeigelei allein durch Oxydationssteigerung giftig wird; ich denke mir den Zusammenhang so, dass das Chlornatrium primär die Grenzschicht verändert und dass diese Grenzschichtânderung ein abnormes Ansteigen der Oxydationsgeschwindigkeit mit der raschen Cytolyse zur Folge hat; dass aber dieselbe Grenzsehichtänderung auch bei Ünterdrückung der Oxydationen auf die Dauer zur Cytolyse führt.

Für eine solche Auffassung spricht die Tatsache, dass die Oxydationsgeschwindigkeit weder in roten Vogelblutzellen, noch in Froschsartorien in reinen Kochsalzlösungen gesteigert ist, obwohl auch diese Gebilde durch die Kochsalzlösung geschädigt werden. Der primäre Vorgang, die Veränderung der Zellgrenzschicht, wird in beiden Fällen wohl der gleiche sein, die Folgen dieser Veränderung jedoch werden für verschiedene Zellen verschiedene sein.

d) Die Wirkung der Schwermetalle auf die Oxydationsgeschwindigkeit. Auf die sehr merkwürdige Wirkung der Schwermetalle kam ich durch einen Zufall. Ich liess Natriumchlorid in einer Mailänder Fabrik umkrystallisieren, weil es kleine Mengen Bikarbonat enthielt. In Salzlösungen, die mit diesem umkrystallisierten Präparat hergestellt waren, blieb die Furchung befruchteter Strongylocentrotuseier sofort stehen, während die Oxydationsgeschwindigkeit um etwa $50 \%$ höher war als in Seewasser

1) Die Theorie Mac-Clendons, dass Natriumchlorid die Plasmahaut für OH-Ionen durchlässig mache, ist durch keine Tatsachen gestützt. 
Beiträge z. Physiologie d. Zelle, insbesondere über die Oxydationsgeschwindigkeit in Zellen. 279

oder künstlichen Salzlösungen, die mit Hilfe anderer Kochsalzpräparate hergestellt waren. Bei näherer Untersuchung des neuen Präparates ergab sich dann, dass es Kupferspuren enthielt, offenbar war es durch Eindampien in kupfernen Schalen umkrystallisiert worden. In der Tat konnten ganz die gleichen Erscheinungen durch Zusatz von Kupferspuren zu Seewasser hervorgerufen werden, also Sistierung der Furchung und gleichzeitig erhebliche Oxydationsbeschleunigung (10).

Es wurde nun systematisch eine grössere Zahl von Schwermetallen durchgeprült und dabei ergab sich, dass ähnlich wie Kupfer auch Silber und Gold wirkten; von Nickel, Kobalt, Eisen, Zinn, Zink, Cadmium, Blei und Platin konnten relativ grosse Mengen dem Seewasser zugesetzt werden, ohne dass sich die Oxydationsgeschwindigkeit änderte. Die Mengen von Kupfer, Silber und Gold, die in der beschriebenen Weise wirkten, waren etwa 1/10000 bis 1/100000 Grammatome pro Liter Seewasser. Da sich die Schwermetalle zum Teil mit den Salzen des Seewassers umsetzen, so haben die Konzentrationsangaben nur versuchstechnische Bedeutung, die wirklichen Ionen-Konzentrationen sind unbekannt. In der folgenden Tabelle bedeutet also $\mathrm{Au} \mathrm{10-5}$, dass einem Liter Seewasser 1!100000 Grammatoma Goldion zugesetzt war. (Oxydationsgeschwindigkeiten in willkürlichen Einheiten.)

Befruchtete Eier.

\begin{tabular}{l|c|c}
\hline \multicolumn{1}{c|}{$\begin{array}{c}\text { Oxydationsgeschwindigkeiten } \\
\text { in Metall-Seewasser }\end{array}$} & $\begin{array}{c}\text { Oxydationsgeschwindigkeiten } \\
\text { in Seewasser }\end{array}$ \\
\hline Au $10^{-5}$ & $6,5 \rightarrow$ & 5,1 \\
$\mathrm{Au} 10^{-5}$ & 6,0 & 4,0 \\
$\mathrm{Ag} 10^{-5}$ & 3,7 & 3,1 \\
$\mathrm{Cu} 10^{-5}$ & 5,4 & 4,4 \\
$\mathrm{Cu} \frac{1}{3} \times 10^{-4}$ & 12,0 & 7,8 \\
$\mathrm{Cu} \frac{2}{3} \times 10^{-4}$ & 8,8 & 5,4
\end{tabular}

Wir haben also Oxydationsbeschleunigungen zwischen 20 und $60 \%$ gegenüber Seewasser.

Es lässt sich nicht allgemein behaupten, ist aber in vielen Fällen so, dass lipoidunlösliche Substanzen, die die Oxydationsgeschwindigkeit in befruchteten Ei beschleunigen, auch die Oxydationsgeschwindigkeit im unbefruchteten $\mathrm{Ei}$ beschleunigen. Diese Beschleunigung ist dann relativ viel stärker als im befruchteten Ei. Folgende Tabelle illustriert das für Silber-, Kupfer- und Gold-Ionen. (Oxydationsgeschwindigkeiten in willkürlichen Einheiten.) 
Unbefruchtete Eier.

\begin{tabular}{|c|c|c|}
\hline \multicolumn{2}{|c|}{$\begin{array}{c}\text { Oxydationsgeschwindigkeiten } \\
\text { in Metall-Seewasser }\end{array}$} & $\begin{array}{c}\text { Oxydationsgeschwindigkeiten } \\
\text { in Seewasser }\end{array}$ \\
\hline $\mathrm{Ag} 10^{-5}$ & $8,0 \longrightarrow$ & 1,0 \\
\hline $\mathrm{Au} 10^{-5}$ & $\tilde{5}, 4$ & 1,8 \\
\hline $\mathrm{Cu} 10^{-5}$ & $\tilde{\jmath}, 4$ & 1,0 \\
\hline
\end{tabular}

Hier also haben wir Steigerungen bis zu $700 \%$.

e) Die Wirkung der OH-Ionen auf die Oxydationsgeschwindigkeit. In dem Gemisch von 100 Molekülen Natriumchlorid, 2,2 Molekülen Kaliumchlorid und 2,0 Molekülen Calciumchlorid, alle ${ }^{6} / 10$ normal, sind die befruchteten Eier von Strongylocentrotus nicht imstande, sich zu furchen. Die Furchung setzt jedoch sofort ein, wenn wir OH-Ionen hinzufügen in solcher Menge, dass die $\mathrm{OH}$-Ionenkonzentration etiwa gleich der des Seewassers wird. Bei Zusatz grösserer Mengen OH-Ionen steht die Furchung wieder still, ohne dass das $\mathrm{Ei}$ zunächst zytolysiert. Diese Tatsachen, die von Herbst (19) und J. Loeb (20) entdeckt wurden, veranlassten mich, den Einfluss der OH-Ionen auf die Oxydationsgeschwindigkeit zu studieren. Es ergab sich, dass die Oxydationsgeschwindigkeit in einem weiten Konzentrationsbereich dauernd langsam mit der OH-Ionenkonzentration wïchst. Die folgenden Daten beziehen sich auf befruchtete Eier von Strongylocentrotus. (Oxydationsgeschwindigkeiten in willkürlichen Einheiten.)

\begin{tabular}{|c|c|}
\hline & Oxydationsgeschwindigkeiten \\
\hline 1. $\mathrm{OH}$ Ionenkonzentration ca. $10^{-8}$ & 1,4 \\
\hline 2. $\mathrm{OH}$ Ionenkonzentration ca. $10^{-6}$ & 3,9 \\
\hline 3. OH Ionenkonzentration ca. $10^{-3}$ & 8,1 \\
\hline
\end{tabular}

Von diesen drei Lösungen verhinderten 1. und 3. die Eifurchung vollständig, während in 2. normale Furchung stattfand (10).

Auch die Oxydationen im unbefruchteten Ei werden durch Erhöhung der OH-Ionenkonzentration beschleunigt und zwar ebenso wie durch die Schwermetalle relativ stärker im unbefruchteten, als im befruchteten Ei. War beispielsweise die Oxydationsgeschwindigkeit des unbefruchteten Strongylocentrotuseies bei der OH-Ionenkonzentration von $10^{-7} 1,3$, so war sie bei der OH-Ionenkonzentration $10^{-3} 8, \overline{0}$.

Die Messung der Oxydationsgeschwindigkeit bei verschiedenen OHIonenkonzertrationen wurde von Jaques Loeb und Wasteneys (21) 
Beiträge z. Physiologie d. Zelle, insbesondere über die Oxydationsgeschwindigkeit in Zellen. 281

wiederholt. Als Versuchsmaterial dienten Eier von Arbacia, die sich ganz ähnlich verhielten, wic die Strongylocentrotuseier; war beispielsweise die Oxydationsgeschwindigkeit bei der OH-Ionenkonzentration $10^{-7} 1,0$, so war sie bei der OH-Ionenkonzentration $10^{-3}$ 2,7. Auch zwei andere amerikanische Forscher, Mac Clendon und Mitchell (14) berichteten kürzlich über Beschleunigung der Oxydationsgeschwindigkeit im Seeigelei durch OH-Ionen.

Wie kommt nun die Wirkung der $\mathrm{OH}-$ Ionen zustande? Wir wissen, dass viele Autoxydationsprozesse in vitro bei steigenden $\mathrm{OH}$-Tonenkonzentrationen schneller verlaufen, und so war hier sicherlich das nëchstliegende, anzunehmen, dass die OH-Ionen in das $\mathrm{Ei}$ hineindiffundierten und dort wirkten, wie auf Autoxydationen in vitro. An dieser Interpretation begann ich zu zweifeln, als ich mit den Arbeiten Overtons (22) bekannt wurde. Wenn man die Tatsachen, die Overton mitteilt, sorgfältig erwägt, und den Überlegungen Overtons auch nur teilweise folgt, so wird man mit der Annahme, dass Ionen glatt in das Innere der Zellen hineindiffundieren, zum mindesten etwas zuräckhaltend werden und die Frage, ob in einem besonderen Fall ein Ion in das Zellinnere hineinkommt, durch besondere Experimente zu entscheiden versuchen. Ein solches Experiment war nun für unsere Anordnung nicht schwer auszudenken, ich brachte in das Ei einen alkalimetrischen Indikator, Neutralrot, und die mit Neutralrot gefärbten Eier darauf in die alkalische Salzlösung. Der Indikator im Innern des Eies gab hierbei nicht die Reaktion der Aussenflüssigkeit an, sondern eine zum mindesten um mehrere $Z$ ehnerpotenzen kleinere OH-Ionenkonzentration. (Bezüglich aller Einzelheiten und auch der Widerlegung von Einwänden muss ich auf die Darstellung im Kapitel VI verweisen). Dass keine OH-Ionen in das Ei hineinkommen, darf hieraus nicht geschlossen werden. Vielleicht nimmt das lebende Ei minimale Mengen OH-Ionen auf, die wir nicht nachweisen können. Soviel aber steht fest, dass eine möglicherweise stattfindende Aufnahme mit der Wirkung, die uns hier interessiert, der Wirkung auf die Oxydationsgeschwindigkeit, nichts zu tun hat.

Während hinsichtlich der Tatsache der OH-Ionenwirkung völlige Einmütigkeit besteht zwischen den amerikanischen Forschern und mir, so stösst die Anschauung, dass die OH-Ionenwirkung eine Grenzschichtwirkung ist, in Amerika noch immer auf Zweifel. Es gibt jedoch keine Tatsachen, die diese Zweifel stützen; der Widerstand ist wohl auch mehr historisch zu erklären: Die Hypothese, dass die Salze in das Innere des Eies hineindiffundieren, hat eine grosse Rolle gespielt bei den berühmten Untersuchungen J. Lo e bs und seiner Schule über die künstliche Parthenogenese und es ist begreiflich, dass eine Arbeitshypothese, die sich als so fruchtbar erwies, nur schwer und ungern verlassen wird. 
Auf e in en Gesichtspunkt jedoch, den Jacques Loeb mehrmals zugunsten seiner Diffusionstheorie angeführt hat (z. B. 21), möchte ich kurz eingehen. Loeb fand nämlich, dass Neutralrot, ein basischer Farbstoff, entwickelungserregend wirkt; dass diese Substanz in das Innere des Eies eindringt, davon kann man sich jederzeit durch einen Blick ins Mikroskop überzeugen. Alle Stoffe, die entwickelungserregend wirken, beschleunigen auch die Oxydationen (O. Warburg 10), höchst wahrscheinlich also, darin stimme ich mit L o e b überein, beschleunigt auch Neutrolrot die Oxydationen. Jacques Loeb kalkuliert nun so: Neutralrot ist eine Base, Neutralrot beschleunigt die Oxydationen und Neutralrot dringt in das Innere des Eies ein. Also haben wir hier einen Fall von Oxydationsbeschleunigung durch eine Base, die im Innern des Eies wirkt, und es ist nicht sehr wahrscheinlich, dass die eine Base durch Veränderung des Eiinnern, andere Basen durch Veränderung der Eigrenzschicht die Oxydationen beschleunigen. Darauf ist erstens zu erwidern, dass eine Grenzschichtwirkung nicht dadurch ausgeschlossen wird, dass ein Stoff in das Zellinnere hineinkommt. Ein Stoff, der in das Innere der Zelle eindringt, kommt zuerst mit der Zellgrenzschicht in Berührung. Bekannt ist ein Versuch von Straub (23) nach dem die Wirkung mancher Gifte auf das Aplysiaherz nur so lange andauert, als sie sich in der Spülungsflüssigkeit befinden; dass die Giftwirkung verschwunden ist, wenn die ganze Giftmenge sich im Innern der Herzmuskelzelle befindet. - Zweitens ist auf das Lo e b sche Argument zu erwidern, dass Neutralrot, obwohl es ein basischer Farbstoff ist, höchstwahrscheinlich nicht als Base, sondern als nichtspezifischer lipoidlöslicher Stoff die Oxydationen im Ei beschleunigt. Das Kriterium für die Zugehörigkeit eines Stoffes in diese Klasse oxydationsbeschleunigender Substanzen ist, wie wir später sehen werden, dass die Oxydationen im befruchteten Ei nicht beschleunigt, soudern, bei grösseren Konzentrationen, umgekehrt gehemmt werden. Ich selbst verfüge über keine Messungen der Oxydationsgeschwindigkeit unter dem Einfluss von Neutralrot, doch möchte ich voraussagen, dass die Oxydationen im befruchteten Ei durch Neutralrot nicht beschleunigt werden.

f) Die Wirkung hypertonischer Lösungen'auf die Oxydationsgeschwindigkeit ist zwar weniger übersichtlich, als die bisher angeführten Wirkungen, beansprucht aber insolern ein besonderes Interesse, als hypertonische Lösungen in der Geschichte der künstlichen Parthenogenese eine grosse Rolle gespielt haben. Bekanntlich ist es mit ihrer Hilfe Jacques Loeb zum erstenmal gelungen, unbefruchteten Seeigeleiern den Anstoss zur Entwickelung schwimmender Larven zu geben (9).

Wenn wir das befruchtete Arbaciaei in Seewasser bringen, dem auf $100 \mathrm{ccm} 1 \mathrm{~g}$ Kochsalz zugesetzt ist, so bleibt die Zellteilung stehen, die Kernleitung wird erheblich verzögert. Eine deutliche Ïnderung der Oxydations- 
Beiträge z. Physiologie d. Zelle, insbesondere über die Oxydationsgeschwindigkeit in Zellen. 283

geschwindigkeit ist nicht $\mathrm{zu}$ konstatieren (O. Warburg [12]). Fügt man mehr Kochsalz hinzu, etwa 2-4 g auf $100 \mathrm{ccm}$, ausserdem noch etwas Natronlauge, so steigt die Oxydationsgeschwindigkeit sehr erheblich an; die stärksten Oxydationsbeschleunigungen, die ich beobachtete, kamen in solchen Lösungen zustande. Wieviel dabei die Erhöhung des osmotischen Drucks, wieviel das Akali, wieviel endlich die Störung des Salzgleichgewichts, in unserem Fall die Vermehrung der Natrium- und Chlor-Ionen ausmacht, wurde bis jetzt nicht festgestellt.

Ebenso wie die Schwermetalle und die OH-Ionen, wirken die hyper tonischen Lösungen auf die Oxydationsgeschwindigkeit im unbefruchteten Ej. relativ stärker als im befruchteten $\mathrm{Ei}$; Oxydationsbeschleunigungen im unbefruchteten Ei um mehr als $1000 \%$, um erheblich mehr als durch die natürliche Befruchtung, sind in hypertonischalkalischen Lösungen keine Seltenheit. Die Entwicklung, Kernteilung und Zellteilung, unterbleibt vollständig in solchen Lösungen.

Schon vor vielen Jahren hat Jacques Loeb die Vermutung ausgesprochen, dass die Entwickelungserregung durch hypertonische Lösungen in irgend einem Zusammenhang mit Ïnderungen der Oxydationsgeschwindigkeit im Ei stände und die äusserst interessante Entdeckung gemacht, dass die Wirkung der hypertonischen Lösung ausbleibt, wenn man die Oxydationen durch Blausäure verhindert. Die Messungen der Oxydationsgeschwindigkeit haben nun in der Tat gezeigt, dass Jacques Loeb mit dieser Theorie das Richtige traf.

\section{Die lipoidlöslichen Stoffe.}

a) Aufnahme in die Zelle. Lipoidlöslich sind die meisten Vitalfarbstoffe und die Beobachtungen von $\mathrm{Ehrlich}$ (25), Pfeffer (26) u. a. über Vitalfärbung sind wohl die ersten sicheren Beobachtungen über die Aufnahme lipoidlöslicher Stoffe in lebende Zellen. Ebenso direkt und sinnfällig, wie die Aufnahme von Farbstoffen, kann an besonderen Objekten die Aufnahme gewisser basischer Substanzen demonstriert werden : in gerbstoffhaltigen Pflanzenzellen bilden manche Basen Niederschläge mit Gerbsäure; Zellen, die alkaliempfindliche Farbstoffe normalerweise enthalten oder mit solchen gefärbt wurden, ändern ihre Farbe, wenn sie in ammoniakhaltige Lösungen gebracht werden.

Systematisch hat zuerst Gryns (4) Substanzen verschiedener Konstitution unter dem Gesichtspunkte geprüft, ob sie in lebende Zellen hineinkommen und welche Eigenschaften über Aufnehmbarkeit oder Nichtaufnehmbarkeit entscheiden. Die Versuche waren ebenso angestellt, wie die obenerwähnten mit lipoidunlöslichen Stoffen. Rote Blutkörperchen wurden in Lösungen gebracht, die dem Serum isoton waren; bei schnell einsetzender Hämolyse 
wurde clann der Schluss gezogen, dass die Zellgrenzschicht für die betreffende Substanz durchgängig sei. Die Substanzen, die nach Gryns in die Blutkörperchen eindringen, gehören grösstenteils zu den lipoidlöslichen.

Bei der Grynsschen Versuchsanordnung wird die Durchlässigkeit indirekt erschlossen auf Grund der Theorie der osmotischen Hämolyse, die, soviel wir heute wissen, in diesen Fällen durchaus das Richtige traf. Weniger zwingend ist eine indirekte Methode Overtons, der vielfach das Eintreten der „Narkose", d. h. irgend einer reversiblen Hemmung vou Lebensvorgïngen als Kriterium des Eindringens und der Geschwindigkeit des Eindringens benutzte; denn wir wissen heute, dass reversible Hemmungen von Lebensvorgängen auch durch Grenzschichtwirkungen herrorgerulen werden können.

Die indirekten Methoden von Gryns und Overton wurden ergänzt durch die direkte Wethode $\mathrm{He}$ dins (כ), der ebenso wie für die lipoidunlüslichen Stoffe, für eine grössere Zahl lipoidlöslicher Stoffe die Verteilung zwischen Zellen und verdünntem Scrum, an Rinderblut, gemessen hat. Seine Resultate stimmten, soweit die gleichen Substanzen untersucht wurden, mit denen von $G$ ryns und Overton überein, die Grenzschicht der Rinderblutkörperchen wurde durchlässig getunden für lipoidlösliche Stoffe.

Die Arbeit Hedins ist die einzige, die über das Qualitative hinausgeht, aus Hedins Daten ist nicht nur zu entnehmen, ob ein Stoff eindringt sondern auch wieviel von ihm eindringt. (Wir sehen dabei ab von vereinzelten Angaben, die sich in der pharmakologischen Literatur finden, z. B. Pohl, Archiv f. exper. Path. u. Pharmak. 28, 239 (1891); Archangelsky, ebenda 46, 347 (1901); Gréhant, C. R. de la soc. de biologie 1899, und die sich immer nur auf vereinzelte Substanzen beziehen, so dass, worauf es hier im wesentlichen ankommt, die Aufnehmbarkeit verschiedener Substanzen nicht verglichen werden kann.) Hedin fand, dass sich viele lipoidlösliche Substanzen gleichmässig auf Zellen und Zwischenflüssig. keit verteilten, dass sich einige aber auch recht erheblich in den Zellen anreicherten. Beispielsweise sollten sich Methylalkohol und Amylalkohol gleichmässig zwischen Zellen und Zwischenflüssigkeit verteilen, Aceton sich in den Zellen anreichem.

Die Frage, wieviel von einer Substanz in die Zelle hineinkommt, ist, wenn man sich mit den Wirlsungen der Substanzen in der Zelle beschältigt, von grösstem Interesse. Sie ist gewissermassen, wenn man die Wirkungen in den Zellen verstehen will, eine Vorfrage. Für eine grössere Anzahl Substanzen, mit deren Wirkung auf die Oxydationen wir uns im folgenden beschäftigen werden, habe ich Verteilungsmessungen angestellt und folgte dabei insofern $\mathrm{Hedin}$, als ich für einige Messungen das Gefrierpunktsverfahren benutzte. In zwei wesentlichen Punkten jedoch hielt ich es für zweckmässiger, Hedin nicht $\mathrm{zu}$ folgen: Ich nahm nicht Rinderblut, sondern Vogelblut, weil, wie ich schon oben erwähnte, 
die kernlosen Säugetierblutzellen keine intakten Zellen sind und es immer ungewiss bleibt, wieweit man Resultate, die an kernlosen Blutzellen gewonnen sind, auf intakte Zellen übertragen darf. Es kam hinzu, dass es zweckmässiger war, die Verteilung an denjenigen Zellen $z u$ studieren, an deuen auch die Beeinflussung der uns interessierenden Lebenserscheinung, der Atmung, studiert wurde. - Die Deutung der Resultate bei Hedins Anordnung wird dadurch etwas erschwert, dass die Aussenflüssigkeit zum Teil aus Serum, einem in physikalisch-chemischer Beziehung wenig übersichtlichen Substanzgemisch bestand. Ich nahm deshalb als Aussenfüssigkeit nicht Serum, sondern dem Serum isotone Kochsalzlösung, bestimmte also die $V^{r}$ erteilung zwischen den kernhaltigen atmenden roten Blutzellen und Kochsalzlösung. Die Resultate wichen zum Teil erheblich von denen Hedins ab, Aceton reicherte sich nicht, wie $\mathrm{H}$ edin es gefunden haben wollte, in der Zelle an, im Gegenteil, es war im Gleichgewicht weniger Aceton in der Zelle als in der Salzlösung. Methylalkohol und Amylalkohol verteilten sich nicht gleichmässig in der Zelle, sondern es wurde melır Amylalkohol aufgenommen als Methylalkohol (27).

Der Anwendungsbereich der Gefrierpunktsmethode ist ein ziemlich enger, wegen der relativen Ungenauigkeit der Methode; die Verteilungen von Stoffen, deren Konzentration aus irgendwelchen Gründen in der Salzlösung klein sein musste, konnten mit ihr nicht bestimmt werden. So wird schon die Verteilungsmessung mittels der Gefrierpunktsnethode für Stoffe von der Löslichkeit des Amylalkohols oder Butylurethans recht ungenau. Für schwerer lösliche Substanzen also mussten andere Wege eingeschlagen werden.

Der folgende Weg ist geeignet, gerade bei solchen Substanzen, bei denen die Gefrierpunktsmethode versagt: Für eine bestimmte Substanz wuxde die Atmungshemmungskurve aufgenommen, d. h. die Abh:ingigkeit der Atmungshemmung von der Konzentration bestimmt. Praktisch wird das so ausgeführt, dass gleiche Quantitäten Zellsuspension mit verschiedenen Konzentrationen einer Substanz durch mehrmaliges Waschen auf der Zentrifuge ins Gleichgewicht gesetzt werden und darauf die Atmungshemmungen bei den verschiedenen Konzentrationen gemessen werden. Angenähert können wir daun aus der Atmungshemmung, die die gleiche Substanz in unbekannter Konzentration bewirkt, auf ihre Konzentration in der Aussenflüssigkeit schliessen. Vermischen wir beispielsweise ein Volumen einer konzentrierten Blutzellensuspension in Kochsalzlösung mit einem Volumen einer Kochsalzlösung, der eine bekannte Menge Phenylurcthan zugesetzt ist, und bestimmen die Atmungshemmung, die das Phenylurethan in diesem Gemisch bewirkt, so können wir aus der Atmungshemmungskurve, die für Phenylurethan an einem Teil der gleichen Zellsuspension aufgenommen wurde, die Konzentration des Phenylurethans ablesen, die nach dem Mischen in der Aussenflüssigkeit herrscht. Aus der Differenz der Konzentrationen vor und nach dem Ver- 
mischen wird dann die von den Zellen fortgenommene Menge berechnet. Die Grenauigkeit dieser Methode ist nicht sehr gross, aber zur Entscheidung der uns interessierenden Fragen vielfach ausreichend.

Eine dritte Methode, die wir gelegentlich inwandten, ist die Messuug der Oberflächenspannung einer Lösung vor und nach dem Mischen mit Zellen. Kennen wir die Konzentration, die einer bestimamten Oberflächenspannung entspricht, so erfahren wir durch die Änderung der Oberflächenspannung die beim Vermischen eintretende Konzentrationsänderung und können die in die Zelle aufgenommene Substanzmenge aus der Differenz der Konzentrationen vor und nach dem Mischen berechnen. Die Methode ist für Verteilungsmessungen von J. Trau be (28) empfohlen; sie ist keiner sehr allgemeinen Anwendbarkeit fähig, weil beim Arbeiten mit konzentrierten Zellsuspensionen, insbesondere mit Blutzellen, stets eine kleine Menge Zellen mechanisch verletyt wird, wobei dann Stoffe in die Aussenflüssigkeit übertreten, die die Oberflächenspannung verändern. Uit Erfolg haben wir die Methode nur angewendet für Verteilungsversuche mit Stromata von Blutzellen, Formelementen, die vorher so lange gewaschen sind, bis nichts mehr in die Aussenflüssigkeit übertritt.

Viertens haben wir auch chemische Methoden augewandt und die Verteilung von Aceton und ron Thymol jodometrisch bestimmt (29 u. 30).

Die Substanzen, auf die sich unsere Untersuchungen erstreckten, waren: Wethylalkohol, İthylalkohol, Propylalkohol, Isobutylalkohol, Amaylalkohol, Methylurethan, Diäthylharnstoff, Butylurethan, Phenylurethan, Aceton, Methylphenylketon und Thymol. Das Resultat war: Amylalkohol und Butylurethan verteilen sich annühernd gleichmässig über Salzlösung und Zellsuspension. Von den übrigen Stoffen findet sich im Gleichgewicht teils mehr, teils weniger in der Zellsuspension als in der Aussenflüssigkeit, bezogen auf gleiche Volumina. Die Abweichungen von gleichmässiger Verteilung sind hierbei recht erheblich. Mischen wir beispielsweise $10 \mathrm{ccm}$ Methylalkohol-Salzlösung mit $10 \mathrm{ccm}$ konzentrierter Zellsuspension, so nimmt die Methylalkoholkonzentration so ab, als ob mit 7,7 und nicht mit $10 \mathrm{ccm}$ Salzlösung verdünnt worden wäre; anders ausgedrückt, die Zellsuspension verhült sich so, als ob $2,3 \mathrm{ccm}$ von $10 \mathrm{ccm}$ keinen Methylalkohol aufnähmen. Mischen wir andererseits $10 \mathrm{ccm}$ 'Thymol-Salzlösung mit $10 \mathrm{ccm}$ Zellsuspension, so nimmt die Thymolkonzentration so ab, als ob nicht mit $10 \mathrm{ccm}$, sondern mit $60-80 \mathrm{ccm}$ Salzlösung verdünnt worden wäre; anders ausgedrückt, die Thymolmenge in der Zellsuspension ist im Gleichgewicht $6-8 \mathrm{mal}$ so gross als in der Salzlösung. Diese Zahlen beziehen sich nicht auf die Zellen, sondern auf die Zells u spensi onen, die etwa zu ${ }^{4 / 5}$ aus Zellen, zu $1 / 5$ aus $Z$ wischenflüssigkeit bestanden. Zieht man das Volumen der $Z$ wischenflüssigkeit mit in Rechnung, so wird das besondere Verhalten der Zellen noch deutlicher, die Verteilungszahlen weichen noch mehr von der Einheit ab. Bemerkenswert ist, dass alle 
Beiträge z. Physiologie d. Zelle, insbesondere über die Oxydationsgeschwindigkeit in Zellen. 287

diese Messungen an lebenden Zellen angestellt sind, insoweit wenigstens, als die verwendeten Konzentrationen die Atmung nicht hemmten oder sie reversibel hemmten.

In den folgenden Tabellen sind die Resultate der Messungen als Teilungskoeffizienten zwischen Zellsuspension und Salzlösung angegeben. Diese Teilungskoeffizienten besagen, wievielmal mehr von irgendeiner Substanz im Gleichgewicht in ei nem Volumen der konzentrierten Zellsuspension vorhanden ist, als in einem Volumen der umspülenden Salzlösung. Die Teilungskoeffizienten haben natürlich keine physikalisch-chemische Bedeutung; denn die Aufnahmefiahigkeit der Zellsuspension setzt sich zusammen aus der Aufnahmefähigkeit der Zwischenflüssigkeit und der Aulnahmefähigkeit der verschiedenen Zellphasen.

Die Konzentrationen, die in der umspülenden Salzlösung nach eingetretenem Verteilungsgleichgewicht herrschen, wollen wir als die „Aussenkonzentrationen" bezeichnen. Diese Aussenkonzentrationen waren in den Versuchen, denen die Daten der Tabelle I entnommen sind, sehr verschiedene: Für Gruppe I 0,3 bis 0,6 molar; für Gruppe II 0,06 bis 0,1 molar; für Methylphenylketon ca. 0,009 molar; für Phenylurethan ca. 0,0025 molar; für Thymol ca. 0,0002 bis 0,001 molar. Es sind das alles Konzentrationen von der Grössenordnung der atmungshemmenden; sie wurden gewählt, weil es mir ursprünglich darauf ankam, die bei der Atmungshemmung in der Zelle befindlichen Substanzmengen zu kennen. (Die Daten der 3 Tabellen stammen aus den Arbeiten von O. Warburg u. Wiesel [27]; O. Warburg und Usui [20! und aus noch unveröffentlichten Versuchen A. Dorners.)

Tabelle I.

\begin{tabular}{|c|c|c|}
\hline & & 'T'eilungsverhältnis $\frac{\text { Zellsuspension }}{\text { Salzlösung }}$ \\
\hline I. Gruppe & $\begin{array}{l}\text { Methylalkohol } \\
\text { Äthyl lkohol } \\
\text { Propylalkohol } \\
\text { Butylalkohol (iso) } \\
\text { Methylurethan } \\
\text { Diäthylharnstoff } \\
\text { Aceton }\end{array}$ & $0,7-0,8$ \\
\hline II. Gruppe & $\begin{array}{l}\text { Amvlalkohol (Gärungs) } \\
\text { Butylurethan }\end{array}$ & $0,9-1,1$ \\
\hline III. Gruppe & $\begin{array}{l}\text { Wethylphenylketon } \\
\text { Pheaylurethan. } \\
\text { Thymol }\end{array}$ & $\begin{array}{c}\text { ca. } 2 \\
\text { ca. } 3 \\
6-7\end{array}$ \\
\hline
\end{tabular}


Für die Theorie der Verteilung ist die Kenntnis der Teilungskoeffizienten verschiedener Substanzen bei gleichen Aussenkonzentrationen wichtig; wir haben deshalb für einen Vertreter der ersten Gruppe, das Aceton, und für einen Vertreter der dritten Gruppe, das Thymol, die Verteilung bei annähernd gleichen Aussenkonzentrationen gemessen. Es ergab sich, dass der Teilungskoelfizient für Aceton bei einer Aussenkonzentration von 0,000ら́ Molen pro Liter etwa 0,8 , der Teilungskoeffizient des Thymols bei der gleichen Aussenkonzentration 7 bis 8 ist. Die Unterschiede der Teilungskoeffizienten für Thymol und Aceton, wie sie Tabelle I zeigt, beruhen also nicht a uf der Verschiedenheit der Aussenkonzentrationen.

Die folgenden beiden Tabellen geben, zur Ergänzung des Gesagten, einige Daten über die Verteilung von Aceton und Thymol bei wechselnden Aussenkonzentrationen.

Tabelle II. Aceton.

\begin{tabular}{c|c}
\hline Aussenkonzentration & $\begin{array}{c}\text { Teilungskoefizient } \begin{array}{c}\text { Zellsuspension } \\
\text { salzlösung } \\
\text { (auf etwa 5\% genau) }\end{array} \\
\text { ca. } 0,05 \text { molar } \\
\text { ca. } 0,005,\end{array}$ \\
ca. 0,0005, & 0,83 \\
& 0,84 \\
& 0,84
\end{tabular}

Tabelle III. Thymol.

\begin{tabular}{l||c|c}
\hline \hline & $\begin{array}{c}\text { Aussenkonzentration (Gewichts- } \\
\text { prozente) in der Salzlösung }\end{array}$ & Teilungsverhältnis $\frac{\text { Zellsuspension }}{\text { Salzlösung }}$ \\
\hline Versuch I & 0,0044 & 7,4 \\
0,0084 & 6,5 \\
$0,015(0,001$ molar) & 6,4 \\
Versuch II & 0,0083 & 6,7 \\
0,016 & 6,6 \\
& - & - \\
$0,0031(0,0002$ molar) & 8,0 \\
0,0038 & 7,4 \\
0,0044 & 7,3
\end{tabular}

Theorie der Verteilung. Wir nehmen im folgenden an. dass die Unterschiede der Teilungsverhältnisse für s äm tliche Substanzen der Tabelle Iauch dann existieren, wenn die Aussenkonzentrationen gleich sind. Erwiesen ist die Richtigkeit dieser Annahme bisher nur für Aceton und Thymol. 
Beiträge z. Physiologie d. Zelle, insbesondere über die Oxydationsgeschwindigkeit in Zellen. 289

Niemand, der die Tabelle I nur flüchtig überblickt, wird sich, im Zeitalter der Lipoidtheorie, des Gedankens erwehren, dass es die verschiedene Löslichkeit in den Zellipoiden ist, die für die Unterschiede der Verteilung verantwortlich zu machen ist. Denn mit wachsendem Teilungsverhältnis zwischen Zellsuspension und Salzlösung wächst auch das Teilungsverhältnis zwischen Lipoiden und Salzlösung und die Annahme liegt nahe, dass sich die Stoffe der ersten Gruppe in den Zelllipoiden weniger, die der zweiten Gruppe etwa ebenso wie in der Salzlösung lösen, während sich von den übrigen Stoffen mehr in den Zelllipoiden löst, als in der Salzlösung.

Gegen diese Interpretation möchte ich zwei Argumente anführen. Ich habe oben erwähnt, dass von $10 \mathrm{ccm}$ Zellsuspension sich $2,3 \mathrm{ccm}$ so verhalten, als ob sie Methylalkohol merklich nicht aufnühmen, bei Berücksich. tigung des Volumens der Zwischenflüssigkeit würde das heissen, dass von $8 \mathrm{ccm}$ Zellen $2,3 \mathrm{ccm}$ Methylalkohol merklich nicht a ufnähmen. Mehr als $1 / .4$ des Zellvolumens käme also als Lösungsmittel für Methylalkohol nicht in Betracht und, wären die Zelllipoide hierfür verantwortlich $\mathrm{zu}$ machen, soverhielte sich mehrals $1 / 4$ des Zellvolumens wie eine lipoide Phase. Diese Zahl halte ich für ganz unwahrscheinlich hoch.

Das zweite und schwerwiegendere Argument ist das Resultat von Messungen an Gänseblut-Stromata, die zu einem erheblichen 'Teil aus Lipoiden bestehen. Diese Formelemente habe ich durch Auskochen mit Alkohol und Ïther von ihren Lipoidstoffen befreit und die Verteilung einiger Substanzen zwischen lipoid haltigen Stromata und Salzlösung einerseits, zwischen lipoidfreien Stromata und Salzlösung andererseits verglichen. Hierbei konnte, für Thymol und Heptylalkohol, ein deutlicher Unterschied nicht gefunden werden; die Anreicherung in den fetthaltigen und fettreien Stromata war für die genannten Substanzen die gleiche. Die Lipoide der Stromata also, soviel lässt sich mit Sicherheit sagen, kommen für die Anreicherung von Thymol und Heptylalkohol nicht in Betracht (Ryuta Usui [30]).

Ich will nun keineswegs behaupten, dass die Zelllipoide in den Blutzellen als nichtwässerige Phasen gar nicht fungieren, sie tun es vielleicht zum Teil, zum Teil nicht ${ }^{1}$ ). Für das verschiedene Aufnahmevermögen unserer Zellen gegenüber den verschiedenen Substanzen ist jedoch meines Erachtens weniger der Lipoidgehalt der Zellen als folgendes verantwortlich zu machen : bei dem beträchtlichen Gehalt der Zelle an festen Stoffen, die teils im Zellinhalt gelöst, teils unlöslich, z. B. als feste Strukturbestandteile, vorhanden sind,

1) Wie sich Lipoide, die aus Zellen mittels Alkohol-Äther gewoncen und so a us ihren natürlichen Verbindungen herausgelöst sind, in vitro als Lösungsmittel verhalten, ist hier nicht entscheidend. Es scheint mir sehr wohl möglich zu sein, dass eine in Wasser aufgequollene Lipoid-Eiweissverbindung sich lediglich wie eine wässerige Phase verhält. 
darf die Zelle nicht einfach als wässeriges Lösungsmittel betrachtet werden. Sie verhält sich vielmehr wie ein Gemisch flüssiger und fester Phasen, in dem das Volumen der festen Phasen nicht $z u$ vernachlässigen ist. Berücksichtigen wir weiterhin, dass alle Substanzen unserer Tabelle an den Grenzflächen zwischen wässerigen Phasen und anderen Phasen verdichtet werden. Diese Verdichtung an den Grenzflächen ist für die verschiedenen Substanzen verschieden, von den untersuchten Stofien wird Methylalkohol am schwächsten, Thymol am stärksten ,,adsorbiert" und dazwischen ordnen sich die übrigen Substanzen hinsichtlich der Stärke ihrer Adsorbierbarkeit in der gleichen Reihenfolge, in der ibr Teilungsverhältnis zwischen Zellen und Salzlösung wächst.

Bringen wir eine unserer Substanzen mit Zellen und Salzlösung in Berührung und sehen zunächst von der Adsorption ab, so würde, wegen des Volumens der festen Zellbestandteile, das Teilungsverhältais zwischen Zelle und Salzlösung stets kleiner sein als 1. Dazu kommt nun die Adsorption. Für viele Substanzen, für die die Verdichtung an den Oberflächen im Vergleich zu den gelösten Mengen keine Rolle spielt, erhalten wir, trotz Adsorption, ein kleineres Teilungsverhältnis als 1. So erklïre ich die Teilungsverhältnisse der 1. Gruppe in Tabelle I. Für andere Substanzen kommt die Adsorption im Vergleich zur Löslichkeit erheblich in Betracht und das Teilungsverhältnis zwischen Zellsuspension und Salzlösung wird grösser als 1. So erkläre ich die Zahlen für Thymol, Phenylurethan und Methylphenylketon. Das Teilungsverhältnis von 1, wie wir es in der 2. Gruppe haben, würde dann gefunden, wenn die Verminderung der Löslichkeit durch die festen Zellbestandteile und die Verdichtung an den Oberflächen sich gerade kompensierten.

Ich halte es für nicht an der Zeit, diese 'Theorie ins einzelne auszuspinnen und will im besonderen die Frage offen lassen, ob die Adsorption an den Kolloidteilchen der Sole, oder die Adsorption an den ,unlöslichen “Struktur teilen" ${ }^{1}$, den Gelen, mehr im Vordergrund steht. Untersuchungen, die hier entscheiden sollen, haben wir begonnen und, für den Spezialfall des Thymols, gefunden, dass die Hälfte des in der Zelle befindlichen Thymols an den unlöslichen Strukturteilen sitzt ${ }^{2}$ ) (Ryuta Usui [30]).

b) Einteilung in spezifisch und nichtspezifisch wirkende lipoidlösliche Stoffe. Die Wirkung einer Anzahl lipoidlöslicher Stoffe auf die Oxydationsgeschwindigkeit wird bestimmt durch ihre im chemischen Sinn reaktionsfähigen Gruppen, beispielsweise die Wirkung vieler aliphatischer Amine durch die Amidogruppe, die Wirkung vieler Aldehyde durch die Aldehydgruppe. Für andere lipoidlösliche Stoffe besteht eine solche Beziehung nicht; die Wirkung vieler Alkobole, Ketone, Nitrile wird nicht bestimmt

1) Die Adsorption aussen an der Zelle kommt wahrseheinlich nicht in Betracht.

3) deren Entfettung, wie oben orwähnt, das Bindungsvermögen für Thymol nicht verändert. Es kann sich also auch nicht um eine "Adsorption an Lipoiden" handeln. 
Beiträge z. Physiologie d. Zelle, insbesondere über die Oxydationsgeschwindigkeit in Zellen. 291

durch die Alkohol-, Keton- oder Nitrilgruppe. Die Begründung dieser Behauptung wird im folgenden gegeben werden. Wir wollen hier ihre Richtigkeit voraussetzen und die lipoidlöslichen Stoffe, je nachdem ihre Wirkung durch die chemisch reaktionsfähigen Gruppen bestimmt wird oder nicht, als spezifisch wirkende und nichtspezifisch wirkende unterscheiden (kurz: spezifische und nichtspezifische). Die nichtspezifischen Stoffe sind im wesentlichen dieselben, die die Pharmakologen als "Alkoholnarkotika" bezeichnen, grösstenteils auch dieselben, die Overton (31) „indifferente Narkotika“ nennt.

Lipoidlösliche Stoffe künnen die Oxydationen hemmen oder beschleunigen; die nichtspezifischen hemmen ganz allgemein, beschleunigen nur ausnahmsweise; unter den spezifischen gibt es eine Klasse, die allgemein sowohl hemmen als auch beschleunigen kann, nämlich Ammoniak und Ammoniakderivate.

c) Oxydationshemmungen durch nichtspezifische lipoidlösliche Stoffe. Bringen wir rote Blutzellen von Vögeln aus einer reinen Ringerlösung in eine solche, die $0,5 \%$ Amylalkohol enthält, so sinkt sofort die Oxydationsgeschwindigkeit. Entfernen wir den Amylalkohol wieder, indem wir die Zellen mit reiner Ringerlösung waschen, so steigt die Oxydationsgeschwindigkeit auf die ursprüngliche Höhe, falls die Amylalkoholwirkung nicht zulange andauerte. In kleineren Amylalkoholkonzentrationen ist die Oxydationshemmung geringer als in grösseren Konzentrationen. Eine derartige Wirkung ist charakteristisch für eine grosse Anzahl lipoidlöslicher Substanzen; die Konzentrationen verschiedener Substanzen jedoch, die die gleiche Wirkung hervorbringen, sind sehr verschieden. Die Konzentrationen derselben Substanzen, die an verschiedenen Zellen die gleiche Wirkung hervorbringen, sind auffallend ähnlich. Die Zellen, für die wir das feststellten, waren: Bakterien, Hefezellen, Seeigeleier, rote und weisse Blutzellen, ThymusLymphozyten vom Kalb, Fischspermatozoen, Leberzellen von Maus und Frosch und schliesslich Nervenzentren vom Frosch. ${ }^{1}$ ) Einige Versuchsreihen, die genau ausgearbeitet wurden, sollen im folgenden in Tabellenform wiedergegeben werden. Unter hemmender Konzentration ist diejenige Konzentration

1) Neine erste Mitteilung erschien in Hoppe-Seyler's Zeitschrift f. physiolog. Chemio Bd. 69 im Jahre 1910. Meine Versuche hat später Herr Vernon in Oxford auf Nierengewebe ausgedehnt. In seinen Publikationen (die erste diesbezügliche 1912) sah Herr Vernon zunächst daron ab, meinen Namen zu nennen; später geschah das mehr beiläufig, indem Herr Vernon den Anschein zu erwecken suchte, als ob es sich bei seinen Experimenten um etwas anderes handle: die von $\mathrm{ihm}$ beobachteten Hemmungen seien irreversibel, die von mir beobachteten reversibel. Abgesehen davon, dass diese Unterscheidnng etwas ungemein gesuchtes hat, möchte ich Herra Vernon darauf aufmerksam machen, dass die Hemmungen bei Mäuselebern, nach Versuchen von Usui und mir (Pflüger's Archiv 147, 100) irreversibel waren. (Vergl. Vernon, Journal of Physiology 45, 197. 1912 und Biochem. Zeitschrift 47, 374. 1913). 
angegeben (in Grammmolekülen pro Liter), die einen Abfall der Oxydationsgeschwindigkeit um $30-70 \%$ bewirkt.

I. Rote Vogelblutzellen (O. Warburg, 29; 7; 32).

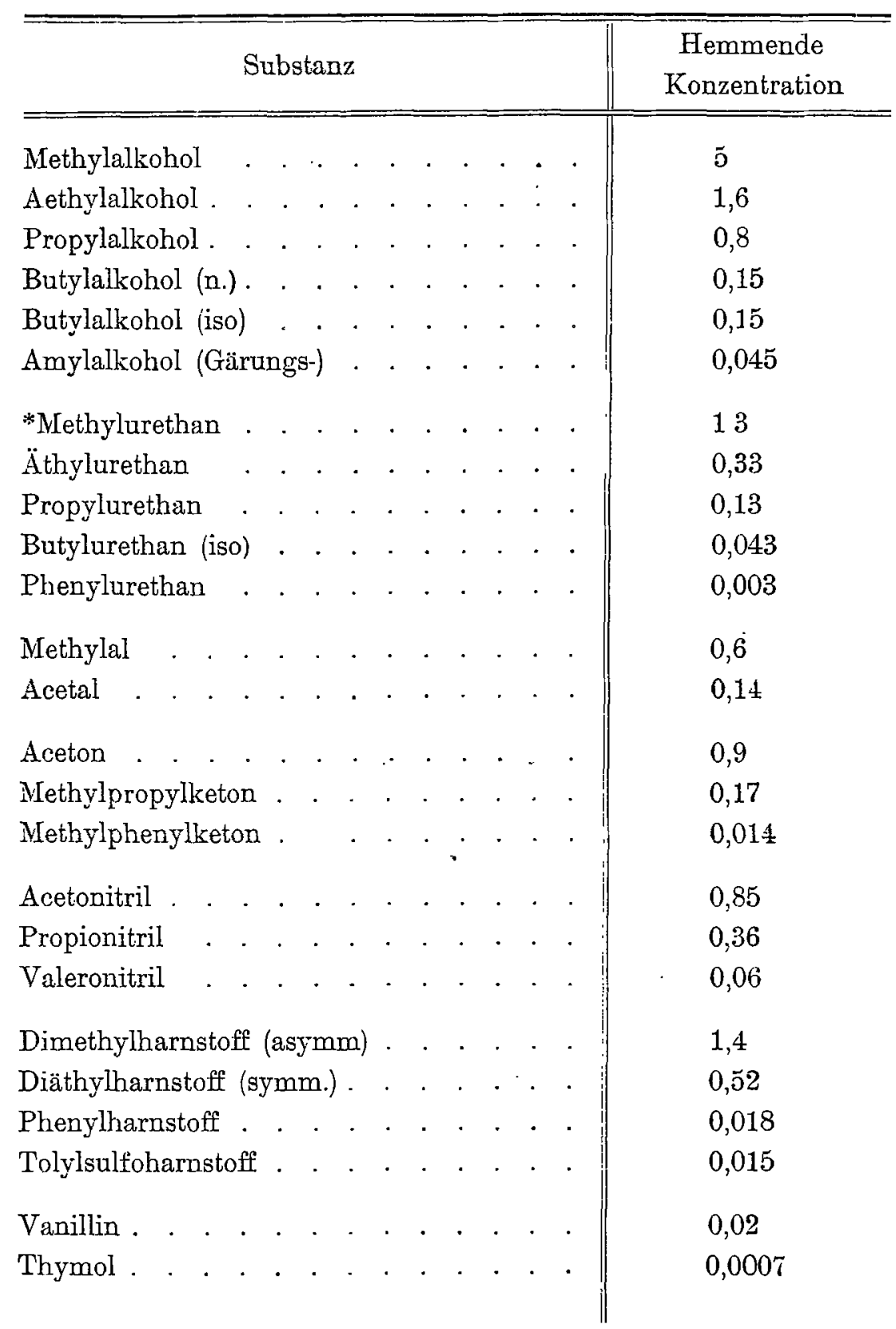


Beiträge z. Physiologie d. Zelle, insbesondere über die Oxydationsgeschwindigkeit in Zellen. 293

II. Vibrio Metschnikoff (O. Warburg u. Wiesel [27]).

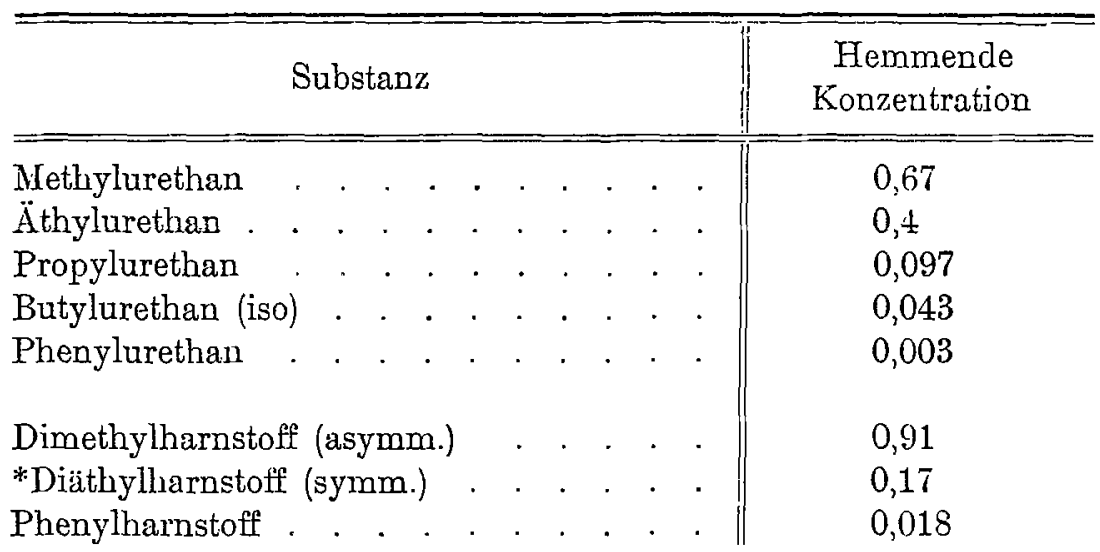

III. Leberläppchen von Mäusen (O. Warburgu. Usui [33]).

\begin{tabular}{|c|c|c|c|c|c|c|c|c|c|}
\hline \multicolumn{9}{|c|}{ Substanz } & $\begin{array}{c}\text { Hemmende } \\
\text { Konzentration }\end{array}$ \\
\hline Aceton . . & & . & . & . & . & & & . & 0,41 \\
\hline Methylpropylketon & . & . & & . & . & & & . & 0,19 \\
\hline Methylphenylketon & n. & . & & 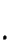 & & & & . & 0,017 \\
\hline Dimethylharnstoff & . & . & & . & . & & & . & 0,57 \\
\hline Phenylharnstoff . & . & . & . & . & . & & & . & 0,037 \\
\hline Äthylurethan & . & & & & & & & . & 0,45 \\
\hline Propylurethan & . & . & . & . & . & & & . & 0,15 \\
\hline Phenylurethan & . & . & - & . & & & & . & 0,0062 \\
\hline Amylalkohol (Gäru & ungs & & & & & & & & 0,06 \\
\hline
\end{tabular}

IV. Zentralnervensystem vom Frosch (O. Warburg u. Usui [33]].

\begin{tabular}{|c|c|c|c|c|c|c|c|c|}
\hline \multicolumn{8}{|c|}{ Substanz } & \multirow{2}{*}{$\begin{array}{c}\begin{array}{c}\text { Hemmende } \\
\text { Konzentration }\end{array} \\
1,3\end{array}$} \\
\hline Methylurethan & . & & & & & & & \\
\hline Äthylurethan. & . & & & . & & ${ }^{\circ}$ & . & 0,45 \\
\hline Propylurethan &. & & & & & . & . & 0,13 \\
\hline Butylurethan (iso) & . . & & & . & & & . & 0,06 \\
\hline Phenylurethan . & . & & & & & . & & 0,0062 \\
\hline Aceton . . & . & & & & & & 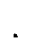 & 0,41 \\
\hline Methylpropylketon & . & - & & . & & & 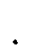 & 0,14 \\
\hline Methylphenylketon & . & & & & & & . & 0,017 \\
\hline Phenylharnstoff . & & . & & & & & . & 0,037 \\
\hline Amylalkohol (Gärur & igs-) & & - & & & & & 0,046 \\
\hline
\end{tabular}


Die Wirkungen der augeführten Substanzen auf Blutzellen und Bakterien waren, mit Ausnahme je einer (in den Tabellen mit einem Kreuzchen bezeichnet) vollständig reversibel. Die Wirkungen auf das Zentralnervensystem rom Forsch waren nur teilweise reversibel, auf die Mäuseleber völlig irreversibel. Die Zahlen der Tabellen III und IV sind also nicht genau vergleichbar mit denen der Tabellen I und II.

Versuchen wir nun, aus unseren Daten zu entnehmen, wodurch die Wirkungen der Stofie bestimmt werden. Aus Tabelle I und II geht hervor, dass die Eigenschaften, auf die es bei der Oxydationshemmung ankommt, ausgeprägter sind bei den höheren Gliedern einer homologen Reihe, als bei den niederen Gliedern, Phenylurethan wirkt $100 \mathrm{mal}$ so stark, wie Ïthylurethan, Amylalkohol 100 mal so stark wie Methylalkohol, Acetal $4 \mathrm{mal}$ so stark wie Methylal, Valeronitril $14 \mathrm{mal}$ so stark wie Acetonitril usw. Und zwar sind die Unterschiede unter Gliedern einer Reihe, beispielsweise der Alkoholreihe, viel grösser als die Unterschiede unter Gliedern verschiedener Reihen mit gleicher oder ähnlicher Zahl nicht verzweigter Kohlenwasserstoffradikale. Die chemisch träge Kohlenwasserstoffkette also bestimmt mehr die Wirkungsstärke, als die chemisch-reaktionsfähigen Gruppen, die Alkohol-, Nitril- oder Ketongruppe. Die Regelmässigkeit, die hier zum Ausdruck kommt, wollen wir als die "Regel der homologen Reihe" bezeichnen; es ist beachtenswert, dass Körperklassen mit recht reaktionsfähigen chemischen Gruppen in ihrer Wirkung auf die Oxydationen sich dieser Regel fügen.

Dass Stoffe, die wir nach unserer Definition als nichtspezifische bezeichnen, mit ihren reaktionsfilihigen Gruppen in der Zelle nicht reagieren, kümnen wir nicht behaupten. Ja, es ist sogar sehr wahrscheinlich, dass Gruppen wie die Ketongruppe oder die aliphatische Doppelbindung a uch chemische Reaktionen eingehen. Diese Reaktionen jedoch haben mit der Wirkung auf die Oxydationsgeschwindigkeit nichts z u tun; da die Wirkung einer bestimmten Menge stundenlang konstant bleibt, können solche Reaktionen auch nicht in einem Umfang eintreten, dass die Mengen der oxydationshemmenden Stoffe merklich vermindert werden.

Vergleichen wir ferner die verschiedenen Tabellen miteinander, so springt ohne weiteres die merkwürdige Regelmüssigkeit in der Wirkungsstärke ein und derselben Substanz auf verschiedene Zellarten in die Augen, beispielsweise wird die Oxydationsgeschwindigkeit durch Äthylurethan um annähernd den gleichen Betrag gehemmt in roten Blutzellen bei der Konzentration 0,33, im Vibrio Metschnikoff durch die Konzentration 0,4 , in der Mäuseleber durch die Konzentration 0,45, im Froschzentralnervensystem durch die Konzentration $0,4 \check{\text { o }}$. Diese merkwürdige Gleichförmigkeit der Wirkungen veranlasste mich, die Geschwindigkeit einer anderen chemischen Reaktion, der alkoholischen Gärung, unter dem Einfluss der gleichen Substanzen zu studieren. Bs 
Beiträge z. Physiologie d. Zelle, insbesondere über die Oxydationsgeschwindigkeit in Zellen. 295

ergab sich, dass die Geschwindigkeitderalkoholischen Gürung in der lebenden Zelle bei ganz ähnlichen Konzentrationen um etwa denselben Betrag, wie die Geschwindigkeit der Oxydationen, gehemmt wurde. Einige Daten gebe ich in der folgenden Tabelle, in der die hemmenden Konzentrationen in Gewichtsprozenten eingetragen sind. Zum Vergleich stehen neben den gärungshemmenden die entsprechenden atmungshemmenden Konzentrationen (O. Warburg und Dorner [34j).

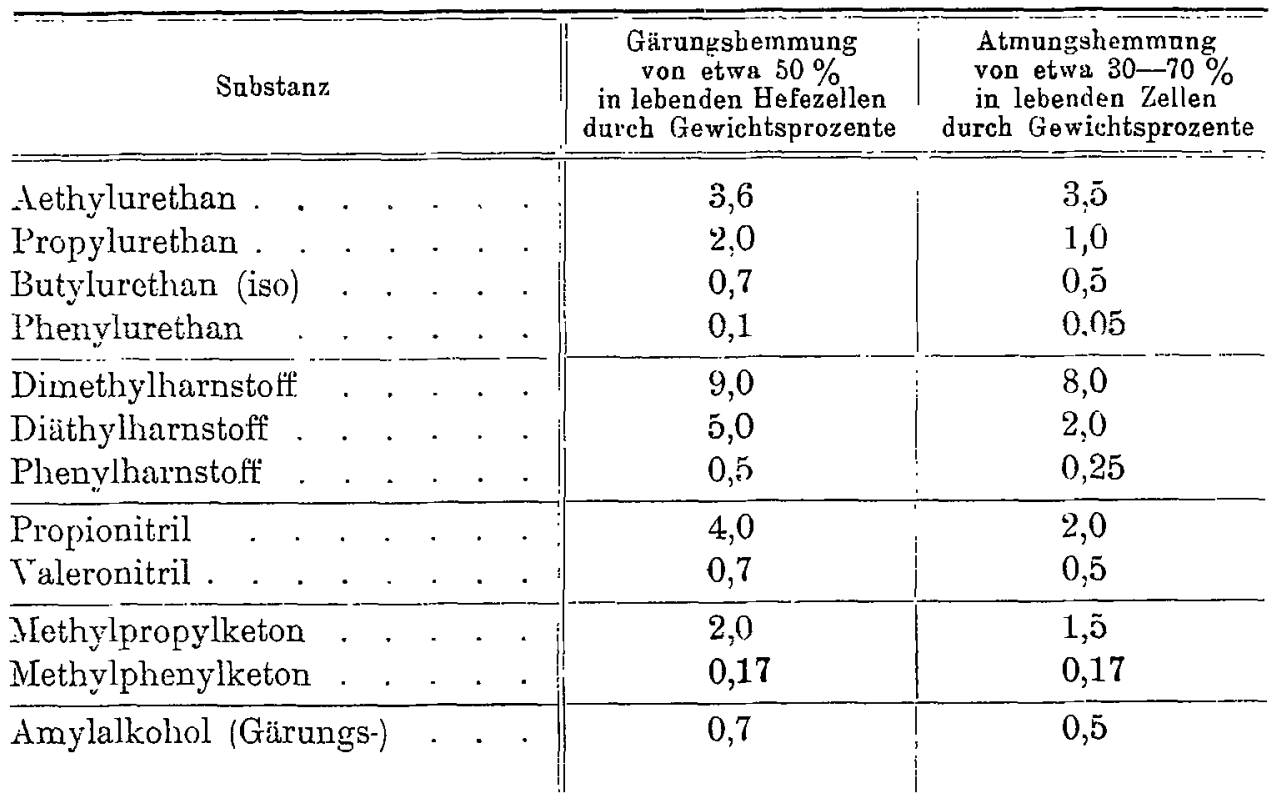

Das Anwachsen der Wirkung mit der Konzentration. Die Kenntnis dieser Beziehung ist in mancher Hinsicht wichtig. Einige Messungen an roten Vogelblutzellen sind in den Kurven auf den folgenden Seiten graphisch wiedergegeben. Geprüft wurden in der Regel drei Kouzentrationen, c, $1 / 2 \mathrm{c}$ und $1 / 4 \mathrm{c}$, von denen $\mathrm{c}$ die Geschwindigkeit um $80-90 \%$ hemmte (O. Warburg [35j]). Physikalisch-chemisch lässt sich mit diesen Kurven zunächst nicht viel anfangen, die „Konzentrationen" sind die in der Aussenflüssigkeit und höchstwahrscheinlich verschieden von den Konzentrationen an den Reaktionsorten.

Der Mechanismus der $\mathrm{H}$ emmungen. Es sind im wesentlichen zwei Tatsachen, die hier von Wichtigkeit sind (O. Warburg und Wiesel [27] und Dorner [34]). Die erste ist die, dass dieselben Substanzen in ähnlichen Konzentrationen, wie in der lebenden Zelle, die Geschwindigkeit einer Fermentreaktionen in vitro hemmen, nämlich die Geschwindigkeit der alkoholischen Gärung im Hefepresssaft. Eine $\frac{2}{10}$ normale Amylalkohollösung wirkt etwa gleich einer 5 fach normalen 
Methylalkohollösung, Ïthylurethan wirkt stärker als Butylurethan, Methylphenylketon stärker als Aceton usw. Die Regel der homologen Reihe gilt also auch für Wirkungen in einem strukturfreien Milieu.
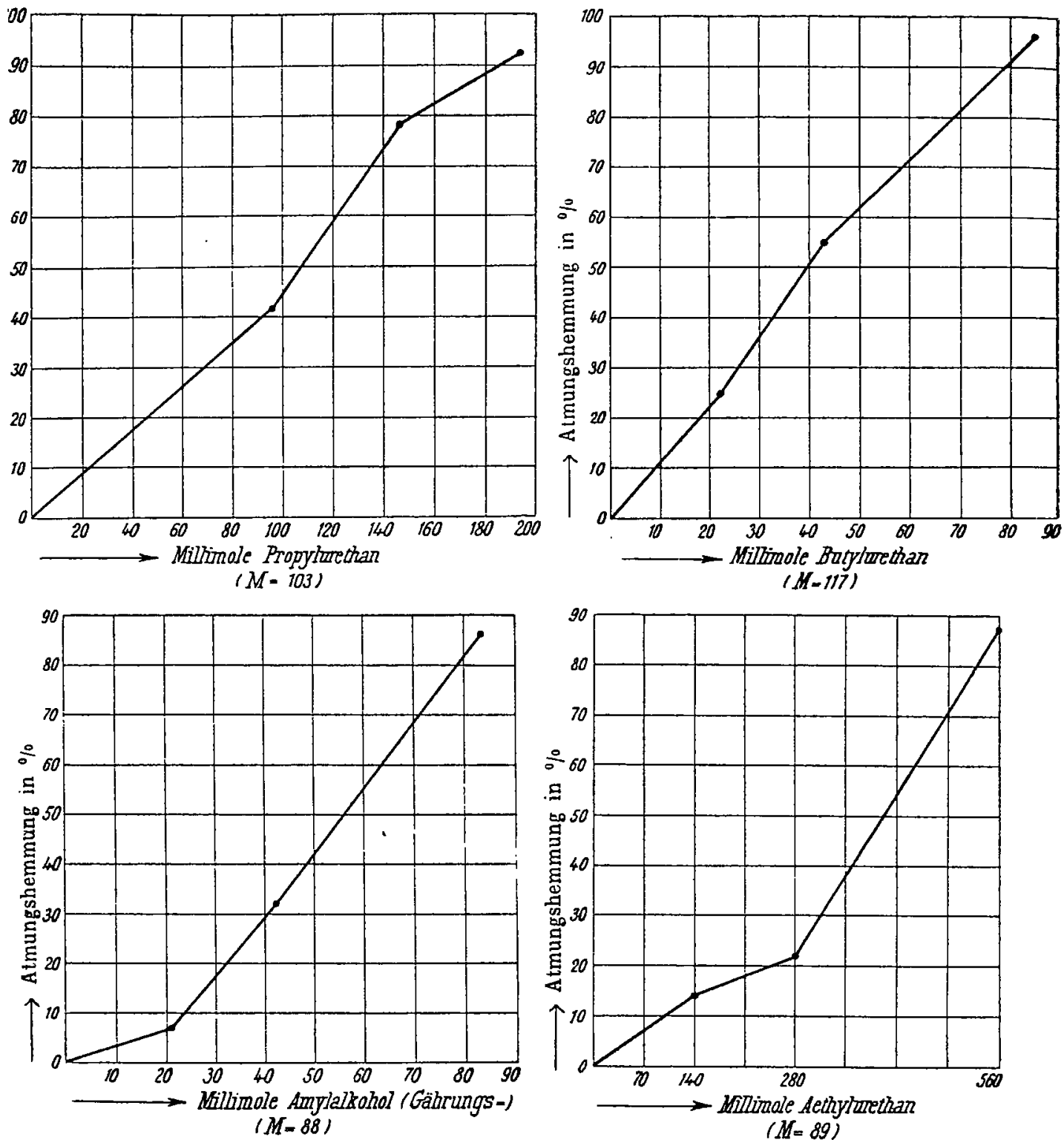

Der einzige Unterschied gegenüber den Wirkungen in der lebenden Zelle - wir verglichen die Wirkungen auf die Presssaftgärung und auf die Gärung in der lebenden Zelle - war der, dass im Presssaft höhere Konzentrationen nötig waren, wenn dieselbe Wirkung wie in der lebenden Zelle erzielt werden sollte. Beispielsweise hemmte $5 \%$ Methylurethan die Gärungsgeschwindigkeit im Presssaft um 20\%, in der lebenden Zelle um 75\%. Ïhn- 
Beiträge z. Physiologie d. Zelle, insbesondere über die Oxydationsgeschwindigkeit in Zellen. 297

lich verhielten sich die anderen Stoffe. Nehmen wir diesen quantitativen Unterschied, mit dessen Erklärung wir uns sogleich beschäftigen wollen, zunächst als gegeben, so ist es nicht merkwürdig, dass ein Stoff wie Phenylurethan auf die Presssaftgärung nur sehr wenig wirkt. Phenylurethan nämlich hemmt erst in gesättigter Lösung die Zellgärung stark; wir müssten also im Presssaft eine höhere Konzentration als die Sättigungskonzentration herstellen, wenn wir die gleiche Wirkung, wie in der Zelle erzielen wollten. Das geht nicht, und so kommt scheinbar ein qualitativer Unterschied heraus. Ähnlich ist wohl die schon seit langem bekannte Tatsache zu deuten, dass Toluol auf die Zellgärung wirkt, nicht aber auf die Presssaftgärung (Eduard Buchner [36]).

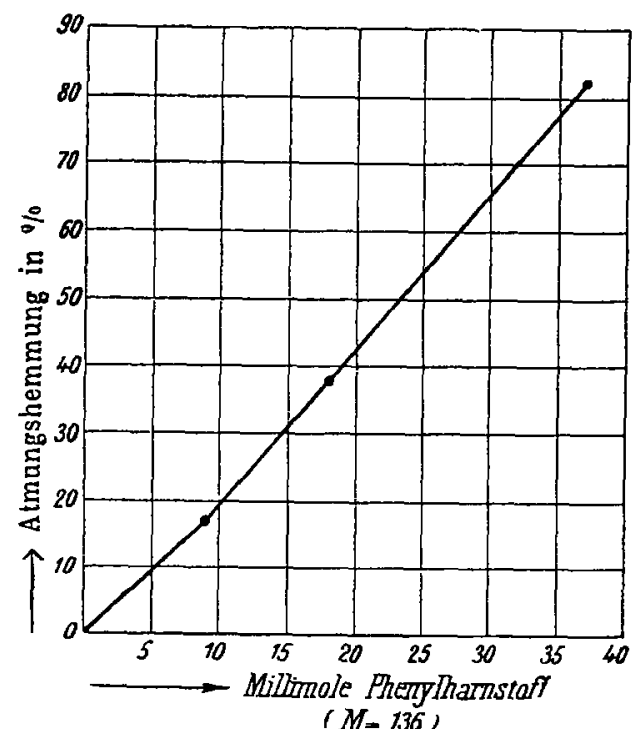

$(M-136)$

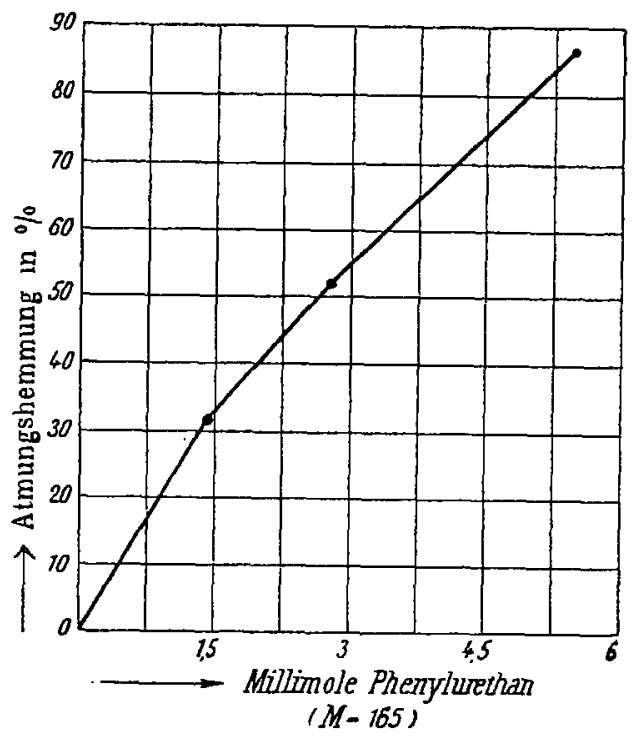

$(M-165)$

Warum sind nun die hemmenden Konzentrationen für die lebende Zelle kleiner als für den Presssaft? Hier müssen wir bedenken, dass wir unter „hemmenden Konzentrationen" für lebende Zellen die Konzentrationen in der Aussenflüssigkeit verstehen und dass, wie wir oben gesehen haben, Aussenkonzentration und Konzentration in der Zelle keineswegs gleichgesetzt werden dürfen. Es liegt sehr nahe anzunehmen, dass die Konzentrationen an den Reaktionsorten der Zelle grösser sind als die Aussenkonzentrationen. Dass es Orte höherer Konzentration für Thymol, Phenylurethan und andere Stoffe in der Zelle geben muss, geht ja ohne weiteres aus den Verteilungsmessungen hervor unter der sebr wahrscheinlichen Voraussetzung, dass die Bildung dieser Stoffe in der Zelle keine chemische ist; hypothetisch ist allein, dass zu diesen Orten die Reaktionsorte gehören.

Die zweite für das Verständnis der Hemmungswirkungen wichtige Tatsache ist folgende: Wenn wir die hemmenden Stoffe in wirk- 
samen Konzentrationen dem Hefepressaft zusetzen, so entstehen nach kurzer Zeit Niederschläge, die um so dichter sind, je stärker die Hemmungen. Bei Konzentrationen, die die Gärungsgeschwindigkeit um $50 \%$ hemmen, sieht der vorher fast durchsichtige Presssaft weiss, etwa wie Milch, aus. Für vier Reihen wurde das festgestellt, die der Alkohole, Urethane, Ketone und Nitrile.

Nimmt man beides zusammen, die Hemmung der Fermentreaktionen in vitro und die Niederschlagsbildung, so wird man kaum zweifeln, dass mit diesen Tatsachen die Wirkung der nichtspezifischen Stoffe auf chemische Reaktionsgeschwindigkeiten dem Verständnis sehr viel näher gerückt ist. Allerdings habe ich in lebenden Zellen Niederschlagsbildungen bisher unter dem Einfuss der nichtspezifischen Stoffe nie gesehen. Zwar werden Mäuselebern unter dem Einfluss atmungshemmender Konzentrationen opak, olne weiteres unterscheidbar von normalen Lebern (O. Warburg und $\mathrm{U}$ s u i [33]); diese Hemmungen sind jedoch, wie ich schon erwähnte, nicht reversibel. Ich denke mir, dass mit groben Ausflockungen in der Zelle stets irreversible Veränderungen einhergehen und dass die reversibeln Ilemmungswirkungen zustande kommen durch feinere Verminderungen des Dispersionsgrades der Fermente. ${ }^{1}$ -

Die Reihenfolge der Wirkungsstärken, wie ich sie für die Beeinflussung von Oxydations- und Gärungsgeschwindigkeit erhielt, wurde schon vielfach für die Beeinflussung von Lebensvorgängen gefunden z. B.: Joffroy und Serveaux, Arch. de méd. exp. 1895. - Ba er, Archiv f. Physiologie 1898, S. 283. - Picaud, Compt. Rend. T. 124. - Bradbury, Brit. Med. Journ. 1899, p. 4. - Cololian, Journ. de physiol. et de path. 1901, p. 535. Hans Meyer, Schmiedebergs Archiv 42, 109; und Baum 42, 119; 46, 338. - Overton, Studien über die Narkose, Jena 1901. - Fühner, Schmiedebergs Archiv 52, 69 (1905). - J. Loeb, Bioch. Zeitschrift 23, 93 [1910]. - Räther, Dissertation, Tübingen. -

Physiko-chemische Theorien sind mehrfach aufgestellt worden, ich beschränke mich auf die Erwähnung der bekannten Lipoidtheorie Meyer-Overtons $(31 ; 38)$ und der Oberflichenspannungstheorie J. Traubes $(39)$. Was die erste Theorie anbetrifft, so ist sie nicht imstande, die Dispersionsverminderung der Kolloide - nach unsrer obigen Darlegung das ursächliche Moment der chemischen Hemmangswirkungen - zu erklären. J. Traubes Theorie dagegen führt vielleicht weiter. Mit der Oberfächenaktivität geht die Adsorbierbarkeit parallel, die Stabilität von Kolloiden könnte durch Adsorption der betreffenden Nichtleiter vermindert werden. Näher kann auf

1) Schon 1875 (Leçons sur les Anesthèsiques, Cinquième Leçon) teilte Claude Bernard die Beobachtung mit, dass der Muskel sich unter dem Einfluss von Chloroform trübt und sprach den Gedanken aus, dass der Muskel infolge einer "Semi-Koagulation" unerregbar wird. Auch Höber (16) sab, am isolierten Nerven, eine "verdichtende" Wirkung von Aethylurethan auf die Kolloide. 
diese Probleme hier nicht mit Nutzen eingegangen werden, weil der Einfuss „oberflächenaktiver" Nichtleiter aul Kolloide bisher nicht genügend studiert ist. Die einzige in diesem Zusammenhang bedeutungsvolle Beobachtung, die ich fand, stammt von Spiro (3i): höhere Glieder der aliphatischen Alkoholreihe flocken Eiweisslösungen in kleineren Konzentrationen aus als niedere Glieder.

d) Oxydationsbeschleunigungen durch nichtspezifische lipoidlösliche Stoffe. Weder in roten Blutzellen noch in Leberzellen noch im Zentralnervensystem konnten Oxydationsbeschleunigungen durch lipoidlösliche nichtspezifische Stoffe konstatiert werden, subhemmende Dosen waren wirkungslos.

Gelegentlich findet man in der Literatur Angaben über ,stimulierende" Wirkung lipoidlöslicher Stoffe auf den Gaswechsel. In der Regel handelt es sich dabei um hungernde Zellen, für die die ,stimulierende" Substanz die Rolle eines Nährstoffes spieit und durch beliebige andere Stoffe, wie Pepton oder Zucker, ersetzt werden kann.

Andererseits gibt es in der Tat Fälle. in denen die beschleunigenden Stoffe nicht als Nährstoffe wirken; das sind die Stoffwechselbeschleunigungen in ruhenden Zellen, denen durch Äther, Alkohole und ähnliche Stoffe der Anstoss zur Entwicklung gegeben werden kann. Derartige Entwicklungserregungen kennen wir sowohl bei phanzlichen, als auch bei tierischen Zellen, ruhender Flieder wird durch kurze Behandlung mit Ïtherdämpfen zum Treiben gebracht (40), das unbefruchtete Seeigelei beginnt sich zu furchen (Jacques Loeb [41]), wenn es einige Minuten mit lipoidlöslichen Stoffen in Berührung gebracht wird. Nach dem, was wir oben über den Zusammenhang zwischen Oxydationsgeschwindigkeit und Entwicklung erfahren haben, ist es nicht merkwürdig, dass Eier, die auf diese Art zur Entwickluug gebracht sind, stärker atmen, als ruhende Eier; die Oxydationsgeschwindigkeit in Eiern, die sich furchen, ist ja für eine bestimmte Temperatur eine konstante, gleichgültig ob den Eiern künstlich oder auf dem Wege der natürlichen Befruchtung der Anstoss zur Entwicklung gegeben wurde. Zwischen der Oxydationsbeschleunigung durch lipoidlösliche und der Oxydationsbeschleunigung durch lipoidunlösliche Stoffe jedoch besteht ein prinzipieller Unterschied. Die Oxydationsbeschleunigung durch lipoidlösliche Stoffe setzt in vollem Umfang erst ein, wenn diese Stoffe durch Waschen mit reinem Seewasser entfernt werden; während sie einwirken, ist die Oxydationsgeschwindigkeit stets kleiner als später in reinem Seewasser. (O. Warburg [10].) Das hängt damit zusammen, dass diese Stoffe neben ihrer entwicklungserregenden und oxydationsbeschleunigenden Wirkung eine zweite, die uns von anderen Zellen her bekannte oxydationshemmende Wirkung ausüben. Der Beweis für die Richtigkeit dieser Auffassung liess sich sehr einfach erbringen; in Eiern, die mit lipoidlöslichen 
Stoffen behandelt waren und dann beim Einbringen in reines Seewasser dell Atmungsanstieg gezeigt hatten, wurde die Oxydationsgeschwindigkeit wieder herabgesetzt, wenn sie in Lösungen derselben lipoidlöslichen Stoffe zurückgebracht wurden. Die Oxydationen im Seeigelei also werden durch lipoidlösliche Stoffe ebenso gehemmt, wie in allen anderen Zellen, dazu kommt jedoch im ruhenden unbefruchteten Ei eine zweite, von der oxydationshemmenden verschiedene Wirkung.

\section{e) Oxydationsgeschwindigkeit und spezifische Stoffe.}

Die Aldehyde. $Z \mathfrak{Z}$ den spezifischen lipoidlöslichen Stoffen rechnen wir nach unserer oben gegebenen Einteilung alle diejenigen, für deren Wirkungsstärken nicht die Regel der homologen Reihe gilt. Die hemmenden Konzentrationen (Material: rote Blutzellen) für eine Anzahl von Aldehyden (hemmend $=$ Oxydationshemmung um 30-70\%) waren folgende (O. Warburg [42]):

\begin{tabular}{|c|c|c|c|c|c|}
\hline Aldehyde & \begin{tabular}{|} 
hemmend \\
gr. Mol. \\
pro Liter
\end{tabular} & Alkohole & $\begin{array}{l}\text { hemmendi } \\
\text { gr. Mol. } \\
\text { pro Liter }\end{array}$ & Acetale & $\begin{array}{l}\text { hemmend } \\
\text { gr. Mol. } \\
\text { pro Liter }\end{array}$ \\
\hline Formaldehyd & 0,001 & Methylalkohol & 5 & Methylal & 0,6 \\
\hline Acetaldehyd & 0,013 & Äthylalkohol & 1,6 & Acetal & 0,14 \\
\hline Propionaldehyd & 0,01 & Propylalkohol & 0,85 & & \\
\hline Butyraldehyd(n) & 0,008 & Butylalkohol (n) & $0,1 \check{0}$ & & \\
\hline Butyraldehyd (iso & 0,01 & Butylalkohol (iso) & 0,15 & & \\
\hline Valeraldehyd (iso) & 0,0035 & Amylalkohol (iso) & 0,045 & & \\
\hline Furfurol & 0,003 & Furfuralkohol & 0,2 & & \\
\hline
\end{tabular}

Aus dieser Tabelle geht unzweideutig hervor, dass die angeführten Aldehyde den spezifisch wirkenden Stoffen zuzuzählen sind, Formaldehyd wirkt stärker als Valeraldehyd, Propionaldehyd und Isobutyraldehyd wirken gleich und auch die übrigen Unterschiede sind ganz unerheblich gegenüber denjenigen, die in homologen Reihen für nichtspezifische Stoffe gefunden wurden. Um den Vergleich mit nichtspezifischen Stoffen zu erleichtern, habe ich den Aldehydzahlen diejenigen der entsprechenden Alkohole gegenübergestellt. Wir haben also in der Tabelle rechts unsere übliche Regel der homologen Reihe. Wir sehen ferner, dass die Unterschiede in den Wirkungsstärken bei gleichem Kohlenstoffskelett ganz enorm sind, Formaldehyd wirkt $5000 \mathrm{mal}$ so stark wie der entsprechende Alkohol, Furfuraldehyd 70 mal so stark wie der entsprechende Alkohol. Durch dcetalisierung verschwindet der spezifische Einfluss der Aldehydgruppe, das Acetal des Formaldehyds wirkt 600 mal so schwach, wie der freie Aldehyd. 
Beiträge z. Physiologie d. Zelle, insbesondere über die Oxydationsgeschwindigkeit in Zellen. 301

Ammoniak und Ammoniakderivate. Ehe wir die Daten für diese Stoffe mitteilen, schicke ich voraus, dass durch noch so häufiges Waschen der Zellen mit Basenlösungen keine Gleichgewichte erreicht wurden. Die basischen Stolfe kamen als freie Basen, gelöst in physiologischer Kochsalzlösung, zur Verwendung; als Versuchsmaterial wurden Vogelblutzellen benutzt, die durch Waschen mit Kochsalzlösung sorgfältig von Serum befreit waren. Bringt man $2 \mathrm{ccm}$ einer konzentrierten Zellsuspension mit $15 \mathrm{ccm}$ einer verdünnten Ammoniaklösung zusammen, zentrifugiert und bestimmt die $\mathrm{OH}$ Ionenkonzentration in der überstehenden Flüssigkeit, so findet man, dass sie erheblich kleiner ist, als einer Verdünnung von 15:17 ccm entspricht. Diese Abnahme der $\mathrm{OH}$-Ionenkonzentration findet bei fortgesetztem Waschen dauernd statt. Die Reaktion zwischen Zellen und Basenlösung, die an dem Verschwinden der OH-Ionen erkannt wird, steht olfenbar in irgend einem Zusammenhange mit der Wirkung der Basen auf die Oxydationsgeschwindigkeit. Denn auch die Wirkung auf die Atmung ändert sich dauernd bei fortgesetztem Waschen mit Basenlösung derselben Konzentration.

Unter diesen Verhältnissen hängt es völlig von der Menge Basenlösung, die mit den Zellen in Berührung kommt, ab, mit welcher Konzentration eine bestimmte Wirkung erzielt wird; je nach der Anordnung lässt sich das gleiche erreichen mit 1/100 oder 1/1900 normal Ammoniaklösung, und es entsteht die Frage, ob zahlenmüssige Angaben überhaupt einen Wert haben. Diese Frage muss bejaht werden. Denn bei einigermassen gleichmässigem Vorgehen sind die Resultate so regelmässig, dass Vergleiche wohl möglich sind. Versuche, die mit verschiedenstem Zellmaterial im Laufe von $1^{1 / 2}$ Jahren angestellt wurden, verliefen ausnahmslos gleich, die Versuchsbedingungen sind also ebensogut reproduzierbar, wie diejenigen, in denen die Zellen mit den angewandten Konzentrationen im Gleichgewicht waren.

Das Verhalten der Oxydationen in roten Vogelblutzellen gegenüber Ammoniak ist folgendes: kleine Mengen beschleunigen recht erheblich, um 30 bis $50 \%$ und mehr, grössere Mengen hemmen reversibel, nach dem Fortwaschen des Ammoniaks steigt die Oxydationsgeschwindigkeit wieder auf die ursprüngliche Höhe; noch grössere Mengen hemmen irreversibel, die Oxydationsgeschwindigkeit steigt nicht wieder auf die ursprüngliche Höhe, wenn das Ammoniak entfernt wird. Alle diese Veränderungen der Oxydationsgeschwindigkeiten werden durch Dosen hervorgerufen, die innerhalb der Versuchszeiten nicht hämolytisch wirken; bei Zusatz sehr erheblicher Ammoniakmengen tritt bekanntlich schnell Hämolyse ein. Die Skala von Wirkungen: Beschleunigung der Oxydationen - reversible Hemmung - irreversible Hemmung ist charakteristisch nicht nur für das Ammoniak, sondern auch für eine grosse dnzahl von Ammoniakderivaten (O. Warburg und E. Grafe [8]).

Die Versuche, deren Resultate in der Tabelle wiedergegeben sind, waren so angeordnet, dass stets $2 \mathrm{ccm}$ Zellsuspension mit $10 \mathrm{ccm}$ Basenlösung ver- 
mischt murden. Dicjenige Konzentration ist als "hemmend" bezeichnet, die unter diesen Bedingungen die Oxydationsgeschwindigkeit um etwa 50\% verminderte.

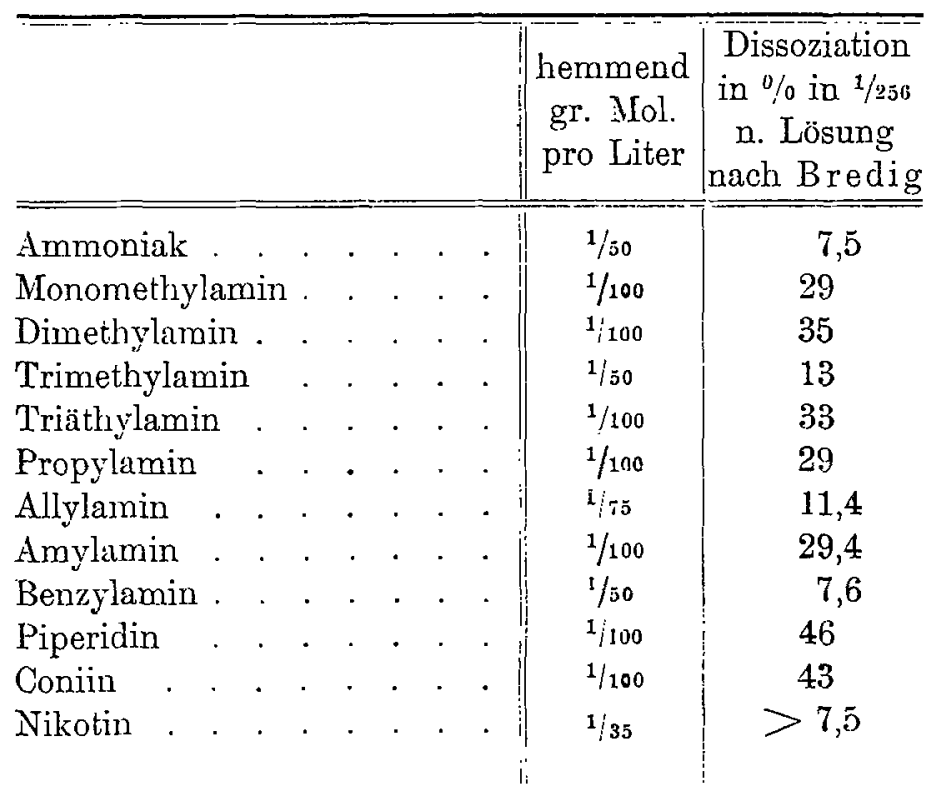

Bei Betrachtung der Zahlen fällt es zunächst auf, dass die hemmenden Konzentrationen nicht sehr auseinander liegen, wir haben im allgemeinen gleiche Wirkung bei $1 / 50-1 / 100$ Normallösungen, nur Nikotin wirkt etwas schwächer. Die Regel der ,homologen Reihe" bestimmt hier auch nicht andeutungsweise die Wirkung. Monomethylamin und Monoamylamin wirken gleich, während Amylalkohol 100 mal so stark wirkt wie Methylalkohol. Auch hier sehen wir übrigens wieder, dass die aliphatische Doppelbindung die Wirkungstärke kaum verändert, Propylamin und Allylamin wirken fast gleich.

Was die Unterschiede anbetrifft, die immerhin vorhanden sind, so stehen sie höchstwahrscheinlich mit dem Dissoziationsgrad der Basen im Zusammenhang, der neben den Wirkungsstärken angegeben ist. Das sehr schwach dissoziierte Nikotin wirkt am schwächsten; Körper mit einem Dissoziationsgrad von $30-45 \%$ wirken etwa gleich, während Ammoniak, Benzylamin und Trimethylamin, bei einem etwas kleineren Dissoziationsgrad, auch etwas schwächer wirken. Offenbar handelt es sich hier um eine spezifische Wirkung der Amidogruppe, und zwar um ihre Affinität als Base, die ja auch in vielen einfachen chemischen Systemen ihre Wirkung bestimmt. Dagegen kommt die Reaktionsfähigkeit der Amidowasserstoffatome nicht in Betracht, das geht daraus hervor, dass die Substitution der Wasserstoffatome durch Methyl- oder Äthylgruppen die Wirkung nicht aufhebt, sondern so gut wie unverändert lässt. 
Beiträge z. Physiologie d. Zelle, insbesondere über die Oxydationsgeschwindigkeit in Zellen. 303

Von komplizierteren Basen mit hohem Molekulargewicht wurden untersucht Brucin, Chinin, Kodein, Kokain und Atropin. Diese Stoffe wirken etwas stärker als die einfacheren Amine, mit Ausnahme vielleicht des Brucins.

Mechanismus der Basenwirkung. Die besprochenen basischen Substanzen sind sämtlich lipoidlöslich und dringen schnell in lebende Zellen ein, für die roten Blutzellen haben wir die Aufnahme in die Zelle durch Ammo. niakbestimmungen direkt gemessen ${ }^{1}$. Schon oben, im Anschluss an eine Überlegung Jacques Loebs, wies ich darauf hin, dass die Wirkung eindringender Stoffe keineswegs immer eine Wirkung auf das Zellinnere zu sein braucht; Stoffe, die eindringen, kommen zunächst einmal mit der Grenzschicht in Berührung. Da wir jedoch bei roten Blutzellen reversible Wirkungen auf die Oxydationsgeschwindigkeit durch direkte Wirkungen auf die Grenzschicht nicht kenmen - lipoidunlösliche Stoffe waren stundenlang ohne Wirkungl - so glaube ich, dass wir die Wirkungen des Ammoniaks und seiner Derivate ohne Bedenken als Wirkungen a uf das Zellinnere auffassen dürfen. Wie diese Wirkungen zustande kommen, darüber können wir begründete Vermutungen nicht iussern. Wichtig für jede Theorie wird die Tatsache sein, dass die Oxydationsgeschwindigkeit unter der Wirkungsteigender Basenmengendurchein Maximum geht, dass mit steigenden Basenmengen zuerst eine Beschleunigung und dann eine Hemmung der Oxydationen eintritt. Es erinnert das einerseits an die Wirkung der OH-Ionen auf Kolloide, deren Dispersionsgrad häufig bei kleinen Konzentrationen vermehrt, bei grösseren vermindert wird; andererseits an die interessante Beobachtung von $\mathrm{Mathew}$ and $\mathrm{W}$ alker (-13), dass die spontane Oxydation von Cystein durch kleine OH-Ionenkonzentrationen beschleunigt, durch grössere gehemmt wird. Also es gibt verschiedene Analoga.

Die Blausäure ist diejenige Substanz, die in kleinsten Konzentrationen die Oxydationen hemmt, eine 1/100000 Normallösung von Cyankali in Seewasser wirkt schon auf die Oxydationsgeschwindigkeit im Seeigelei, 1/50000 Normallösung, in physiologischer Kochsalzlösung, auf die Oxydationsgeschwindigkeit in den roten Blutzellen.

Die Wirkung der Blausäure ist seit langer Zeit bekaunt; wie sie zustande kommt, wissen wir nicht. Die Blausäure hemmt nicht nur die Sauerstoffatmung, sondern auch die alkoholische Gärung in der lebenden Hefezelle, aber erst bei erheblich höherer Konzentration als die Oxydationen. Sie hemmt ferner viele Katalysen im heterogenen System; sie hemmt endlich auch die Geschwindigkeit von Oxydationen im homogenen System, beispielsweise die Oxydation des Cysteins (Mathews und Walker (44]).

Was meine eigenen Beobachtungen über die Blausäurewirkung anbetrifft, so ist die wichtigste die, dass sie sich sehr erheblich abschwächen lässt durch

1) Ünveröffentlichte Versuche von Alfred Dorner. 
eine Anzahl nichtspezifischer lipoidlöslicher Stoffe. Bei Besprechung der Kombinationswirkungen werden wir hierauf genauer einzugehen haben (vgl. den folgenden Abschnitt). Im übrigen möchte ich auf zwei Punkte aufmerksam machen. 1. Die Nitrile wirken auf die Atmung nicht wie Blausäure, Acetonitril wirkt durchaus wie ein nichtspezifischer lipoidlöslicher Stolf: (in mehr als der 10000 fachen Konzentration der Blausäure). 2. Die Blausäure gehört zu den positiv adsorbierbaren Stoffen, beispielsweise nimmt $\breve{\mathbf{g}} \mathrm{g}$ Tierkohle aus $100 \mathrm{ccm}$ einer 1/10000 normalen Kaliumcyanidlösung ${ }^{1}$ ) in wenigen Minuten den grössten Teil des Cyanids fort. Die Blausäure reichert sich auch in lebenden Blutzellen an, im Gleichgewicht enthült ein Volumen Zellen bedeutend mehr Blausäure als ein Volumen Aussenflüssigkeit. Die Konzentrationen in der Aussenflüssigkeit waren bei diesen Versuchen in Bereich der atmungshemmenden. Die Anreicherung der Blausäure in den Blutzellen ist jedoch keineswegs besonders stark und geringer, als für das schwächer oxydationshemmende Thymol. Ich deuke mir, dass die Verdichtung der Blausäure an den Oberflächen für ihre Wirkung in der Zelle eine gewisse Rolle spielt, dass aber dazu noch ein rein chemischer Einfluss kommt.

Kombinationswirkungen. Wenn die Konzentrationen $c_{1}$ und $c_{2}$ verschiedener Substanzen jede für sich allein die Oxydationsgeschwindigkeit um $90 \%$ hemmen, und wenn auch ein beliebiges Gemisch beider Substanzen von den Konzentrationen $c_{1}$ und $c_{2}$ die Oxydationsgeschwindigkeit um $90 \%$ hemmt, so heisst das, dass die betreffenden Substauzen sich an den Reaktionsorten in der Zelle nicht stören. Eine derartige einfache Addition, wie sie für die narkotische Wirkung Nussbaum, Claude Bernard, Overton (31) und andere mehrfach beobachteten, wird für die oxydationshemmende Wirkung vieler lipoidlöslicher Substanzen annähernd gefunden.

Die Versuche waren so angeordnet (O. Warburg [35]), dass die Atmungshemmung durch die Konzentration $c_{1}$ einer Substanz, durch die Konzentration $c_{2}$ einer $z$ weiten Substanz und schliesslich durch $\left(c_{1}+c_{2}\right)$ gemesseu wurde; wenn beispielsweise eine Lösung $2 \%$ Urethan enthielt, die andere $0,2 \%$ Phenylharnstoff, so enthielt die Kombinationslösung $2 \%$ Urethan und $0,2 \%$ Phenylharnstoff. Diese Anordnung hat Vorteile, aber auch Nachteile. $\mathrm{Ob}$ nümlich eine einfache Addition stattindet, ist nicht direkt zu ersehen, sondern erst bei Benutzung der Konzentrationshemmungskurven der einzelnen Substanzen. Folgendes Beispiel macht das klar: die Konzentration c einer Substanz hemme um 25\%, die Konzentration $2 \mathrm{c}$ derselben Substanz um 80\%; die Konzentration $c_{1}$ einer zweiten Substanz hemme um $25 \%$, die Konzentration $2 c_{1}$ um $75 \%$. Dann wird die Hemmung

ग) $\mathrm{KCN}$-Lösungen setzen sich mit $\mathrm{CO}_{2}$ um; wenn nicht für Entfernung der $\mathrm{C}_{2}$ Sorge getragen wird, so genügen die $\mathrm{CO}_{2}$-Mengen im gewöhnlichen destillierten Wasser, um die kleinen Cyanidmengen umzusetzen. 
Beiträge z. Physiologie d. Zelle, insbesondere über die Oxydationsgeschwindigkeit in Zellen. 305

durch $c_{1}+c_{2}$ bei einfacher Addition nicht $25+25=50 \%$ sein, sonderu $\frac{80+75}{2}=78 \%$. Wenn man unter diesem Gesichtspunkt, mit Benutzung der Kurven in Abschnitt $c$ dieses Kapitels, die folgenden Additionswirkungen betrachtet, wo wird man finden, dass in der Regel einfache Additionen zu beobachten sind. In manchen Fällen ist vielleicht eine geringfügige Verstärkung da. Die Konzentrationen sind in Millimolen, mit M bezeichnet, angegeben, daneben stehen in Klammern die Gewichtsprozente. Als Versuchsmaterial wurden ausschliesslieh rote Blutzellen benutzt.

Diäthylharnstoff (symm.) + ̈̈thylurethan.

280 M. Äthylurethan $(2,5 \%)$

195 , Diäthylharnstoff $(2,25 \%)$. . . . . . . . . 21

$195 " \quad$ + $" 280$ M. Äthylurethan . .57

Phenylharnstof $\mathrm{f}+\mathrm{Butylurethan}$ (iso).

30 M. Butylurethan $(0,35 \%)$. . . . . . . . . . 27

18 „, Phenylharnstoff $(0,25 \%)$. . . . . . . . . . 37

30 , Butylurethan +18 M. Phenylharnstoff . . . 87

Äthylurethan + Butylurethan.

340 M. Äthylurethan $(3 \%)$. . . . . . . . . . . . . 29

30 , Butylurethan $(0,35 \%)$. . . . . . . . . . . 31

$340, \quad$ Äthylurethan +30 v. Butylurethan . . . . 85

Formaldehyd + Butylurethan.

1 ML. Formaldehyd $(0,003 \%)$. . . . . . . . . 36

30 , Butylurethan $(0,35 \%)$. . . . . . . . . . . 33

1 "Formaldehyd +30 ㄱ. Butylurethan . . . 64

Butylurethan + Propylurethan.

30 ‥ Butylurethan $(0,35 \%)$. . . . . . . . . . . 35

97 , Propylurethan $(1,0 \%)$. . . . . . . . . . . . 39

30 , Butylurethan +97 Mr. Propylurethan . . .97

Amylalkohol $\left.{ }^{3}\right)+$ Athylurethan.

340 II. Äthylurethan $(3 \%)$. . . . . . . . . . . 35

42 , Amylalkohol $(0,37 \%)$. . . . . . . . . . . . 47

340 "Aethylurethan + 42 M. Amylalkohol . . . 91 
Ganz andere Resultate erhielt ich, als ich die nichtspezifischen Stoffe mit Blausäure kombinierte. Die Konzentrationshemmungskurve für Blausäure ist annähernd eine gerade Linie, die Hemmung wächst annähernd der Konzentration proportional. Fand also einfache Addition statt, so war bei der oben beschriebenen Versuchsanordnung Summierung der Hemmungen oder eine etwas stïkere Hemmung zu erwarten, als durch die Komponenten allein. Statt dessen blieb die Hemmung im Gemisch fast stets erheblich hinterder Summeder Komponentenhemmung zurück, nur Phenylharnstoff und Blausĩure addierten sich teilweise. In einigen Fällen, den interessantesten, war die $\mathrm{H}$ emmung in dem Gemisch sogar erheblich kleinerals die Hemmung in der Blausäure allein (Fall Butylurethan-Blausäure und Methylurethan-Blausäure). Die Angaben in der Tabelle wie oben.

$$
\text { A ethylurethan + KCN. }
$$

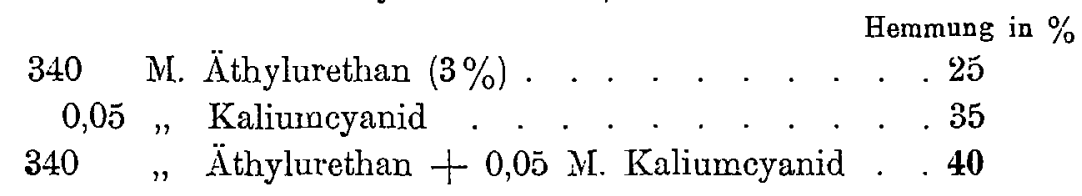

113 M. Äthylurethan (1\%) . . . . . . . . . . 7

0,05 " Kaliumcyanid . . . . . . . . . . . 30

113 " Ithylurethan + 0,05 M. Kaliumcyanid . 25

Propylurethan + KCN.

29 M. Propylurethan $(0,3 \%)$. . . . . . . . . . . 13

0,05 " Kaliumcyanid . . . . . . . . . . 38

29 " Propylurethan + 0,05 M. Kaliumcyanid . . 38

97 MI. Propylurethan (1\%) . . . . . . . . . . 36

0,05 , Kaliumcyanid . . . , . . . . . . . 57

97 "Propylurethan $+0,05$ M. Kaliumeyanid . 56

Butylurethan (iso) $+\mathrm{KCN}$.

30 M. Butylurethan $(0,35 \%)$. . . . . . . . . . 34

0,05 , Kaliumeyanid . . . . . . . . . . . . 35

30 "Butylurethan + 0,05 M. Kaliumcyanid . . 39 
Beiträge z. Physiologie d. Zelle, insbesondere über die Oxydationsgeschwindigkeit in Zellen. 307

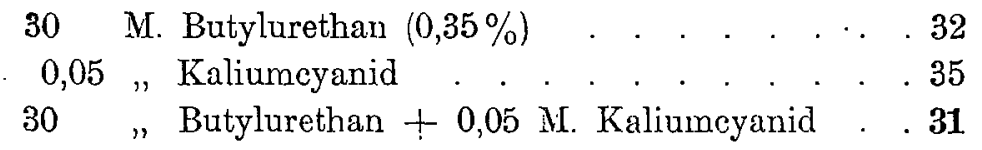

8,5 M. Butylurethan $(0,1 \%)$. . . . . . . . . 8

0,05 , Kaliumcyanid . . . . . . . . . . . . 43

8,5 " Butylurethan . . . . . . . . . . . 17

Methylurethan $+\mathrm{KCN}$.

666 M. Methylurethan $(5 \%)$. . . . . . . . . . 0

0.05 , Kaliumcyanid . . . . . . . . . . . . . 37

666 ". Methylurethan $+0,05$ MI. Kaliumcyanid . . 19

Phenylharnstoff $+\mathrm{KCN}$.

7 M. Phenylharnstoff $(0,1 \%)$. . . . . . . . 20

0,05 , Kaliumcyanid . . . . . . . . . . . . . . 49

7 „Phenylharnstoff $+0,05$ M. Kaliumcyanid . 65

22 M. Phenylharnstoff $(0,3 \%)$. . . . . . . . . . 56

0,05 " Kaliumcyanid . . . . . . . . . . . . 38

22 "Phenylharnstoff $+0,05$ M. Kaliumcyanid . 77

Es steht also fest, dass die Blausäurewirkung durch die nichtspezifischen Stoffe gehemmt wird; ob auch das Umgekehrte der Fall ist, ob also eine gegenseitige Beeinflussung vorliegt, ist nach den bisher vorliegenden Versuchsdaten nicht zu entscheiden, weil nie eine kleinere Hemunung in dem Gemisch beobachtet wurde als in der nichtspezifischen Komponente allein.

Die Hemmung der Blausïurewirkung wird deutlicher bei grösseren Blausäurekonzentrationen. Es grelingt dann für die meisten nichtspezifischen Stoffe eine Kombination mit Blausäure herzustellen, in der die Hemmung kleiner ist als in der Blau. säure allein. Wir können das auch so ausdrücken, dass die Atmung blausäurebeladener Zellen gesteigert wird durch Hinzufügung nichtspezifischer Stoffe. In der folgenden Tabelle sind einige Beobachtungen zusammengestellt, die Zahlen neben den Konzentrationen (wieder in Millimolen) sind die Oxydationsgeschwindigkeiten in willkürlichen Einheiten. Die Beschleunigung der Atmung durch Zusatz der nichtspezifischen Stoffe ist dann bezogen auf die Atmoung in der Blausäure allein und als prozentische Beschleunigung ausgerechnet. 


\begin{tabular}{|c|c|c|c|c|}
\hline & & & & $\begin{array}{l}\text { Steigerung der } \\
\text { Oxydationsge- } \\
\text { sch windigkeit }\end{array}$ \\
\hline 0,1 & & Kaliumcyanid . & 84 & \\
\hline 260 & , & Methylurethan + 0,1 W. Kaliumcyanid & 124 & $48 \%$ \\
\hline 0,1 & $"$ & Kaliumcyanid . . . . . . . . . . . . & 113 & \\
\hline 0,1 & $"$ & $\eta+113$ M. Äthylurethan $(1 \%)$ & 151 & $33 \%$ \\
\hline 0,1 & $"$ & 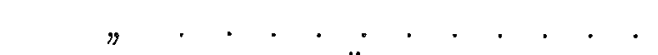 & 75 & \\
\hline 0,1 & $n$ & $n+226$ M. Äthylurethan $(2 \%)$ & 108 & $44 \%$ \\
\hline 0,1 & $n$ & $\begin{array}{lllllllllll} & . & . & . & . & . & . & . & . & . & .\end{array}$ & 68 & \\
\hline 0,1 & $"$ & $" \quad \frac{1}{1} 39 \mathrm{M}$. Propylurethan $(0,4 \%)$ & 91 & $34 \%$ \\
\hline 0,1 & $n$ & $\# \quad . \quad . \quad . \quad . \quad . \quad . \quad . \quad . \quad . \quad . \quad$. & 109 & \\
\hline 0,1 & $n$ & $"+17$ 入. Butylurethan $(0,2 \%)$ & 143 & $31 \%$ \\
\hline 0,1 & ” & 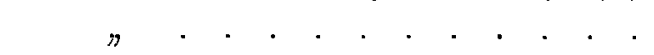 & 85 & \\
\hline 0,1 & $n$ & $"+17$ M. Butylurethan $(0,2 \%)$ & 118 & $39 \%$ \\
\hline 0,1 & 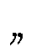 & 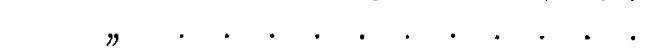 & 68 & \\
\hline 0,1 & $"$ & $»+54 \mathrm{M}$. Butylalkohol $(0,4 \%)$ & 93 & $37 \%$ \\
\hline 0,1 & $n$ & 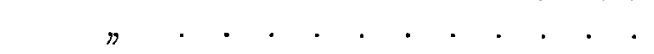 & 63 & \\
\hline 0,1 & $\eta$ & $" \quad+46 \mathrm{M}$. Amylalkohol(iso) $(0,4 \%)$ & 95 & $51 \%$ \\
\hline 0,1 & $n$ & . . . . . . . . . . . . . & 109 & \\
\hline 0,1 & $"$ & + $70 \mathrm{M}$. Äthylalkohol $(0,32 \%)$ & 124 & $14 \%$ \\
\hline 0,1 & " & $"+43$, Butylalkohol $(0,32 \%)$ & 160 & $47 \%$ \\
\hline 0,1 & $n$ & $"+18$, Amylalkohol $(0,16 \%)$ & 172 & $58 \%$ \\
\hline 0,1 & $\eta$ & 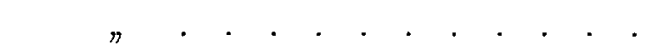 & 126 & \\
\hline 0,1 & $\pi$ & $"+107$ M. Methylurethan $(0,8 \%)$ & 128 & - \\
\hline 0,1 & $"$ & $n+78$, Propylurethan $(0,8 \%)$ & 159 & $26 \%$ \\
\hline
\end{tabular}

Besonders aus Versuch 9 und 10 geht hervor, dass die beschleunigende Wirkung für äquimolekulare Mengen nichtspezifischer Stoffe recht verschieden ist, 18 Millimole Amylalkohol wirken stärker als 43 Millimole Butylalkohol und diese wieder stärker als 70 Millimole Äthylalkohol. 78 Millimole Propylurethan wirken stärker als 107 Millimole Methylurethan.

Theorie: Nach unseren chemischen Kenntnissen reagieren die verwendeten nichtspezifischen Stoffe unter den Versuchsbedingungen in vitro nicht mit Blausäure. Die Wirkung auf die Blausüure findet also offenbar in der Zelle statt. Von Möglichkeiten, die hier in Betracht kommen, ist mir die wahrscheinlichste, dass die Blausäurekonzentration an den Reaktionsorten in der Zelle vermindert wird durch eine Verdrängung von Oberflächen. Dazu stimmt gut, dass stärker adsorbierbare Stoffe die Blausäurewirkung stärker hemmen, als schwächer adsorbierbare Stoffe. Auch in vitro verdrängen von ähnlichen Stoffen die stärker adsorbierbaren eine bestimmte Substanz stärker von Oberflächen, als schwächer adsorbierbare Stoffe. Ein derartiges Beispiel wurde beschrieben von Ron a und Michaelis (45), in dem Essigsäure von der Oberfläche der Tierkohle verdrängt wurde. 
Kapitel V.

\section{Die Beeinflussung der Oxydationsgeschwindigkeit durch die Temperatur.}

\section{Literatur.}

1. W. Nernst, Zeitschr. f. physikal. Chemie. 47. 52 (1904).

2. van t'E off, Vurlesungen äber theoret. u. physik. Chemie. Bd. I. S. 225 (1901).

3. O. Warburg, Hoppe-Seyler. 57. 1 (1908).

4. O. Meyerhof, Pflügers Archiv. 146. 159 (1912).

5. S. Arrhenius, Lehrbuch d. Elektrochemie. (S. $99 \mathrm{ff}$ ) Leipzig 1910.

6. Slator, Journal of the Chemic. Society. 89. 128 (1906).

7. O. Warburg, Hoppe-Seyler. 76. 331 (1912).

Die chemische Umsatzgeschwindigkeit in heterogenen Systemen wird bestimmt entweder durch die Reaktionsgeschwindigkeit der reagierenden Moleküle oder durch die Geschwindigkeit, mit der die reagierenden Moleküle an die Reaktionsorte des Systems hindiffundieren. Welche dieser beiden Möglichkeiten realisiert ist, hängt davon ab, ob die Reaktionsgeschwindigkeit im Vergleich zur Diffusionsgeschwindigkeit gross oder klein ist (Nernst [1]), und lässt sich in vielen Fällen entscheiden, wenn wir den Einfluss der Temperatur auf die Umsatzgeschwindigkeit feststellen. Denn die chemische Reaktionsgeschwindigkeit ändert sich sehr stark mit der Temperatur, einer Temperaturerhöhung um $10^{\circ}$ entspricht oft ein Geschwindigkeits zuwachs von $100 \%$ und mehr; die Diffusionsgeschwindigkeit dagegen wächst bedeutend langsamer mit der Temperatur, bei Temperaturerhöhung um $10^{\circ}$ nur um etwa $25 \%$.

Einer herrschenden Gewohnheit entsprechend, soll der Zuwachs der chemischen Umsatzgeschwindigkeit im folgenden auf $10^{\circ}$ bezogen werden; unter „Temperaturkoeffizient" verstehen wir dann:

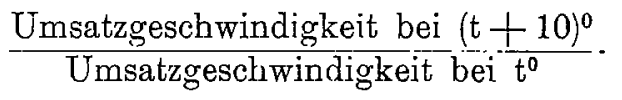

1. Eine Reihe chemischer Reaktionen im heterogenen System, darunter gerade die für den Biologen interessanten, haben einen so hohen Temperaturkoeffizienten, dass die Diffusion als geschwindigkeitsbestimmender Faktor ausgeschlossen werden kann. Das gilt nicht nur für viele Fermentreaktionen $\left.{ }^{1}\right)$ in vitro, sondern auch für chemische Reaktionen in leben-

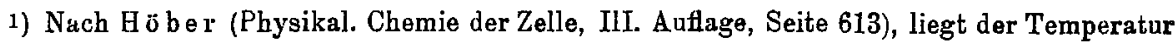
koeffizient für die Wirkung der Amylase, des Trypsins, Emulsins, Erepsins und Labs zwischen 2 und 3. 
den Zellen, wie die Kohlensäureproduktion von Pflanzen (Koeffizient ca. 2,5 siehe van t'Hoff [2]). Auch die Oxydationsgeschwindigkeit im Seeigelei (O. Wa rburg [3]) und in roten Blutzellen (O. Me yerh of [4]) ändert sich mit der Temperatur viel stärker als eine Diffusionsgeschwindigkeit. In allen diesen Fällen also diffundieren die reagierenden Moleküle schneller an die Reaktionsorte der Zelle, als sie dort umgesetztwerden. Eine wichtige Konsequenz ist folgende: das Anwachsen der Oxydationsgeschwindigkeit in der Zelle durch irgendwelche Einflüsse darf nicht auf günstigere Diffusionsbedingungen zurückgeführt werden, es sei denn, dass die gesteigerte Oxydationsgeschwindigkeit einenkleineren Temperaturkoeffizienten als den chemischen zeigt. Diese Konsequenz wird häufig übersehen, z. B. wenn Ïnderungen der Oxydationsgeschwindigkeit darauf zurückgeführt werden, dass die Zellgrenzschicht für Sauerstoff durchlässiger wird.

2. Nach van t'Hotf (2) ist die ,empirische Hauptbeziehung" zwischen Temperatur und chemischer Reaktionsgeschwindigkeit die, „dass ein gleiches Ansteigen der Temperatur einen gleichen Geschwindigkeitsquotienten bedingt", mit anderen Worten, dass sich der Temperaturkoeffizient mit der Temperatur praktisch nicht iudert. Theoretisch allerdings muss sich der Koeffizient mit der Temperatur etwas ïndern; diese Inderungen jedoch sind sehr geringfügig, in der Formel von Arrhenius (5) umgekehrt proportional dem Quadrat, der absoluten Temperaturen"1).

Auf meinen Vorschlag hat Fierr Ryuta Us u i untersucht, ob auch der Temperaturkoeffizient der Atmung diese annähernde Konstanz bei verschiedenen Temperaturen zeigt. Es hat sich ergeben, dass in dem kleinen Temperaturintervall von $0^{\circ}$ bis $38^{\circ}$ - ein grösseres Intervall kommt für Versuche an lebenden Zellen kaum in Betracht - der Koeffizient sich sehr erheblich ändert, wie aus den folgenden Zahlen hervorgeht.

Material: rote Vogelblutzellen.

\begin{tabular}{c|c} 
Temperaturintervall & Temperaturkoeffizient \\
$38^{\circ}-28^{\circ}$ & 2,4 \\
$28^{\prime \prime}-16,4^{\prime \prime}$ & 3,2 \\
$16,4^{0}-0^{\circ}$ & 5,0
\end{tabular}

Eine derartig starke Änderung des Temperaturkoeffizienten mit der Temperatur ist schon für eine andre Fermentreaktion in del lebenden Zelle, die alkoholis che Gärung beobachtet worden; Slator 6 . bestimmte die Gärungsgeschwindigkeit in lebenden Hefezellen bei verschiedenen remperaturen und fand die nachstehenden Werte:

1) Solange die Wärmetönung als konstant betrachtet werden darf. 
8

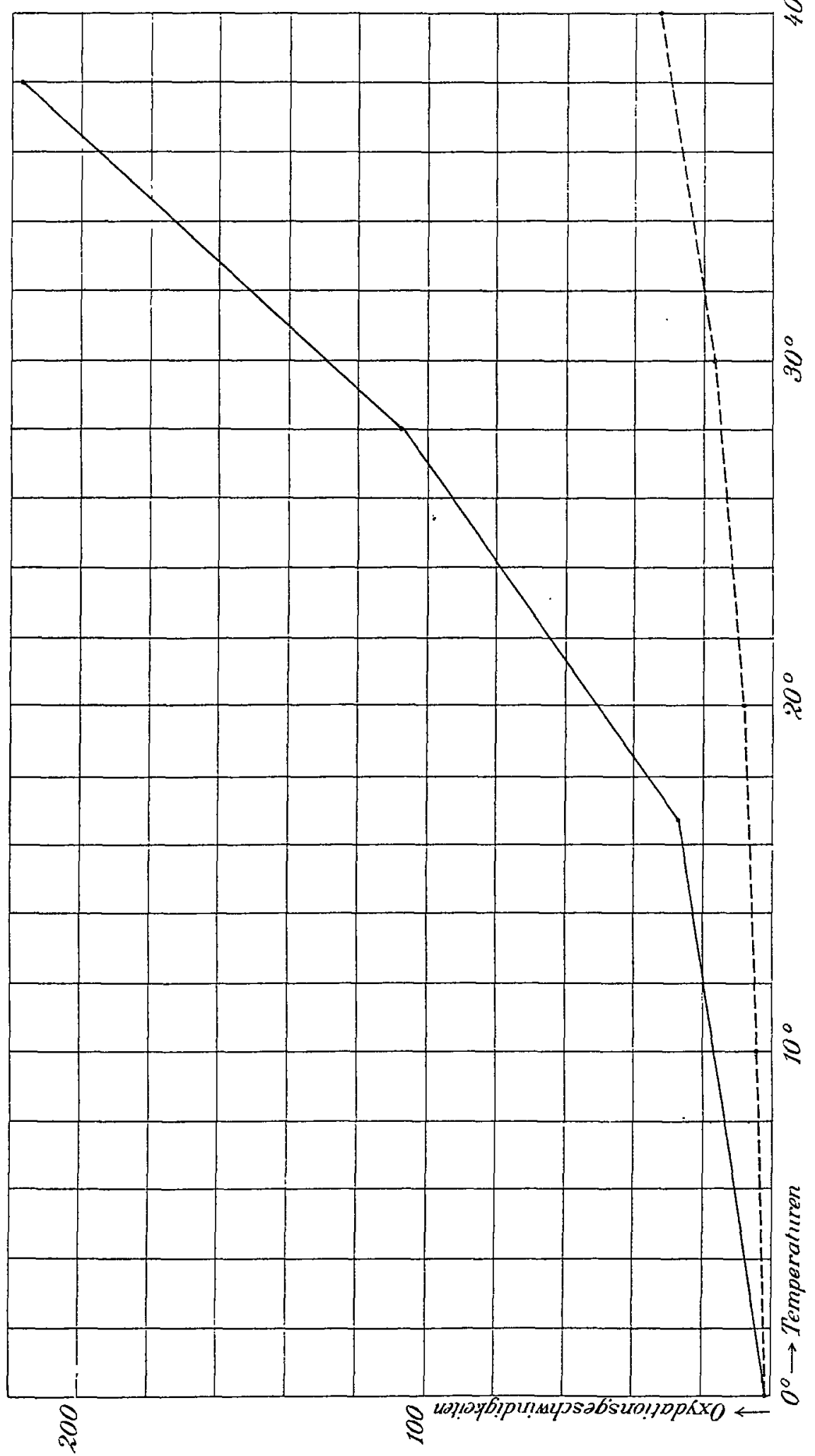




\begin{tabular}{c|c}
\hline Temperatur : & Temperaturkoeffizient \\
$5^{0}$ & 5,6 \\
$10^{\circ}$ & 3,8 \\
$20^{\circ}$ & 2,2 \\
$30^{\circ}$ & 1,4
\end{tabular}

Soviel sich aus den Buchnerschen Zahlen ersehen lässt, findet man diese starke Änderung des Temperaturkoeffizienten mit der Temperatur im Hefepressaft nicht; wie sie in der lebenden Zelle zustande kommt, ob die Temperatur durch Änderung von Löslichkeiten oder Adsorptionsgleichgewichten das Mrilieu verändert, in dem die Fermentreaktionen ablaufen, soll hier nicht diskutiert werden. Diffusionen spielen jedenfalls auch bei tiefen Temperaturen keine Rolle, der Koeffizient entfernt sich ja mit sinkender Temperatur immer mehr von dem Diffusionskoeffizienten.

Wenn sich der Temperaturkoeffizient mit der Temperatur stark ändert, so ist es natürlich nicht sehr genau, „Koeffizienten“ über 10 Grade oder überhaupt „Koeffizienten“ anzugeben. Ich habe das trotzdem getan, weil eine derartige Darstellung des Temperatureinflusses den Biologen besouders geläufig ist. Richtiger ist es, die Beziehung graphisch darzustellen; in der beigegebenen Kurve sind die Temperaturen (in Celsiusgraden) als Abszissen, die zugehörigen Oxydationsgreschwindigkeiten (in willkürlichen Einheiten) als Ordinaten eingetragen. Die ausgezogene Linie gibt die tatsächliche Änderung der Oxydationsgeschwindigkeit; die gestrichelte Linje zeigt, wie die Kurve aussehen würde, wenn der Temperatureinfluss sich mit der Temperatur nicht änderte, sondern auch bei tiefen Temperaturen gleich dem zwischen 28 und $38^{\circ}$ wäre.

Die Technik der Versuche, die an anderer Stelle nicht publiziert werden sollen, war folgende: $15 \mathrm{ccm}$ einer konzentrierten Suspension roter Vogelblutzellen in Ringerlösung wurden mit $15 \mathrm{ccm}$ Ringerlösung vermischt. Die Mischung wurde durch Schütteln an der Luft bei $38^{\circ}$ mit den Gasen der Luft ins Gleichgewicht gebracht und dann in Röbrchen von $5 \mathrm{ccm}$ Inhalt abgefüllt. Ein Röhrchen wurde sofort mit 0,15 ccm einer $1 \%$ igen KCN-Lösung vergiftet, kam dann auf Eis und diente als "Vorkontrolle“. Die anderen kamen in Thermostaten verschiedener Temperatur, wurden nach passenden Zeiten herausgenommen und wie die Vorkontrolle weiterbehandelt. Für alle 5 Rohrchen wurde dann die Druckverminderung in der üblichen Weise (0. Wa rburg [7]) bestimmt. Bei tiefen Temperaturen liessen wir die Zellen, damit die Genauigkeit hinreichend gross warde, entsprechend länger atmen; in dem Versuch, der in der Kurve wiedergegeben ist, waren dio Atmungszeiten folgende:

bei $38^{\circ}: 1^{1 / 2}$ Stunden
bei $28^{\circ}: 3 \quad "$
bei $16,7^{\circ}: 8 \quad "$
bei $0^{\circ}: 50 \quad "$

Durch besondere Kontrollen baben wir uns überzeugt, dass die Oxydationsgeschwindigkeit bei ein und derselben Temperatur konstant war, dass also bei $38^{0}$ innerhalb von $1^{1 / 2}$ Stunden und bei $0^{\circ}$ innerhalb von 50 Stunden in gleichen Zeiten gleichviel Sauerstoff verbraucht wurde. Eine derartige Konstanz ist natürlich Vorbedingung. 
Beitriige z. Physiologie d. Zelle, insbesondere über die Oxydationsgeschwindigkeit in Zellen. 313

Der Temperatureinfluss ist gegenüber verschiedenem Zelimaterial nicht ganz gleich, so dass in eine Kurve nur Daten eingetragen werden dürfen, die an demselben Zellmaterial gewonnen

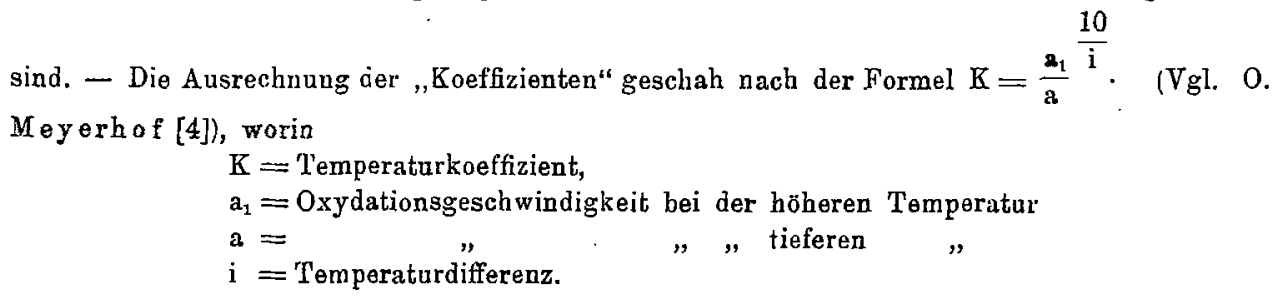

Kapitel VI.

\section{Über den Mechanismus der Sanerstoffatmung.}

\section{Literatur.}

1. Fick, Pflü̉gers Archiv. 53. 606 (1893).

2. Wetzner, Archiv f. (Anat. u.) Physiologie. 1893. S. 74.

3. E. Buchner, H. Buchner u. M. Hahn, „Die Zymasegärung". München u. Berlin 1903.

4. Harden, "Alkoholic Fermentation". London 1911.

5. O. Warburg u. O. Meyerhof, Pflügers Arcliv. 148. 295 (1912).

6. Catbcart u. Hahn, Archiv f. Hygiene. 44. 295.

7. Kostytscheff, Berichte d. deutsch. botan. Gesellsch. 22. 207 (1904).

8. Herzog u. Meier, Hoppe-Seyler, s. Zeitschr. 59. 57 (1909). 57. 35 (1908).

9. Batelli u. Stern, Bioch. Zeitsehr. 21. 487 (1909).

10. Palladin, Hoppe-Seyler, s. Zeitscbr. 47. 407 (1906).

11. Batelli u. Stern in Abderhaldens Handbuch der bioch. Arbeitsmethoden III. 444. (1910).

12. Usui, Pflügers Archiv. 147. 100 (1912).

13. Battelli u. Stern, Bioch. Zeitschr. 34. 263 (1911).

14. Harden u. Maclean, Journ. of physiology. 43. 34 (1911).

15. Fletcher u. Hopkins, Journ. of physiology. 35. 247 (1906-7).

16. Pf ef fer, Pflanzenphysiologie. Bd. I.

17. O. Warburg, Hoppe-Seyler, s. Zeitschr. 59. 112 (1909).

18. Morawitz, Schmiedebergs Archiv 60, 298 (1909).

19. Itami u. Pratt, Biochem. Zeitschr. 18. 302 (1909).

20. M. Onaka, Hoppe-Seyler, s. Zeitschr. 70. 433 (1911).

21. E. Masing, Schmiedebergs Arcbiv. 66. 71 (1911).

22. O. Warburg, Hoppe-Seyler, s. Zeitschr. 70. 413 (1911).

23. Barnard u. Hewlett, Proc. of the Royal Soc. B. 84 (1911).

24. O. Warburg, PfIügers Archiv. 145. 277 (1912).

25. Derselbe, Hoppe-Seyler, s. Zeitschr. 57. 1 (1908).

26. Derselbe, Hoppe-Soyler, s. Zeitschr. 66. 305 (1910).

27. O. Meyerh of, Biochem. Zeitschr. 35. 246; 35. 280 ; 35. 316 (1911).

28. J. Loeb a. Wasteneys, Biochem. Zeitschr. 36. 345 (1911).

29. Il a c Clendon w. Mitchell, Journ. of Biol. Chemistry. 10. 459 (1912).

30. Battelli u. Stern, Diese Ergebnisse. 12. 215. 
31. Maximow, Berichte d. deutsch. bot. Gesellschaft. 22. 225 (1904).

32. Pf $\theta f \in \operatorname{f}$, Abhandl. der math.phys. Klasse der Königl. Sächs. Gesellsch. der Wissensch. 15. $375(1889)$.

33. 0 . Warburg u. O. Meyerhof, unveröffentlichte Versuche.

34. J. Loeb, Die chemische Eintwickelungserregung des tierischen Wies. Berlin 1909.

35. T. Thunberg, Skandin. Arch. f. Physiol. 24. 90. (1911).

36. E. J. Lesser (mit Grode), Zeitsch. f. Biologie. 60. 371 (1913).

\section{Fragestellung.}

In lebenden Zellen werden organische Substanzen bei niedrigen Temperaturen mit grosser Geschwindigkeit verbrannt, während dieselben Substanzen, bei denselben 'l'emperaturen, ausserhalb der Zelle sehr langsam verbrenuen. Lebende Zellen beschleunigen also die Oxydation organischer Substanzen. Die Menge organischer. Substanz, deren Verbrennung beschleunigt wird, ist sehr gross im Vergleich zur Menge Zellsubstanz. Die Oxydationsbeschleunigung durch Zellen ist also eine Katalyse.

Mit dieser Erkenntnis ist ein tieferer Einblick in den Mechanismus der Oxydation nicht verbunden; denn es gibt zahllose Arten von Katalyse. Immerhin ist die Fragestellung etwas eingeengt; wir können sie so formulieren: Welcher Art ist die Katalyse?

Die Antwort wird in diesem Kapitel gegeben werden und wird lauten, dass wir zwei Arten von Katalysen zu unterscheiden haben; einerseits eine reiu chemische Katalyse, d. h. es gibt in Zellen Substanzen, die die Oxydationen beschleunigen; andererseits eine mehr physiko-chemische Katalyse, die an eine besondere Anordnung der Substanzen in der Zelle, an die Struktur der Zelle, gebunden ist. Diese beiden Arten von Katalyse sind höchstwahrscheinlich zu einem einheitlich funktionierenden Mechanismus verkettet.

\section{Physiko-chemische Definition der Zellstruktur.}

Eine kurze Überlegung wird uns zeigen, dass von termodynamischen Gesichtspunkten aus eine enge Beziehung zwischen Zellstruktur und OxydationsWechanismus abgeleitet werden kann.

Wir gehen aus vom arbeitenden quergestreiften Muskel, dessen Wärmeproduktion gleichzeitig mit der Arbeitsleistung einigermassen genau gemessen werden kann, und fragen uns nach dem Weg, auf dem die mechanische Arbeit gewonnen wird. Wir können, wie Fick gezeigt hat, einen Weg, nämlich den über die Wärme, ausschliessen; der Muskel arbeitet nicht wie eine Wärmemaschine. 
In der Würmemaschine wird dadurch Arbeit gewonnen, dass Wärme von höherer auf niedere Temperatur übergeht. Die Arbeit, die man günstigsten Falls erhält, hängt allein ab von der Menge der übergehenden Wärme und den Temperaturen, zwischen denen der Übergang stattfindet ${ }^{1}$ ). Bedingung ist, dass der arbeitlielernde Teil der Maschine nicht verändert wird, dass er nach Wärmetransport und Arbeitsleistung wieder im selben Zustand ist wie vorher. Nelımen wir nun an, die Nuskelarbeit würde durch einen derartigen Temperaturausgleich gewonnen. Gegeben durch das Experiment ist die Arbeit und die bei der Arbeitsleistung gebildete Wärme; bekannt ist ferner die tiefere Temperatur, im günstigsten Falle die Körpertemperatur. Daraus lässt sich die höhere Temperatur berechnen, $d . h$. die Temperatur, auf die sich der arbeitliefernde Teil des Muskels erhitzen müsste, wenn die gewonnene Arbeit die maximale wäre. Legen wir mit Fick das Verhältnis 1:4 für Arbeit: abgegebener Wärme zugrunde (Fick [1]) und nehmen wir die Körpertemperatur zu $37^{\circ}$ an, so müsste der arbeitliefernde Teil des Muskels bis auf $114^{\circ}$ (387 $7^{\circ}$ absoluter Zählung) erhitzt werden. Diese Zahl gilt nur für den Idealfall, dass die Vorrichtung reversihel arbeitet, wäre also unter allen Umständen in Wirklichkeit noch höher. Eine derartige Erhitzung des arbeitliefernden Teils des Muskels ist schon deshalb unmöglich, weil die freiwerdenden Wärmemengen dazu nicht ausreichen.

Seit Ficks Zeiten sind viel günstigere Verbältnisse $z$ wischen Arbeit und abgegebener Wärme gefunden worden; v. Kries and Metzner (2) geben für den herausgeschnittenen ermüdeten Kaltblitermuskel Zahlen bis $1: 1$ an, was einen Wirkungsurad von $50 \%$ bedeuten würde. Es handelt sich aber hitr stets um Fälle, in denen sich der arbeitliefernde Teil des Muskels dauernd veränderte. Das geht schon daraus hervor, dass bei dauernder Arbeitsleistung das Verbältnis $\frac{\text { Arbeit }}{\text { Wätmeabgabe }}$ sich dauernd verschob. Aaf diese Fälle sind die thermodynamischen Formeln natürlich nicht anwendbar.

Für einen quergestreiften Warmblütermuskel ist im stationären $\mathrm{Zu}$ stand die Sauerstoffatmung die Quelle der Arbeitsleistungen, sie ist die arbeitliefernde Reaktion ${ }^{1}$, wir dürfen also auf Grund der vorhergehenden Überlegung behaupten, dass die chemische Energie der Atmung, zu einem erheblichen Teil jedenfalls, nicht direkt in Wärme übergeht. Das gilt zunächst nur für den Mluskel, auf den sich streng genommen die folgenden Schlussfolgerungen beschränken müssten. Doch wollen wir annehmen, dass auch die andern Zellen und Gewebe, für deren Arbeitsleistungen die Wirkungsgrade heute noch unbekannt sind, nicht wie Wärmemaschinen arbeiten.

1) Ist $Q_{1}$ die bei der höheren absoluten Temperatur $\left(T_{1}\right)$ aufgenommene Wärmemenge, $\mathrm{Q}_{0}$ die bei der tieferen absol. Temperatur $\left(\mathrm{T}_{n}\right)$ abgegebene $\mathrm{W}$ ärmemenge, so ist die maximale Arbeit $=Q_{1} \frac{\mathrm{T}_{1}-\mathrm{T}_{0}}{\mathrm{~T}_{1}}$.

2) Wobei es gleichgültig ist, ob der Muskel eine Quellungsmaschine, eine Oberflächenspannungsmaschine etc. ist. Hier kommt es nur auf das an, was in Su mma vor sich gegangon ist, wenn der Muskel gearbeitet hat und in seinen ursprünglichen Zustand zurückgeführt ist. (Vgl. auch Kap. I.) 
Diese Überlegung führt zu einer wichtigen Konsequenz: In der arbeitenden Zellewird der Mechanismus der energieliefernden chemischen Reaktionen ein anderer scin, als wenn die Zellstruktur soweit zerstört ist, dass anstelle der Arbeit Wärme erscheint. Der Wasserstoff der organischen Verbindungen wird in der arbeitenden Zelle, zum Teil wenigstens, verbrennen wie in der Gaskette, dem van t'Hoffschen Reaktionskasten oder in ähnlich geordneter Weise, nicht aber wie in einem Explosionsmotor. Anders ausgedrückt: mit Zerstörung der arbeitliefernden Struktur wird höchstwahrscheinlich der Reaktionsmechanismus der arbeitliefernden Reaktionen verändert. ${ }^{1 j}$

An diese Beziehung soll unsere Definition der Zellstruktur anknüpfen. Unter Zellstruktur verstehen wir die Formen, an die die mechanische Zellarbeit gebunden ist. Wir werden also sagen, die Zellstruktur ist intakt, wenn die Arbeitsfähigkeit intakt ist; wir werden sagen, die Zellstruktur ist zerstört, wenn die Formen zerstört sind, an die die mechanische Zellarbeit gebunden war.

Zerreiben wir einen Zellkern in tausend Teilchen und denken uns diese Teilchen in Zellleib verteilt, so ist nach unserer Definition die Kerustruktur zerstört, die geordnete Bewegung der Kernmasse, wie wir sie z. B. bei der Kernteilung beobachten, ist nicht mehr möglich: Auf den Einwand, dass vielleicht einzelne Kernsplitter mechanische Arbeit leisten, die nicht nachweisbar wäre, ist zu entgegnen, dass wir umbekamnte Dinge nicht definieren können. Die Kernsplitter sind für uns solange keine arbeitliefernden Teile, als eben Arbeitsleistungen von ihrer Seite nicht beobachtet wurden. -

Die Methoden, die wir angewandt haben, un Struktur zu zerstören, waren verschiedenartige. Die radikalste und anschaulichste ist die mechanische Zerkleinerung der Zellen; doch gibt es sehr viel feinere Wethoden, für die ich als Beispiel die Zerstörung der semipermeablen Zellgrenzschicht, (vgl. d. folg. Abschnitt dieses Kapitels) ohne gleichzeitige Zerstörung der sichtbaren Struktur anführen möchte. Diesen Fall erwähne ich hier deshalb, um unsere Definition vor einer unzulässigen Umkehrung zu bewahren: Wenn

1) Eine Beziehung zwischen Arbeitgewinnung und Struktur einer Maschine besteht natürlich immer, auch in der Wärmemaschine; die Strukturbeziehung, auf die es hier ankommt, ist die zum chemischen Reaktionsmechanismus.

Dass die Geschwindigkeit der arbeitliefernden Reaktion nach Zerstörung der Struktur sich ändern wird, lässt sich hiernach zwar nicht mit Sicherheit, aber doch mit grosser Wahrscheinlichkeit voraussaven; denn es ist äusserst unwahrscheinlich, dass sich die Geschwindigkeit einer Reaktion nicht ändert, wenn sich ihr Mechanismus ändert. - Im ganzen liegen die Verhältnisse recht ähnlich, wenn wir ein geschlossenes galvanisches Element zerstören, etwa pulverisieren. Die stromliefernde chemische Reaktion kann dann schnelier abjaufen oder langsamer als im intakten geschlossenen Element, das hängt ganz ab von der besonderen Natar der energieliefernden Reaktion und von dem Widerstand, mit dem das Element geschlossen war. 
Beiträge z. Physiologie d. Zelle, insbesondere über die Oxydationsgeschwindigkeit in Zellen. 317

die sichtbare Zellstruktur zerstört ist, so ist die arbeitliefernde Struktur zerstört; wenn aber die sichtbare Zellstruktur intakt ist, so ist keineswegs a ch die arbeitliefernde Struktur intakt.

\section{Trennung von Arbeitsfähigkeit und arbeitliefernder chemischer Reaktion mittels des Acetonverfahrens.}

Seit E. Buchner (3) nachwies, dass Hefezellen durch Behandeln mit Aceton und Ïther teilungsunfühig gemacht werden, ohne dass gleichzeitig das Gärvermögen völlig verschwindet, hat das "Acetonverfahren" in der Biochemie eine gewisse Rolle gespielt; seine grosse Bedeutung liegt darin, dass es ermöglicht, Arbeitsfühigkeit und arbeitliefernde chemische Reaktion nicht nur auf einfache Weise zu trennen, sondern auch die chemische Reaktionsfähigkeit lange Zeit zu konservieren.

Befolgt man die Buchnersche Vorschrift, trïgt die Zellen in Aceton ein und wäscht sie mit $\ddot{A}$ ther, so resultiert ein trockenes Pulver. Wahrscheinlich ist der springende Punkt der Methode die rasche Trocknung; abgesehen von der Entwässerung ändert sich die chemische Zusammensetzung der Zellen wohl nur wenig und im besonderen bleiben die Lipoide grösstenteils im Niederschlag.

Die sichtbare Struktur vieler Zellen wird durch das Acetonverfahren nicht wesentlich verändert, nicht einmal die Struktur einer so empfindlichen Zelle, wie sie das Seeigelei ist. Ein Seeigelei lüsst sich in beliebigen Furchungsstadien durch Aceton-Äther schön konservieren, und ist dann, in Seewasser zurückgebracht, von einem frischen Ei gleichen Alters nicht ohne weiteres unterscheidbar. ${ }^{1}$ ) Trotzdem ist die feinere Struktur zerstört: überträgt man normale frische Eier aus Seewasser in destilliertes Wasser, so schwellen sie sofort an und platzen (osmotische Cystolyse); überträgt man jedoch Acetoneier aus Seewasser in destilliertes Wasser, so schwellen sie nicht, sondern behalten ihr Volumen und soustiges Aussehen unverïndert bei. Allgemein wirken Änderungen des osmotischen Aussendruckes auf das Volumen der Acetoncier nicht ein, die Grenzschicht der Acetoneier ist nicht mehr semipermeabel. (O. Warburg und O. Meyerhof (3?).

Wahrscheinlich ist auch die Grenzschicht der Acetonhefe nicht mehr intakt. Durch Waschen mit Zuckerlösung nämlich kann das Gärvermögen der Acetonhefe aufgehoben werden, wobei nach Harden (4) das zur Gärung nötige Phosphat ausgelaugt wird.

Die Gärungsgeschwindigkeit der Acetonhefe ist bedeutend kleiner, als die der entsprechenden Menge intakter Zellen. Die Angaben über den Abfall der Geschwindigkeit schwanken; nach Buchners Zahlen würde sie etwa auf $1 / 30$ bis $1 / 50$ fallen, nach einer Angabe von Harden (4) auf $1 / 8$.

1) Furcht sich abor nicht mehr! 
Der Nachweis, dass das Buchnersche Acetonverfahren auch auf sauerstoffatmende Zellen mit Erfolg übertragbar ist, wurde in Palladins Laboratorium von Kostytscheff (7), an aspergillus niger, erbracht. Zunächst allerdings stiess Kostytscheff auf die Schwierigkeit, dass seine Präparate nicht steril waren; es blieben bei der Aceton-Ätherbehandlung immer einige Zellen teilungsfähig. Die gleiche Beobachtung machten später an Bakterien Cathcart und Hahn (6), die sich im übrigen nicht mit der Atmung, sondern mit der Reduktionskraft ihrer Acetonpräparate beschäftigten. Der bei der Acetonbehandlung bleibende teilungsfähige Rest jedoch lässt sich sowohl nach Kostytscheff als auch nach Cathcart und Hahn durch Erhitzev der trockenen Präparate leicht teiluugsunfähig machen.

Wie gross die Oxydationsgeschwindigkeit in sterilen Präparaten von aspergillus im Vergleich zur Oxydationsgeschwindigkeit im intakten aspergillus war, hat Kostytscheff nicht genauer angegeben, sondern die Oxydationsgeschwindigkeit in den sterilen Präperaten nur als „kolossal schwach" bezeichnet.

Oxydation in Acetonpräparaten ron aspergillus niger haben ferner Herzog und Meier (8) wahrscheinlich gemacht. Organische Süuren, wie Milchsäure, wurden zerstört und Kohlensäure gebildet. Allerdings arbeiteten Herzog und Meier nicht mit sterilen Präparaten; Abimpfung ergab stets positive Resultate [die Präparate waren nicht erhitzt!]. Herzogs Versuche waren auch insolern unvollständig, als Sauerstoffaufnahme nicht einnaal qualitativ nachgewiesen wurde.

Dass die ,akzessorische Atmung“ der Tiergewebe nach Batelli und Stern in dern Acetonniederschlag der Organextrakte wiedergefunden wird (9), ist vielleicht so zu erklären, dass die Bakterien mit Azeton ausfallen; da wir wissep, dass Aceton Bakterien bei dem angewandten Verfahren am Leben lässt, so kann aus den Angaben von Batelli und Steru ein bestimmter Schluss nicht gezogen werden.

Die Versuche von O. Meyerh of und mir erstreckten sich auf Staphylokokken, Vibrionen, Blutzellen und Seeigeleier (zum Teil publiziert in 5). Gänzlich negativ fielen die Experimente mit Vibrio Netschnikoff aus. Eine Atmung des Acetonniederschlags liess sich nicht nachweisen; abgeimpft haben wir nicht - weil ja die Atmung feblte.

Acetonniederschläge von roten Vogelblutzellen nahmen stets Sauerstoff auf, wenn sie mit Ringerscher Lösung oder Wasser bei etwa $30^{\circ}$ gehalten wurden. Doch konnte eine entsprechende Kohlensäureproduktion nicht rachgewiesen werden, und die Möglichkeit, dass der Sauerstoff von Hämoglobin, das beim Trocknen der Präparate im Vakum-Exsikator aus Oxyhämoglobin entstanden war, aufgenommen wurde, konnte nicht von der Hand gewiesen werden. 
Beiträge z. Physiologie d. Zelle, insbesondere über die Oxydationsgeschwindigkeit in Zellen. 319

Was die Acetoupräparate von Seeigeleiern anbetrifft, so ist scharf zwischen unbefruchteten und befruchteten Eiern zu unterscheiden. Die Oxydationsgeschwindigkeit im unbefruchteten Ei ist von der Struktur unabhängig; das lässt sich so beweisen, dass Strukturzerstörung die Oxydationsgeschwindigkeit für einige Zeit unverändert lässt. Die Oxydationsgeschwindigkeit im befruchteten Ei dagegen steht in engem Zusammenhang mit der Struktur und im besonderen der semipermeablen Zellgrenzschicht; durch Strukturzerstörung fällt hier die Oxydationsgeschwindigkeit um $90 \%$ und mehr - je nach dem Furchungstadium - ab (vgl. Abschnitt 4 dieses Kapitels). Erinnern wir uns ferner, dass bei der Acetonbehandlung die semipermeable Grenzschicht des Seeigeleies zerstört wird, so haben wir also zu erwarten, dass durch Acetonbehandlung die Oxydationsgeschwindigkeit des befruchteten Eies sehr stark, die des unbefruchteten Eies nicht erheblich abfallen wird. Das ist in der Tat - bei passender Versuchsanordnung - der Fall. - Die Kohlensïurebildung ist auch im unbefruchteten $\mathrm{Ei}$ an die Intaktheit der Struktur gebunden; Strukturzerstörung, die die Oxydations. geschwindigkeit unverändert lïsst, bringt die Kohlensäureproduktion zum Verschwinden. Auch hiermit harmonieren die Erfahrungen an Acetoneiern die Kohlensäureproduktion des unbefruchteten Eies erlischt durch Acetonbehandlung. (O. Warburg u. O. Neyerhof [33]).

Acetonpräparate von Staphylokokken. Trägt man eine durch scharfes Zentrifugieren konzentrierte Bouillonsuspension von Staphylococcus albus in Aceton ein, saugt ab, wäscht mit $\ddot{A}$ ther und erhitzt den Niederschlag einige Stunden auf $100^{\circ}$, so erhält man ein steriles Präparat, das in Bouillon aufgeschwemmt, Sauerstoff verbraucht und Kohlensäure in typischem Verhältnis bildet (respirator. Quotient 0,65 bis 0,9 ). Innerhalb uicht zu langer Zeiten und bei niedriger Temperatur ist die Grösse des Gaswechsels konstant, in gleichen Zeiten wird gleichviel veratmet. Die Umsatzgeschwindigkeit ist auf etwa $\frac{1}{36}$ von der der lebenden Zellen gesunken, also weniger vermindert als nach den Buchnerschen Zahlen die Gärungsgeschwindigkeit der Acetonhefe. Bei dem starken Gaswechsel der Bakterien wird, trotz dieses Abfalls, in den tcetonpräparaten sehr intensiv geatmet, vergleichsweise ebenso intensiv wie in der lebenden Leberzelle eines Warmblüters, wenn man die Geschwindigkeiten auf gleiche Gewichtsmengen bezieht.

Wie schon erwähnt, werden viele Bakterien durch Aceton-Äther nicht abgetötet; auch die Staphylokokken-Präparate, die nicht erhitzt wurden, waren nie steril. Allerdings glaube ich, dass durch die Aceton-ïtherbehandlung doch der grösste Teil der Individuen abgetötet wurde; denn während die Atmungsgrösse lebender Bakterien dauernd stark zunahm, eben weil ihre Individuen-Zahl zunahm, zeigten die nicht sterilen Acetonpräparate von Staphylococcus albus diese Erscheinung nicht. Solche Präparate atmeten 
immer viel stärker als die erhitzten, etwa 10 mal so stark; die Hauptschädigung der Atmung trat erst beim Erhitzen auf $100^{\circ}$ ein. Fasst man die nicht erhitzten Präparate als ein Gemisch von wenigen lebenden und rielen toten Kokken auf, so würde für die Hauptmenge der Kokken die Atmungsgeschwindigkeit beim Abtöten nur auf ein Drittel, nicht auf ein Sechsunddreissigstel abfallen, und nur für einige wenige, besonders widerstandsfähige Individuen wäre Trennung von Teilungsfähigkeit und Atmung nicht so weitgehend möglich. Diese Überlegung stützt sich jedoch allein auf den Nichtanstieg der Atmungsgrösse der Acetonniederschläge, also auf eine Beobachtung, die immerhin mehrere Deutungen zulässt.

Nach dem Gesagten beruht die Trennung von Teilungsfähigkeit und Atmung in Staphylokokken auf der Kombination zweier Methoden, der AcetonÄtherbehandlung und Erhitzung. Es ist nicht uninteressant, dass eine Trennung von Teilungsfähigkeit und Atmung nie gelang, wenn wir feuch te Kokken, z. B. Bouillonsuspensionen, erhitzten. Stets verschwand mit der reilungsfähigkeit auch die Atmung.

\section{Zellstruktur und Oxydationsgeschwindigkeit.}

Zweifellos ist das geeignete Material, wenn man den Einfluss der Zellstruktur kennen lernen will, die isolierte Zelle, nicht das Gewebe, bei dem eine höhere Ordnung der Struktur, das Gefüge der Zellen, die Experimente und ihre Deutung erschwert. Indessen wurde bisher nie mit isolierten Zellen in dieser Richtung experimentiert, sondern stets mit Geweben; so waren denn auch die Versuche, die ich vorfand, recht wenig übersichtlich. Nach Palladin wirkt bei Pflanzen jede Schädigung des anatomischen Baues und der zelligen Struktur ,störend" auf den Stoffwechsel (10). Wenn er zerriebene Weizenkeime in Wasser brachte, schieden sie in einer bestimmten Zeit erheblich weniger Kohlensiure aus als die unverletzten Keime; die Art der Zerreibung ist von Palladin nicht genauer angegeben, ebensowenig über das mikroskopische Bild der Objekte nach dem Zerreiben berichtet. Wir können also irgendwelche Schlüsse nicht ziehen, zumal nach Palladin der Abfall der Kohlensäure a uscheidung nach dem Zerreiben zum Teil nicht auf eine geringere Kohlensäure produktion, sondern auf Ausscheidung präformierter Kohlensäure während des Zerreibens zurückzuführen ist.

In anderen Experimenten Palladins war die Zellstruktur zweifellos geschädigt (10). Pflanzenteile wurden längere Zeit bei $-20^{\circ}$ gefroren gehalten, dann aufgetaut und im Gasrezipienten auf Atmung untersucht. Dabei ergab sich, dass die Sauerstoffatmung verschwunden war, während die Kohlensäureproduktion noch fortdauerte. Eine Reihe der sonderbarsten und nicht regelmässig beobachteten Erscheinungen werden im Anschluss an diesen Befund beschrieben. Manchmal soll die Sauerstoffatmung wieder erscheinen, wenn 
Beiträge z. Physiologie d. Zelle, insbesondere über die Oxydationsgeschwindigkeit in Zellen. 321

die erfrorenen Objekte einige Zeit in sauerstofffreier Atmosphäre gehalten werden. Pigmenthaltige Pflanzen sollen eine Ausnahme machen, bei ihnen soll durch Erfrieren die Sauerstoffatmung überhaupt nicht verschwinden usw. Entnehmen wir den zahlreichen und häufig unverständlichen Experimenten das für uns wichtige, so würde also schon eine relativ unerhebliche Strukturschädigung, wie sie durch Gefrieren und Auftauen erreicht wird, unter gewissen Umständen die Sauerstoffatmung herabsetzen. Wir werden später sehen, dass die gleiche Schädigungsmethode bei Blutzellen die Atmung völlig unverändert lässt.

Vielleicht gehören in diesen Zusammenhang auch einige Beobachtungen von Batelli und Stern $(9,11)$. Nimmt man einem Tier sofort nach dem Tode die Leber heraus, zerkleinert sie in einer Fleischhackmaschine - wobei also im wesentlichen das Gefüge der Zellen, nicht die Struktur der einzelnen Zellen verändert wird - und misst den Sauerstoffverbrauch, so findet man nach kurzer Zeit, etwa einer Stunde, nur noch $1 / 3-1 / 4$ der Anfangsatmung. Dieser Abfall ist nicht durch die Entfernung des Organs aus dern Körper verursacht; denn Experimente an intakten Leberläppchen, die ich mit Herrn Ryuta Usui (12) ausführte, zeigen, dass der Gaswechsel stundenlang nach Herausnahme des Organs aus dem Körper konstant bleibt. Möglicherweise also tritt in den Versuchen von Batelli und Stern ein Finfluss des Zellg efüges zutage.

Die Struktur der Zelle versuchten Batelli und Stern (13) auf eigenartige Weise zu schädigen, nämlich durch eiweissverdauende Fermente. Leberbrei wurde mit Trypsin geschüttelt und verbrauchte dann in einer bestimmten Zeit viel weniger Sauerstoff als die Kontrollprobe ohne Trypsin. Über das mikroskopische Bild der mit Trypsin behandelten Zellen ist nichts angegeben, doch glauben die Autoren, dass das Trypsin durch Strukturzerstörung und nicht direkt chemisch auf die Atmung wirkt. Sehr beweisend ist die Versuchsanordnung natürlich nicht, denn nehmen wir einmal an, wir hätten in Zellen eiweissartige Oxydationsfermente, so könnte das Trypsin die Fermente verdauen.

Wichtig dagegen scheinen mir zwei Angaben von Harden und Maclean (14) zu sein. Wurde Muskelbrei von Kaninchen mit Sand zerrieben, so fiel der Sauerstoffverbrauch einmal von 17 auf 13, ein zweites Mal von 10 auf 6. Da kaum anzunehrnen ist, dass der Sand Fermente direkt irgendwie unwirksam machte, war bier die Strukturzerstörung offenbar die Ursache der Atmungsverminderung. Am Froschmuskel machten schon früher Fletcher und Hopkins (15) Beobachtungen, die nach der gleichen Richtung wiesen. Intakte isolierte Froschmuskeln nämlich zerstörten Milchsäure durch Oxydation, dagegen konnte eine Milchsäureverbrennung nicht nachgewiesen werden, wenn die Muskeln mechanisch geschädigt („damaged“) waren. 
Eine besondere Art von Strukturschädigung ist die künstliche Abtreunung kernloser Protoplasmastücke vom Zellleib. Solche Experimente an Zellen mit Protoplasmaströmung haben zu dem interessanten Resultat gelührt, dass auch kernfreie Protoplasmastücke atmen; denn die Plasmaströmung, die in kernfreien Stücken fortdauerte, hörte auf, wenn der Sauerstoff entzogen wurde (Pfeffer [16]'. Spüter habe ich die Sauerstoffatmung kernloser Zellen, der roten Säugetierblutzellen, direkt gemessen (O. Warburg [17]; vgl. auch Morawitz [18]). Der Strukturrest, den diese Zellen besitzen, ist in verschiedener Beziehung interessant. Er ist das feine Gerüstwerk, das als Stroma bezeichnet wird und chemisch im wesentlichen aus Lipoiden und Nukleinsäureverbiudungen besteht. Dieses Gerüstwerk fürbt sich mit Methylenblau. Es fiel mir nun sofort auf, dass eine Zellsuspension intensiver atmete, wenn sie eine grössere Zahl intensiver färbbarer Elemente, sogenannter basophiler Zellen, enthält. Auf Anregung von Morawitz bestimmten dann Itami und Pratt (19) die Stromamenge, oder, wie wir auch sagen können, die Strukturmenge, bei stark und schwach atmenden kernlosen Blutzellen einigermassen quantitativ und fanden bei stark atmenden Zellen eine Vermehrung auf das 10- bis 15-fache.

Dass kernhaltige rote Blutzellen in der Regel stärker atmen als kernlose, ist eine Strukturbeziehung (O. Warburg [17]), auf die wir hier keinen besonderen Wert legen wollen. Dagegen ist bemerkenswert, dass auch in kernhaltigen roten Blutzellen die Oxydationsprozesse intensiver sind, wenn die Kerne grösser sind und das Protoplasma sich mit Methylenblau stärker färbt, also offenbar dann, wenn die Menge der unlöslichen Zellbestandteile oder Strukturteile vermehrt ist (O. Warburg und Onaka [20]; Masing [21]).

Natürlich dürfte aus solchen Beobachtungen allein nie auf eine direlite Beziehung zur Struktur geschlossen werden, es könnte ja einfach so liegen, dass unsere Zellen sowohl reicher an Struktur wïren, als a uch intensiver atmeten, dass aber ein ursächlicher Zusammenhang nicht bestände. Diese Unsicherheit kommt im wesentlichen daher, dass wir nicht dieselbe Zelle bei verschiedenem Strukturgehalt verglichen; sie besteht nicht in den folgenden Versuchen, in denen die Atmung ein - und derselben Zelle unter verschiedenen Strukturbedingungen verglichen wurde.

Bringt man rote Vogelblutzellen unter geeigneten Bedingungen zum Gefrieren und taut sie rasch wieder auf, so wird die Zellmembran verletzt, der flüssige Protoplasmainhalt tritt aus; es ertolgt, wie man in der Serologie sagt, „totale Hümolyse". Im Mikroskop sieht man in solchem Waterial noch Kern- und Zellgrenzen, die aber offenbar, da der flüssige Protoplasmainhalt austrat, Risse bekamen. Solche Elemente atmen nun noch ebenso intensiv, wie die intakten Zellen, wenn nur einige besonderen Kautelen beobachtet werden (O. Warburg [22]), im besonderen die benutzte Zellsuspension so wenig wie möglich Zwischenflüssigkeit enthält. 
Die Atmungsgrösse einer intakten Blutzelle ist ganz unabhängig ${ }^{1}$ ) von der Menge Flüssigkeit, in der sie suspendiert ist, sie ist die gleiche in einem Kubikzentimeter und in einem Liter. Bringen wir dagegen cytolisierte Zellen in verschiedene Volumina von Ringerlösung, Serum oder Wasser, so ist die Atmungsgrösse einer Zelle um so kleiner, je grösser das Volumen. Beispielsweise verbrauchten $2 \mathrm{ccm}$ einer konzentrierten cytolisierten Zellsupension in $0,9 \% \mathrm{NaCl}$ die Sauerstoffmenge 66 (in willkürlichen Einheiten); wurde mit $3 \mathrm{ccm}(0,9 \% \mathrm{NaCl}$ verdünnt, so sank der Sauerstoffverbrauch, immer bezogen auf gleiche Zellenzahl, auf 31, bei Verdünnung mit $11 \mathrm{ccm}$ auf 15. Eine Verdünnungsflüssigkeit, die nicht schädigte, wurde nicht gefunden, obwohl die verschiedenartigsten Kombinationen ausprobiert wurden, wie Glykokoll, Kaliumphosphat, Asparagin, inaktiviertes Serum und andere.

Da jede Verdünnung die Atmung schädigt, so ergibt sich, dass die Zellen so dicht wie möglich nebeneinander liegen sollten, wenn man die Atmung nach der Hämolyse unveründert erhalten will. In der Tat sind die Resultate ganz unregelmässig, wenn die Suspensionsdichte nicht berücksichtigt wird; benutzt man dagegen Suspensionen, wie sie durch scharfes Zentrifugieren in einer Runneschen Zentrifuge leicht herzustellen sind, so ist die Atmung nach der Cytolyse nicht kleiner als die der intakten Zellen. Wir sehen also, wie vorsichtig ein Abfall der Atmung nach Strukturänderungen beurteilt werden muss. Zerstört man die Zellen in verdünnter Suspension, so sinkt die Atmung fast auf Null, und der Trugschluss, dass die Atmung an die Intaktheit der Zellen gebunden ist, liegt gefuhrlich nahe.

Sind die Tatsachen einmal bekannt, so fällt es nicht schwer, den Einfluss der Suspensionsdichte zu erklären. Je dichter die Suspension, um so geringer ist die Veränderung des Milieus nach der Cytolyse; könnten wir die Zellen völlig von der Zwischenflüssigkeit befreien, so würde sich bei der Cytolyse nur der flüssige Zellinhalt vermischen; der flüssige Inhalt der einen Zelle würde mit dem flüssigen Inhalt der anderen Zelle verdünnt, die Formelemente würden auch nach der Cytolyse nur vom Zellinhalt umspült. Diesen Grenzfall köunen wir praktisch nie erreichen, aber wir kommen ihm mit unseren zusammenzentrifugierten Suspensionen sehr nahe.

Das Resultat, dass Zellen mit gesprengten Membranen weiter atmen, ist in mancher Hinsicht beachtenswert. Auf einen Punkt sei besonders hingewiesen. Wenn eine Zelle, wie vielfach angenommen wird, aus fachwerkartig getrennten Reaktionskammern besteht, so wissen wir jetzt, dass die Oxydationsgeschwindigkeit nicht steigt und nicht fällt, wenn die Fachwerkwände ihre trennenden Eigenschaften eingebüsst haben.

Nach der beschriebenen Art der Cytolyse schwimmen die Formelemente gewissermassen frei im flüssigen Protoplasma. Hier also war die Möglichkeit

1) Wenu man von Bedingungen, unter denen die Stoffwechselprodukte nicht entfernt werden, absieht. 
gegeben, Strukturteile und Protoplasmaflüssigkeit zu trennen und so der Frage nach der Lokalisation der Atmung näher zu kommen. Die cytolysierte Zellmasse wurde schark zentrifugiert und trennte sich dabei in eine obere klare strukturfreie Schicht und eine tiefere, die die Formelemente enthielt. In den verschiedenen Schichten wurde dann die Atmung gemessen; esergabsich, dass sieverschwindendklein warinderstrukturfreien Schicht, dagegen in dertieferen Schicht etwa von derselben Grösse wie in der nicht getrennten Kontrollmischung. Die Atmung ist also im wesentlichen an die Strukturteile gebunden.

Wenn man hier einwendet, dass die Atmung möglicherweise doch im flüssigen Zellinhalt vor sich gehe, und dass bei unserer Cytolysemethode vielleicht gerade die Hohlrïume, die die „Atmungshüssigkeit enthielten, nicht eröffnet worden wïren, so ist darauf zu antworten dass die Atmung der Formelemente beim Waschen mit beliebigen Flüssigkeiten völlig verschwindet: dass also jedenfalls „die Atmung“, wie wir ganz allgemein sagen wollen, nach der Cytolyse durch Flüssigkeit von aussen erreichbar ist.

Ich ging nun weiter so vor, dass ich die Struktur viel energischer als durch Gefrieren und Auftauen zerstörte, so gründlich, dass Kerne und Zellgrenzen verschwanden und dass weder im frischen noch im fixierten und gefärbten Präparat irgendwelche Gebilde zu sehen waren, die an die Herkunft von Zellen erinnerten. Das lässt sich auf zweierlei Art erreichen. Erstens durch Zerreiben einer konzentrierten Zellsuspension mit Sand, wobei man, bei passender Versuchsanordnung, ziemlich rasch zum Ziel kommt. Nach dem Zerreiben mit Sand war die Oxydationsgeschwindigkeit ganz enorm gesunken, ein Sauerstoffverbrauch mit unseren recht empfindlichen Methoden nicht mehr nachweisbar.

Die Gegenwart von Sand ist aus methodischen Gründen nicht sehr schön; die zerkleinerte Zellmasse und der Sand rerkleben zu einer zähflüssigen Paste und es war immerhin daran zu denken, dass der Sand durch diese Verklumpung oder durch Adsorption von Fermenten den Abfall der Atmung bewirkte. Wenn dieser Einwand auch nicht gerade sehr wahrscheinlich war, so habe ich mich doch bei der fundamentalen Bedeutung der Frage, bemüht, ihn beiseite $z u$ schaffen und die Zellen ohne Zusatz irgendwelcher Substanzen zu zerkleinern. Das ist nun gar nicht so leicht bei flüssigen Suspensionen, die kleinen und biegsamen Gebilde weichen dem Druck von Zerreibungswerkzeugen grösstenteils aus. Ich kam auch nicht zum Ziel, als ich die Zellsuspension in flüssiger Lult frieren liess und damn in dem bekannten Apparat von Ma cfadyen maschinell mit einem Pistill bearbeitete. Es wurden wohl immer Zellen zerstört, aber selbst in langen Zeiten nur kleine Bruchteile der zur Atmungsmessung nötigen Menge. Schliesslich gelang die Zerkleinerung mit einem kürzlich in England konstruierten Apparat (Barnard und Hewlett [23]), der im wesentlichen ein stählernes Kugellager ist. In dieser Vorrichtung konnten ausreichende Quantitäten Zellen in kurzer Zeit und 
Beiträge z. Physiologie d. Zelle, insbesondere über die Oxydationsyeschwindigkeit in Zellen. 325

bei niedriger Temperatur bis zur völligen Unkenntlichkeit verstümmelt werden. Das Resultat war dasselbe, wie bei der Zerreibung mit Sand, die Atruung sank enorm ab. (O. Warburg [24].) Folgende Tabelle gibt einige Belege.

\begin{tabular}{|c|c|c|}
\hline & & $\begin{array}{l}\text { Sauerstoffrerbrauch } \\
\text { in cem }\left(0^{\circ} 760 \mathrm{~mm}\right)\end{array}$ \\
\hline \multirow{2}{*}{1.} & Zellen intakt & $0,46 \tilde{5}$ \\
\hline & "zerstört & 一 \\
\hline \multirow{2}{*}{2.} & Zellen intakt & 0,206 \\
\hline & " zerstört & 一 \\
\hline \multirow{2}{*}{3.} & Zellen intakt & $0,31 \tilde{n}$ \\
\hline & $" \quad$ zerstört & 0,053 \\
\hline \multirow{2}{*}{4.} & Zellen intakt & 0,431 \\
\hline & " zerstört & - \\
\hline \multirow{2}{*}{5.} & 'Lellen intakt & 0,334 \\
\hline & $" \quad$ zerstört. & 0,003 \\
\hline \multirow{2}{*}{6.} & Zellen intakt & 0,360 \\
\hline & $" \quad$ zerstört & 一 \\
\hline
\end{tabular}

In einem der Versuche, Nr. 3, war nach der Struktur-Zerstörung die Oxydationsgeschwindigkeit, wenn auch sehr stark gesunken, immerhin noch messbar. $\mathrm{Ob}$ das mit ejner unvollständigen Zerreibung zusammenhängt oder ob unter gewissen Bedingungen die Restatmung grösser ist, wollen wir hier nicht diskutieren, sondern das Hauptgewicht auf die Inderung der Oxydationsgeschwindigkeit legen. Die Restgeschwindigkeit kann ja schon aus theoretischen Gründen nie gleich Null sein, und je nach der angewandten Methode wird sie messbar oder nicht messbar sein.

Aus den Versuchen mit Blutzellen geht dreierlei hervor:

1. Wenn mehr Struktur da ist, wird intensiver geatmet. (Vergleich verschieden stark atmender kernloser Blutzellen.)

2. Die Atmung ist an die Strukturteile gebunden. (Herauszentrifugieren der "Atmung" aus dem flüssigen Protoplasmainhalt.)

3. Die Atmung sinkt enorm ab, wenn die Strukturteile zerrieben werden. 
Die Möglichleiten, Struktur experimentell abzuändern, sind bei Blutzellen ziemlich begrenzt; wir können nichts weiter tun, als die Struktur mehr oder weniger vollständig zerstören, wir haben kein Mittel, Struktur neu in einer Zelle entstehen zu lassen. Viel feinere Strukturänderungen und besonders $N$ e u bildungen von Struktur in der Zelle lassen sich bei Seeigeleiern hervorruten, die deshalb für unser Problem besonders interessante Versuchsobjekte sind.

Das ungefurchte Seeigelei ist eine Riesenzelle im Vergleich zu den meisten tierischen Zellen, etwa tausendmal so gross als eine rote Blutzelle. Es enthält einen Kern, der nicht viel grüsser ist als der Kerm normaler tierischer Zellen. Grenzflächen also, wie Zellgrenzen und Kerngrenzen treten im ungefurchten $\mathrm{Ei}$ ganz zurück gegen die Zellmasse, der Quotient $\frac{\text { Strukturfläche }}{\text { Zellmasse }}$ ist sehr klein. Wir haben es nun in der Hand, diesen Quotienten in weiten Grenzen beliebig nach der Richtung zu verändern, dass er wächst; wir künnen durch Sperma oder mit Hilfe der Loebschen Methoden der künstlichen Parthenogenese den Anstoss zur Strukturentstehung, zur Furchung geben. Die sichtbare Struktur nimmt dann in raschem Tempo $\mathrm{zu}$, es entstehen neue Kerne und Zellgrenzen und nach wenigen Stunden kann dieselbe Masse statt eines Kernes tausend Kerne enthalten. Wenn allen Zellen gleichzeitig der Anstoss zur Entwickelung gegeben wurde, so gehen alle Zellen fast gleichzeitig durch das 2-Zellen-, 4-Zellenstadium usw., so dass wir ein ganz einheitliches Material unter verschiedenen Strukturverhiltnissen für unsere Oxydationsmessungen zur Verlügung haben. So habe ich die Atmung gemessen vor dem Anstoss zur Furchung, während der Furchung in den verschicdensten Stadien und bei a uf gehobener Furchung. (O. Warburg [25], [26]). Von den Resultaten interessiert uns hier zunächst, dass mit der Neubildung von Struktur die Oxydationsgeschwindigkeit zunimmt, so erheblich, dass das für jedes Furchungsstadium gut messbar ist. Also im Vierzellen-Stadium wird in der Zeiteinheit mehr Sauerstoff verbraucht als im Zweizellen-Stadium, im Achtzellen-Stadium mehr als im Vierzellen-Stadium usw. Wenn man die quantitativen Verhältnisse, die hier bestehen, eingehender berücksichtigt, so stösst man auf die Tatsache, dass die Atmung nicht der Zunahme der Struktur, etwa der Kernzahl, proportional wächst, sondern viel langsamer. Die Atmung bei der Kernzahl 1000 ist nicht 1000 mal so gross wie bei der Kernzahl 1, sondern nur 3 mal so gross. Wir können das auch so ausdrücken, dass die Atmung im ungefurchten Ei gewissermassen zu gross ist für seine Strukturflächen. Das führte auf die Vermutung, dass im ungefurchten $\mathrm{Ei}$ die Atmung oder ein Teil der Atmung möglicherweise noch nicht in Beziehung zur Struktur stände. War dieser Gedankengang richtig, so durfte Strukturzerstörung im ungefurchten Ei die Atmung viel weniger . beeinflussen, als bei Zellen mit normalem $\frac{\text { Struktur }}{\text { Masse }}$ - Quotienten. 
Beiträge z. Physiologie d. Zelle, insbesondere über die Oxydationsgeschwindigkeit in Zellen. 327

In der Tat gelang es, die Struktur des unbefruchteten Eies völlig zu zerstören, ohne dass die Oxydationsgeschwindigkeit gleichzeitig abfiel, während schon eine teilweise Zerstörung der Struktur des befruchteten Eieseinensehrstarken Abfall der Oxydationsgeschwindigkeit, um $90 \%$ oder mehr, zur Folge hatte ${ }^{1}$ ). Die Technik der Versuche war, bei der Empfindlichkeit des Seeigeleies, besonders einfach. Die Eier wurden in Seewasser scharf zentrifugiert, das Seewrasser wurde abgegossen, ein dem Sediment gleiches Volumen destillierten Wassers zugefügt und einige Minuten mit der Hand krüftig im Reagensglas geschüttelt. Die Struktur der unbefruchteten Eier war dann völlig verschwunden, es resultierte eine in dünnen Schichten durchscheinende, sehr feine Emulsion, die einige Zeit nach der Zerschüttelung ebenso viel oder noch etwas mehr Sauerstoff verbrauchte, als die Kontrolle intakter Eier in Seewasser. Die befruchteten Eier liessen sich nie so vollständig zerschütteln, wie die unbefruchteten, trotzdem aber - also trotz nur unvollständiger Strukturzerstörung - fiel die Oxydationsgeschwindigkeit stets sofort um den erwähnten Betrag ab (O. Warburg und O. Meyerhof, 33). - Im Gegensatz zur $\mathrm{CO}_{2}$-Aufnahme ist die Kohlensäureproduktion auch im unbefruchteten Ei mit der Struktur in irgend einer Weise verbunden. Denn die $\mathrm{CO}_{2}$-Produktion erlosch völlig beim Zerschütteln. Wir können also Sauerstoffaufnahme und Kohlensäurebildung durch Zerschütteln qantitativ trennen ${ }^{2}$ ).

Die Struktur des Seeigeleis lässt sich nun noch aut eine besondere Weise ändern und damit kommen wir vielleicht auf die interessanteste Beziehung zur Oxydationsgeschwindigkeit. Wenn bei der Befruchtung der Spermakopf in das Ei eingedrungen ist, so schnellt plötzlich die Atmung um mehrere hundert Prozent in die Höhe, eine Tatsache, die seit ich sie an dem Ei ron Arbacia pustulosa fand ${ }^{3}$ ), von J. Loeb, O. Meyerhof und Mac Clendon

1) In einigen Vorversuchen von 0 . Warburg und 0 . Meyerhof (5) war dieses Resultat schon angedeutet, jedoch nicht so glatt, weil die Strukturzerstörung auf eine für quantitative Versuche nicht sehr zweekmüssige Art und Weise vorgenommen warde (Zerreiben mit Sand).

3) Dass es gelänge, Sauerstoffaufnahme und Kohlensäureproduktion zu trennen, ist schon von Batelli und Stern behauptet worden (9). Mit steigender Alkalinität sollte die „akzessorische Atmung “ eine Tendenz zur Steigerung aufweisen, die Kohlensäurebildung jedoch abnehmen, „so dass der respiratorische Quotient in dem Masse, wie die Alkalinität zunimmt, niedriger wird “. Sie glaubten, das so nachweisen zu können, dass sie Gewebebrei, der mit wechselnden Mengen Alkali versetzt war, mit Lnft schüttelten und Sauerstoffubnahme und Kohlensäurezunahme im Gasraum bestimmten. Sollte bier nicht das Alkali die Kohlensäure in der Flüssigkeit zurückgehalten haben?

3) Der Unterschied in den Oxydationsgeschwindigkeiten des unbefruchteten und befruchteten Eies wächst mit der Zeit nach der Befruchtung, weil, wie oben, erwähnt, die Oxydationsgeschwindigkeit im Lauf der Furchung zunimmt. Legt man also auf die genaue zahlenmässige Kenntnis dieses Unterschiedes bei verschiedenen Seeigeleiern Wert, so ist die erste Bedingung, dass befruchtete Hier nur in gleichen Furchungsstadien mit unbefruchteten ver. glichen werden. 
auch an anderen Seeigeleiern beobachtet wurde. (O. W ar burg [25], J. L oeb und Wasteneys [28], O. Meyerhof [27], Mac Clendon [29].) Gibt es nun irgend eine sichtbare Strukturänderung, die zu dem Emporschnellen der Atmung in Beziehung gesetzt werden kann? Vergegenwärtigen wir uns die morphologischen Vorgänge bei der Befruchtung. Während der Spermakopf eindringt oder sofort nachher, verändert sich die Oberfläche des Eis, sie wird etwas runzlig und scheidet häufig, jedoch nicht immer, eine breite durchsichtige Lamelle, die sogenannte Befruchtungsmembran ab. Der Spermakern wandert daun dem Eikern entgegen, die Astrosphären entstehen und es erfolgen alle diejenigen Vorgänge, die als „,mitotische Kernteilung“ bekannt sind. Aus dem zeitlichen Einsetzen des Atmungsanstiegs einerseits, der Strukturänderungen andererseits, können wir zunächst schliessen, welche Strukturänderungen nich t mit dem Atmungsanstieg in Zusammenhang gebracht werden können. Das sind alle diejenigen, die später als der Atmaungsanstieg einsetzen, und es bleiben nur zwei, für die eine Beziehung überhaupt mög. lich ist: die Wanderung des Spermakerns und die Veränderung der EioberHäche. Die Atmung des Spermakerns kennen wir der Grössenordnung nach; ich habe sie im lebenden Spermatozoon gemessen und mehrere hundertmal kleiner als die Atmung des unbefruchteten Eis gefunden (25). Allerdings könnte der Spermakern im Ei stürker atmen als im Spermatozoon, um aber den Atmungsanstieg bei der Befruchtung bervorzubringen, müsate seine Atmung auf den 1000 fachen Wert emporschnellen, was als röllig ausgeschlossen zu betrachten ist. Es kommt hinzu, dass wir denselben Atmungsanstieg ohne Spermatozoon mit Hilfe von Chemikalien wie Kupfer, Silber, Fettsäuren und vielen anderen Stoffen erzielen können (O. Warburg [26]). Von dem Spermakopf und seinen Bewegungen also können wir hier absehen, die einzige dem Atmungsanstieg synchrone Strukturänderung, die in Betracht kommt, ist die Veränderung der Eioberflüche.

Das beweist natürlich noch keineswegs, dass ein ursächlicher Zusammenhang besteht, dass das Ei nach der Befruchtung deshalb stärker atmet, weil seine Oberfläche verändert ist. Ein solcher Zusammenhang jedoch wurde mir wahrscheinlich, als ich sah, dass alle Chemikalien, die die Atmung des unbefruchteten Eis erheblich steigerten, ausnahmslos. die Oberfläche in ähnlicher Weise veränderten, wie es durch die Befruchtung geschieht. Schliesslich gelang es, für einen besonderen Fall, eine ursächliche Beziehung direkt nachzuwisen (26). Wenn man nämlich das befruchtete lebende Ei aus Seewasser in eine alkalische Salzlösung bringt (H-Ionenkonzentration ca. $10^{-11}$ ), so verdoppelt sich die Oxydationsgeschwindigkeit annähernd. Fürbt man die Eier vorher mit Neutralrot, wobei sie einen tiefroten Ton annehmen, so ändert sich in der alkalischen Salzlösung die Färbung des Eis nicht, obwohl das umspülende Alkali schon in hundertfacher Verdünnung Neutralrot zum Umschlag in Gelb bringt. 
Beiträge z. Physiologie d. Zelle, insbesondere über die Oxydationsgeschwindigkeit in Zellen. 329

Die Farbe im Ei schlägt jedoch sofort in Gelb um, wenn man das Ei lädiert ${ }^{1}$ ).

Es findet also sicher kein Ausgleich der OH-Ionen durch die Oberfläche hindurch statt. Es wäre höchstens daran zu denken, dass minimale Spuren von OH-Ionen eindringen und dass die Atmung empfindlicher gegen $\mathrm{OH}$-Ionen ist als Neutralrot. Das ist nun offenbar nicht der Fall, wie man mit einer anderen Base, dem Ammoniak, zeigen kann. Ammoniak dringt eshr schnell durch die Oberfläche in das Ei ein, bewirkt in kleinen Konzentrationen keinen Oxydationsanstieg, in grösseren, in denen das Neutralrot im Ei schon gelb ist, einen geringeren, als die Natronlauge.

Der Versuch beweist also, dass eine Veränderung der Eioberfläche einen Atmungsanstieg zur Folge haben kann; im Zusammenhang mit den oben mitgeteilten Beobachtungen macht er recht wahrscheinlich, dass auch der Atmungsanstieg bei der Befruchtung die Folge der Oberflächenveränderung ist $\left.{ }^{2}\right)$. $\mathrm{Zu}$ dieser Auffassung passt gut, was wir über die Folgen der Strukturzerstörung erfahren haben. Ist nämlich der Atmung sanstieg nach der Befruchtung die Folge einer Grenzschichtänderung, so muss er wieder verschwinden, wenn wir die Zellgrenzschicht zerstören; und wirklich war ja der Abfall der Oxydationsgeschwindigkeit, für befruchtete Eier, nach Zerschütteln oder nach Zerstörung der Grenzschicht durch Aceton, stets mindestens gleich dem Anstieg nach der Befruchtung.

Die Resultate an Seeigeleiern lassen sich kurz so zusammenfassen: 1. In ein- und derselben Zelle ist Oxydationsgeschwindigkeit um so grösser, je mehr Struktur sie enthält. 2. Im unbefruchteten Ei, in dem die Struktur im Verhältais zur Masse ganz zurücktritt, finden wir keinen deutlichen Einfluss der Struktur auf die Oxydationsgeschwindigkeit. 3. Die

1) Mac Clendon (29) hat die Vermutung ansgesprochen, dass der Indikator sich in den Eilipoiden befände and deshalb nicht umschlüge, auch wenn OH-Ionen in das Ei hineinkämen. Herr MacClendon hätte nur nötig gehabt, das Ei zu lädieren; er hätte dann gesehen, dass seine Interpretation falsch ist. Auch rotgefärbte Acetoneier, die, wie oben erwähnt, keine semi permeable Grenzschicht mebr besitzen, schlagen sofort in gelb um, wenn sie in die alkalischo Salzlösung gebracht werden.

Der Neutralrotversuch wurde in letzter Zeit von Halwey (Americ. Journal of Physiology Bd. 31, 335. 1913) wiederholt und etwas variiert, ohne dass sich wesentlich Neues ergeben hätte.

$\left.{ }^{2}\right)$ Jacques Loeb hat früher die Vermutang ausgesprochen (34), dass die Veränderung der Eioberfläche von grosser Bedeutung für die Entwickelnngserregung sein könnte. Wie im Kapitel IV erwähnt, neigt jedoch J. L o eb zu der Auffassung, dass die Änderung der Oxydationsgeschwindigkeit in alkalischer Salzlösung $\mathrm{nich}$ t durch eine Grenzschichtänderung zustande kommt, sondern dass das Alkali in das Innere des Eies hineindiffundiert und dorterstauf die Oxydationen wirkt. 
Oxydationsgeschwindigkeit kann um mehrerehundert Prozent emporschnellen, wenn die einzige Veränderung, diewirsetzen, eine Veränderung der Zellgrenzschicht ist.

\section{Zellstruktur und Gärungsgeschwindigkeit.}

Eine Beziehung zwischen Zellstruktur und Gärung haben wir schon kennen gelernt (Kap. IV, c); die Struktur macht die Gärung empfindlicher gegen die Wirkung nicht spezifischer lipoidlöslicher Stoffe. Wir wollen hier die Beziehung zur Struktur von einer anderen Seite betrachten.

Jeder, der sich nicht eingehender mit Buchners Experimenten beschäftigt hat, wird zu der Ansicht neigen, dass gerade die Buchnersche Entdeckung der zellfreien Gärung die Unabhängigkeit der Gürung von der Struktur erwiesen hat. Berücksichtigt man jedoch die quantitativen Verhältnisse, so zeigt sich, dass' eine solche Unabhängigkeit durchaus nicht besteht. Die Gürungsgeschwindigkeit im Presssaft ist enorm viel kleiner als in der entsprechenden Menge lebender Zellen, sie beträgt nur wenige Prozente davon. Das kommt nicht etwa daher, dass bei der Presssaftbereitung der grössere Teil der Gärwirkung in dem Presskuchen zurückbleibt. Schon allein die Zerreibung der Hefezellen mit Sand führt, wie ich mich überzeugt habe, zu einem sehr erheblichen Geschwindigkeitsabfall (die Versuche waren ganz ähnlich angeordnet, wie die Blutversuche, die in diesem Kapitel, Abschnitt 4, beschrieben sind. Hefezellen wurden mit Sand vermischt, ein Teil dieser Mischung wurde etwa 10 Winuten zerrieben und darauf die Gürungsgeschwindigkeit in dem zerriebenen und nicht zerriebenen Gemisch bestimmt).

Vielleicht hat Buchner nnter dem Eindruck seiner Entdeckung, dass nach Strukturzerstörung eine Restgärung übrig bleibt, diesen Geschwindigkeitsabfall nicht genügend hervorgehoben; dort, wo er von ibm spricht, ist er mit einer nicht sehr befriedigenden Hypothese darüber hinweggegangen. Die Gärungsgeschwindigkeit im Presssaft nämlich soll nach Buchner dem Fermentyorrat entsprechen, der im Augenblick des Zerkleinerns in der Zelle vorhanden ist; während aber die lebende Zelle Ferment dauernd weiter produziert, ist der Presssaft natürlich dazu nicht imstande, und so soll der Geschwindigkeitsunterschied herauskommen. Nun ist die Überlegung, dass die Fermentproduktion in der lebenden Zelle beim Vergleich der Geschwindigkeiten eine Rolle spielen und das Verhältnis zuungunsten des Presssaftes verschieben kann, sicher richtig, aber nur dann, wenn die lebenden Zellen in Lösungen gehalten werden, in denen sie sich vermehren können, und wenn die Versuchszeiten lange sind. Nichts ist leichter, als diese komplizierenden Bedingungen auszuschalten, man vergleicht nur kurze Zeiten, in denen die Vermehrung der Zellen nicht in Betracht kommt, oder man bringt die Zellen 
Beiträge z. Physiologie d. Zelle, insbesondere über die Oxydationsgeschwindigkeit in Zellen. 331

in nährsalzfreie Zuckerlösungen, in denen überhaupt keine Vermehrung stattfindet und in denen ihre Gärungsgeschwindigkeit nicht wächst, sondern konstant bleibt. Auch dann findet man den Unterschied der Gärungssgeschwindigkeiten zwischen Presssaft und lebenden Zellen. Hält man diese Bedingungen nicht ein, so findet man natürlich viel grössere Unterschiede, die aber gar keine irgendwie definierte Bedeutung haben und mit den Versuchszeiten unbegrenzt wachsen.

Wenn wir einerseits wissen, dass die alkoholische Gürung durch ein Fermentgemisch, die Buchnersche Zymase, beschleunigt wird, andererseits, dass die Gürungsgeschwindigkeit beim Zerreiben der Hefezellen stark absinkt, so liegt die Erklärung nicht fern, dass beim Zerreiben der Hefezellen die Gärungsfermente zerrieben werden. Wir hätten es dann nicht mit der Zellstruktur zu tun, sondern mit der Molekularstruktur oder mit Strukturen, die den molekularen Dimensionen nahekommen. Diese Vorstellung war sehr leicht auf ihre Richtigkeit zu prüfen, wir hatten nur nötig, den zellfreien Presssaft mit Sand zu mischen und das Gemisch den gleichen mechanischen Bedingungen auszusetzen, wie früher das Gemisch von Sand und Hefezellen. Dabei zeigte sich, dass der Hefepresssaft an Gürwirkung so gut wie nichts einbüsste. Die Gärungsfermente also werden bei unserem Zerreibungsverfahren nicht zerrieben, mit anderen Worten, es ist die Zerstörung der Zellstruktur, und nicht der Molekularstruktur, die den Abfall der Gärungsgeschwindigkeit zur Folge hat.

Durch die Strukturzerstörung wird, das geht aus einer interessanten Beobachtung Hardens hervor (t), von dem Fermentgemisch des Helepresssaftes offenbar nur eine Komponente in ihrer Wirksamkeit erheblich geschwächt. Durch Zugabe von Phosphat zu Hefepresssaft kann die Gürungsgeschwindigkeit wieder gleich der in der entsprechenden Nenge lebender Hefezellen werden; die Phosphatwirkung dauert stets nur kurze Zeit an, so lange, bis das Phosphat in organische Bindung übergeführt ist; erneuter Zusatz von Phosphat hat einen erneuten Anstieg der Gürungsgeschwindigkeit zur Folge. Nun wissen wir, dass Phosphat in die Gleichung der alkoholischen Gärung eingeht und dass sich im Helepresssait ein Ferment findet, das Phosphat aus seiner organischen Bindung wieder befreit. Wohl mit Recht schliesst Harden aus seinen Versuchen, dass im Hefepresssalt die Phosphatspaltung der Zuckervergärung nicht "nachkommt", dass es also nicht an zuckerspaltendem, sondern an phosphatspátendem Ferment fehlt. Aus diesem Beispiel sehen wir, wie die Struktur die Umsatzgeschwindigkeit modifizieren kann, wenn sich ihre Wirkung nur a uf ein einziges Glied der Kette von Einzelvorgängen erstreckt, aus denen sich der Umsatz zusammensetzt. (Vgl. auch Kap. IV, 1.) 


\section{Die chemische Oxydationskatalyse.}

Dass die Oxydationskatalyse in Zellen nicht allein eine Strukturkatalyse ist, beweist die Tatsache, dass nach Strukturzerstörung Restlkatalysen übrig bleiben. Diese Restkatalysen sind in den meisten Fällen sehr klein, an der Grenze der Messbarkeit, in einem Fall jedoch, dem des unbefruchteten Seeigeleies, kann die Restkatalyse gleich der Katalyse in der intakten Zelle sein. Das unbefruchtete Seeigelei also ist besonders geeignet zum Studium der Restkatalyse oder, wie wir sie auch nennen können, der chemischen Katalyse; in der Tat gelang es hier, die chemische Katalyse ziemlich weitgehend aufzuklïren. - Ehe ich zur Beschreibung der einzelnen Versuche übergehe, seien die Fälle von Restkatalyse, über die andere Forscher berichtet haben, kurz referiert.

In einer grösseren Zahl von Mitteilungen haben Batelli und Stern $(9 ; 11 ; 30)$ angegeben, dass wässerige Extrakte von tierischen Organen eine recht beträchtliche Sauerstoffatmung zeigen. Allerdings gelang es nur, einen Teil des Atmungsvermögens aus der Zelle zu extrahieren. Diesen extrahierbaren Teil nennen Batelli und Stern ,aknessorische“ Atmung und stellen ihn in Gegensatz zu dem nicht extrahierbaren Teil, der „Hauptatmung:. Wenn man die Zahlen dieser Autoren überblickt, so ist das auffallendste Unregelmässigkeit, ja man kann sagen, völlige Regellosigkeit der Werte. Die Muskeln mancher Tiere sollen so gut wie keine ,akzessorische" Atmung zeigen; die Hundeleber eine besonders starke. Das Temperaturoptimum ist meistens $\overline{0} 5^{0}$ : „Die Leber des Hundes und des Rindes, die Niere des Pferdes, des Rindes und des. Hundes, die Lunge des Pferdes und die Milz des Rindes verhalten sich in dieser Beziehung ganz analog der Leber des Pferdes . . die Leber des Hammels hingegen zeigt eine grössere Empfindlichkeit gegen höhere Temperaturen" (9). Die Dauer der akzessorischen Atmung wird ganz verschieden angegeben. Sie bleibt „,mehrere Stunden bis mehrere Tage" (9) konstant, nach einer späteren Angabe ,ziemlich lange, 80 Minuten z. B." (30), manchmal aber nur 15 bis 20 Minuten. Um die ,akzessorische Atnung" möglichst frei von der "Hauptatmung" zu erhalten, lassen Batelli und Stern die Organe einige Stunden im toten Tier, und nehmen sie dann erst heraus. Nirgends in den Arbeiten dieser Forscher findet sich der Hinweis, dass auf Bakterien geprüft wurde, die sich doch in der Leber eines getöteten Tieres mit grosser Schnelligkeit entwickeln. Aus eigener Erfahrung weiss ich, wie ernst die Bakteriengefahr bei derartigen Experimenten einzuschätzen ist, man arbeitet mit ausgezeichneten Nährböden und in der Regel nicht steril, auch wenn man die Organe dem direkt getöteten Tier entnimmt. Die Bakteriengefahr wird nun noch grösser, wenn man die Gewebe nicht intakt lässt, sondern, wie Batelli und Stern, zu Brei zermahlt. Ich vermute, dass die , akzessorische" Atmung, die Atmung 
Beiträge z. Physiologie d. Zelle, insbesondere über die Oxydationsgeschwindigkeit in Zellen. 333

in den Organextrakten, auf Bakterienwirkung zurückzuführen ist. Diese Annahme ist wenigstens so lange die wahrscheinlichere, bis Batelli und Stern über aseptisch ausgeführte Versuche - Lebern von Föten würden sich dazu wohl-besonders eignen - berichten können $\left.{ }^{1}\right)$.

Auch Presssäfte mit erheblicher Oxydationsgeschwindigkeit sind bis jetzt wohl nicht erhalten worden. Eigene, zahlreiche Versuche mit Vogelblut verliefen stets negativ, d. h., eine deutliche Atmung in Presssäften wurde nie beobachtet. Die Erklärung ist zum Teil in Abschnitt 4 dieses Kapitels gegeben, die Atmung verschwindet ja schon beim Zerreiben der Zellen fast völlig. Auch wenn ich Zerreiben vermied -- für die Presssaltbereitung aus empfindlichen tierischen Zellen ist Zerreiben überflüssig - und einfach die mit Kieselgur gemischten Zellen auspresste, resultierten keine atmenden Säfte. Stets aber, wenn ich bei solchen Experimenten einen deutlichen Sauerstoffverbrauch beobachtete, ergab die mikroskopische Untersuchung die Anwesenheit an Bakterien. Im ganzen bin ich derselben Ansicht wie Harden und Maclean, dass in Presssäften Atmung bisher nicht nachgewiesen ist.(14).

Allerdings steht hiergegen auch eine vorläufige Mitteilung aus dem Palladinschen Institut vom Jahre 1904 (Maximow [31]). Das Myzel von aspergillus niger wurde mit Quarzsand und Wasser zerrieben und der Brei mit einer Handpresse durch ein Leintuch durchgepresst. J Laxi mow erhielt so eine milchartige Flüssigkeit, die sich beim Stehen etwas bräunte. Fin doppeltes Papierfilter befreite diesen Saft von den Zellfetzen, in dem Filtrat konnten mikroskopisch nur noch kleine Kügelchen nachgewiesen werden. $50 \mathrm{ccm}$ Saft verbrauchten in der ersten Stunde 1,36 ccm Sauerstoff und produzierten $1,82 \mathrm{ccm}$ Kohlensäure, der Quotient war also 1,3. Nach 3 Stunden war der Quotient 4,1, nach 10 Stunden 1,1 usw. Diese Atmung soll auch vor sich gehen bei Gegenwart von Toluol, doch zog es Maximow vor, sich in der Regel ohne Antiseptika zu behelfen, und mit grösseren Traubenzuckermengen das Bakterienwachstum zu ,hemmen“. Der Sauerstoffverbrauch im Presssaft betrug etwa $10 \%$ von demjenigen der entsprechenden Myzelmenge.

Die Richtigkeit der Gasanalysen rorausgesetzt, kommt als Einwand hier wohl nur Infektion mit fremden Mikroorganismen oder mit aspergillus selbst in Betracht. Es dürfte sich jedenfalls empfehlen, die angekündigte ausführliche Publikation Maximows abzuwarten.

Die Versuche am unbefruchteten Seeigelei (O. Warburg und $O$. Neyerhof, 33) wurden mit der zerschüttelten strukturfreien Eisubstanz angestellt, deren Gewinnung in Abschnitt 4 dieses Kapitels beschrieben ist. Folgende Tatsachen ergaben sich:

1) Vgl. auch die Kritik der Batelli-Sternschen Versuche durch Harden and Maclean (14). 
1. Während eine grosse Reihe von Tatronsalzen auf die Oxydationsgeschwindigkeit ohne Einfluss war, bewirkte Zusatz von weinsaurem oder zitronensaurem Tatron tast völlige Hemmung der Oxydationen. Bekanntlich entionisieren weinsaures und zitronensaures Natron Metalle und so richtete sich unsere Aufmerksamkeit auf Metalle.

2. Wir veraschten grössere Mengen Eisubstanz und fanden in der Asche, abgesehen von Alkalien und alkalischen Erden, erhebliche Quantitäten Eisen.

3. Mit Rodankali und rerdünnter Salzsäure übergossen, fürbte sich die Eisubstanz (für die Reaktion verwendet man am besten das ziemlich farblose Acetonpulver) rötlich, das Eisen, oder ein Teil des Eisens, liegt also offenbar im Ei als Eisensalz oder in sehr lockerer Bindung vor.

4. Wir setzten der zerschüttelten Eisubstanz kleine Mengen verschiedener Metallsalze zu und fanden, dass die Oxydationsgeschwindigkeit durch Eisensalz (Oxydul- oder Oxydform), sehr erheblich gesteigert werden konnte, dureh andere Metallsalze, auch durch Mangan, nicht. Die zugesetzten Eisenmengen waren von der Grössenordnung der in der Eiasche gefundenen. - Wir schlossen also, dass auch das im Ei vorhandene Eisen die Oxydationen beschleunigte.

5. Wenn wir die Eisubstanz durch Aceton oder Alkohohl ausfüllten und dann mit warmem Alkohol auslaugten, war in dem Rückstand kein Sauerstoffverbrauch mehr nachweisbar, auch dann nicht, wenn wir Eisensalz zusetzten.

6. Der Alkoholextrakt wurde im Vakuum verdampft, der Rückstand mit $\ddot{A}$ ther aufgenommen, wobei ein Teil ungelöst blieb. Der ungelöste Teil verbrauchte weder allein noch bei Zusatz vor Eisensalz Sauerstoff. Aus der ätherischen Lösung wurde der Äther verjagt und der Rückstand in Wasser suspendiert; die wässerige Suspension verbrauchte allein keinen Sauerstoff, jedoch bei Zusatz von Eisensalz. Die hierbei erreichten Oxydationsgeschwindigkeiten waren nicht geringer als die Oxy dationsgeschwindigkeiten der intakten Eimenge, die zur Darstellung des Ätherextrakts gedient hatte.

7. Wir schlossen also, dass die Oxydation in der zerschütelten Eisubstanz Oxydation von Lipoiden unter dem Einfluss von Eisensalz sei.

8. Lecithin, verbraucht in wässeriger Suspension bei Zusatz von Eisensalz, wie Thunberg zuerst beobachtet hat (35̃), Sauerstoff mit grosser Geschwindigkeit. Eine kleine Menge H-Ion, wie sie in den käuflichen Präparaten sich findet, ist zum Zustandekommen der Reaktion notwendig. Zu reinen Präparaten setzten wir ein wenig Essigsäure.

9. Das Ei enthält reichliche Mengen Lecithin. Die Reaktion der zerschüttelten Eisubstanz ist schwach sauer (aus zugesetztem Bicarbonat wird 
Kohlensäure ausgetrieben). Es treffen also in der zerschüttelten Eisubstanz Eisen, H-Ion und Lecithin zusammen, wobei dann dieselbe Reaktion, wie in vitro, sich abspielen muss.

Natürlich ist nicht ausgeschlossen, dass sich $\mathrm{jm}$ Ei noch andere Lipoide an der Reaktion beteiligen.

10. Andere wichtige Zellbestandteile, wie Eiweiss, Histon, Nucleinsäure, Traubenzucker, Ölsäure und Triolein, reagieren nach Zusatz von Eisensalz, bei An- oder Abwesenheit von H-Ion, nicht mit Sauerstoff'). Von den Spaltungsprodukten des Lecithins gibt die Reaktion die Linolensäure.

11. Was aus dem Lecithin bei Gegenwart von Eisen und Sauerstoff wird, wissen wir nicht. Kohlensäure bildet sich, bei den angewandten Fisenkonzentrationen, nicht. Auch in der zerschüttelten Eisubstanz findet sich, wie ich in Abschnitt 4 dieses Kapitels erwähnte, keine Kohlensäure.

Die chemische Seite der Oxydationsvorgänge in der zerschüttelten Eisubstanz ist also soweit aufgeklärt, dass wir sagen können, es handelt sich um die Oxydation von Lipoiden bei Gegenwart von Eisensalz. Dass die Oxydationen im intakten unbefruchteten $\mathrm{Ei}$ auf den gleichen chemischen Torgängen beruhen, ist deshalb sc ungemein wahrscheinlich, weil die Oxydationsgeschwindigkeiten in der intakten und zerschüttelten Eisubstanz, einige Zeit nach dem Zerschütteln, sich sehr nahe kommen. Allerdings ändert sich beim Zerschütteln der Mechanismus der Oxydationen insofern, als die Verbrennungen nicht mehr bis zur Kohlensäureproduktion weitergeführt werden, sondern auf früheren Stadien stehen bleiben. Dies ist noch eine Lücke, und ehe sie nicht ausgefüllt ist, wird naan nicht behaupten dürfen, dass der Chemismus der Sauerstoffatmung völlig aufgeklärt ist.

Was die Beziehung der Lecithin-Eisenreaktion zur Strukturkatalyse betrifft, so ist bemerkenswert, dass die Struktur zum Teil aus Lecithin besteht und dass durch Zusałz von Eisensalz zu Strukturteilen, die keinen Sauerstoff verbrauchen, sehr erhebliche Oxydationsgeschwindigkeiten erzielt werden können; beispielsweise durch Zusatz von Eisensalz zu den gewaschenen, nicht atmenden Vogelblut-Stromata. Das Lecithin befindet sich also in den Strukturteilen in einer solchen Form, dass es auf Zusatz von Eisen wie freies Lecithin reagiert. Wären die Strukturteile imstande, Eisensalz an ihrer

1) Einige dieser Substanzen, auch Lecithin, werden in den Lehrbüchern häufig als autoxy* dabel bezeichnet. Unter Autoxydation verstehen wir freiwillige Oxydation durch Sauerstoffgas bei niedrigen Temperataren. Da sich die meisten Koblenstoffverbindungen an der Luft, allerdings mit sehr verschiodener Geschwindigkeit, oxydieren, so sind die meisten Kohlenstoffverbindungen autoxydabel; ohne Angabeder Oxydationsgeschwindigkeit ist also die Be. zeichñng, ,autoxydabel“ für die meisten Kohlenstoffverbindungen so gut wie inhaltslos. Die Autoxydationsgeschwindigkeit von Eiweiss, Fett, Kohlehydrat, Lecithin oder anderen Zellbestandteilen ist im Vergleich zu ihrer Oxydationsgeschwindigkeit in der Zelle so goring, dass sie die Zelloxydationen nicht erklären kann. 
Oberfläche zu verdichten, so wäre dadurch eine Brücke zwischen Strukturkatalyse und chemischer Katalyse geschlagen. Doch wollen wir uns nicht auf spezielle Vorstellungen festlegen, sondern im folgenden Abschnitt den Zusammenhang zwischen beiden Arten von Katalyse allgemeiner behandeln.

\section{Theorie der Strukturwirkung.}

Schliessen wir auf eine Strukturbeziehung daraus, dass Strulkturzerstörung eine Terminderung der Oxydationsgeschwiudigkeit zur Folge hatte, so kann stets der Einwand gemacht werden, dass gleichzeitig mit der Struktur labile oxydationsbeschleunigende Substanzen, chemisch oder mechanisch, zerstört wurden, dass also der Schluss auf eine Strukturbezielıung falsch ist. Dieser Einwand wird umsomehr an Wahrscheinlichkeit verlieren, je zahlreicher und verschiedener die Methoden sind, mit deren Hilfe wir die Struktur zerstören. Gegen den Einwand sprechen sehr beredt Versuche wie die am unbefruchteten und befruchteten Seeigelei; bei genau der gleichen Methode der Strukturzerstörung auf sehr gleichartige Zellen fehlt der Abfall der Oxydationsgeschwindigkeit oder ist sehr erheblich, je nachdem die zerstörte Zelle wenig oder viel Struktur besass. Der Einwand ist jedoch binfüllig, wenn aus S t e igerung en der Oxydationsgeschwindigkeit bei $N$ e u en ts te h ung von Struktur auf Strukturbeziehungen geschlossen wurde. - Der Struktureinfluss ist also für einige Fälle sehr wahrscheinlich, für andere feststehend.

Ein Struktureinfluss, wie er in einer althergebrachten Vorstellung, der Theorie der Reaktionskammern, angenommen wird, kann ohne Schwierigkeit ausgeschlossen werden. Nach der Reaktionskammerhypothese besteht die Zelle aus fachwerkartig getrennten Reaktionskammern; trifft der Inhalt dieser Kammern zusammen, so sollen die reaktionstähigen Stoffe sich gegenseitig zerstören, Fermente sich gegenseitig abbauen usw. Auf diese Art würden die chemischen Unsetzungen, die in der lebenden Zelle vor sich gehen, schnell zum Stillstand gebracht. Die Struktur kann hier eine verschiedene Rolle spielen, sei es rein passiv, indem sie die Stoffe trennt, sei es aktiv, indem sie die Stoffe in einem bestimmten Tempo zusammentreten lässt. Diese Theorie wäre vereinbar mit dem Ausfall der Experimente, in denen Strukturzerstörung die Oxydationsgeschwindigkeit herabsetzte, also vereinbar mit dem Ausfall der Zerreibungsversuche. Die Theorie ist jedoch unvereinbar mit der Tatsache, dass der flüssige Zellinhalt, der Inhalt der „Reaktionskammern", vermischt werden konnte (Abschnitt 4 dieses Kapitels), ohne dass die Oxydationsgeschwindigkeit absank. Von der Reaktionskammerhypothese also können wir hier ${ }^{1}$ ) absehen.

$\left.{ }^{1}\right)$ Damit soll die Hypothese keineswegs a $1 \mathrm{~g}$ e m e in als Erklärung für chemische Struktureinflüsse abgelehnt werden. Im Gegonteil, wenn Struktur zerstörung Reaktions be sc hleunig u $\mathrm{g} \theta \mathrm{n}$ zur Fiolge hat, liegt die A uffassung sur hale, dass Substanzen, z. B. Fermente und Substrate beim Zerreiben der Zelle ausgıebiger in Berührung kommen. (Vgl. z. B. die Versuche von E.J. L esser [36]), nach denen die Glykogenzersetzung schneller abläuft, wenn die Zellstruktur zerstört wird.) 
Beiträge z. Physiologie d. Zelle, insbesondere über die Oxydationsgeschwindigkeit in Zellen. 337

Meine eigene Auffassung des Struktureinflusses geht von der Hypothese aus, dass die zwei Arten von Katalyse, die chemische und die Strukturkatalyse, keine wesentlich verschiedenen Reaktionsmechanismen sind, sondern dass die Strukturkatalyse nichts anders ist, als eine Beschleunigung der chemischen Katalyse.

Allerdings wäre es von vorneherein durchaus möglich, das zwei Arten von Katalyse in der Zelle als getrennte Mechanismen nebeneinander existierten, die organischen Stoffe auf eine Methode im flüssigen Zellinhalt, auf eine andere Methode an den Strukturteilen verbrannt würden. Hier wollen wir uns jedoch daran erinnern, dass wir nur eine einzige Zelle, das Seeigelei, kennen, in der die chemische Katalyse in Betracht kommt gegen die Strukturkatalyse; in normalen Zellen, die ihre Entwickelung beendigt haben, gibt es praktisch keine chemische Katalyse, sondern allein Strukturkatalyse; wir müssten also annehrnen, dass es in jungen Zellen zwei Methoden, in fertig entwickelten Zellen nur eine Methode der Verbrennung gäbe. Eine solche Annahme halte ich für recht unwahrscheinlich, vielmehr drängt sich der Gedanke geradezu auf, dass die junge Zelle, bereit zur Entwickelung Struktur und Strukturkatalyse, die chemischen Katalysatoren als Material zur Organisation der Strukturkatalyse bereit hält. Die chemischen Katalysatorenträtendannim La uf der Entwickelungin Beziehung zur Struktur, würden an die Strukturteile gebunden und beschleunigten dort die Oxydationen in anderem Tempo, weil in anderem Milieu, unter anderen Konzentrationsverhältnissen, als im flüssigen Zellinhalt.

In der historischen Einleitung zu Abschnitt 4, Kapitel VI, ist nachzutragen, dass ausser den genannten Autoren auch Thunberg (Festschrift f. Hammarsten, Wiesbaden 1906 und Skand. Archiv f. Physiol. 22, 1909) dio Sauerstoffaufnahme zerkleinerter Gewebe gemessen hat.

Ferner hat nicht nur Palladin, sondern auch Thunberg mit erfrorenem Gewebe Respirationsversuche angestellt. (Festschrift f. Hammarsten, Wiesbaden 1906.) 